Office of Technology Development Robotics Technology Development Program
ORNL/TM--12185

DE93 002874

\title{
Waste-Surface Mapping of the Fernald K-65 Silos Using a Structured Light Measurement System
}

\author{
B. L. Burks \\ F. W. DePiero \\ M. A. Dinkins \\ J. C. Rowe \\ Robotics \& Process Systems Division \\ C. B. Selleck \\ Sandia National Laboratories \\ Albuquerque, New Mexico \\ D. L. Jacoboski \\ Westinghouse Environmental Management Company \\ Fernald, Ohio
}

Date Published - October 1992

\author{
Prepared by the \\ OAK RIDGE NATIONAL IABORATORY \\ Oak Ridge, Tennessee 37831 \\ managed by \\ MARTIN MARIETTA ENERGY SYSTEMS, INC. \\ for the \\ U.S. DEPARTMENT OF ENERGY \\ under contract DE-AC05-84OR21400
}




\section{CONTENTS}

Page

ABSTRACT …............................................................................................ 1

1. INTRODUCTION

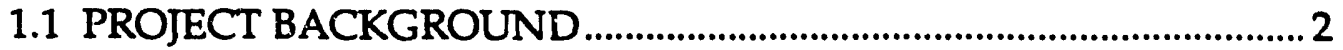

1.2 SELECTION OF MAPPING APPROACH .......................................... 4

1.3 FEASIBILITY DEMONSTRATION ..................................................

2. DESCRIPTION OF MEASUREMENT SYSTEM ……....................................

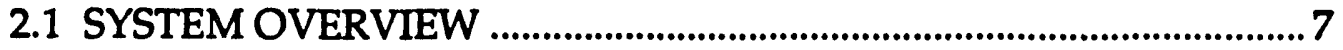

2.2 IN-SILO HARDWARE ......................................................................... 7

2.3 NEAR-SILO HARDWARE ........................................................... 12

2.4 CONTROL STATION HARDWARE .................................................. 12

3. DESCRIPTION OF DATA ACQUISITION …….........................................14

3.1 STRUCTURED LIGHTING METHOD ................................................. 14

3.2 LOW-LEVEL IMAGE PROCESSING ....................................................... 14

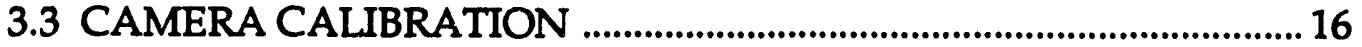

3.4 MEASUREMENT UNIT KINEMATICS ............................................. 23

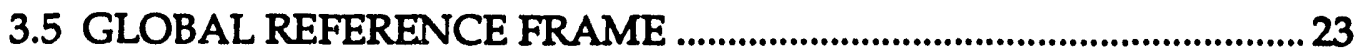

3.6 SURFACE POINT CALCULATION ....................................................26

3.7 OPERATOR INTERFACE OVERVIEW ............................................. 28

3.8 OPERATOR INTERFACE, MENU BAR ............................................30

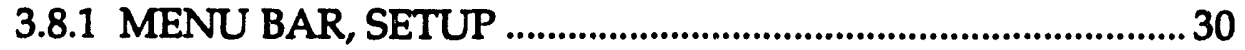

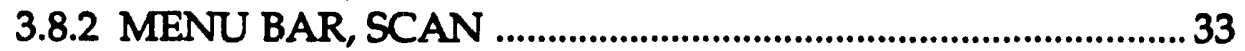

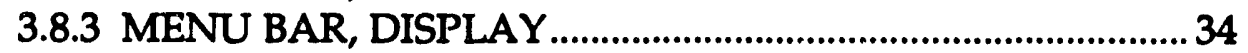

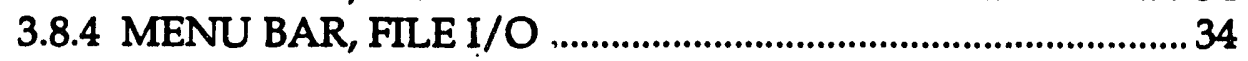

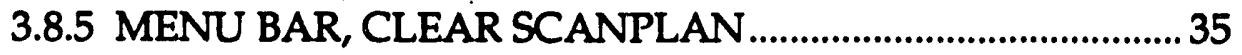

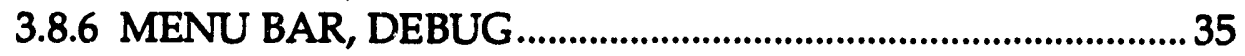

3.9 OPERATOR INTERFACE, STATUS AREA …….................................35

3.10 OPERATOR INTERFACE, SILO GRAPHIC ..........................................36

3.11 OPERATOR INTERFACE SUMMARY ....................................................38

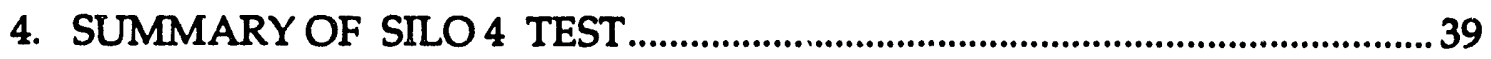

5. SUMMARY OF FIELD DEPLOYMENT ……................................................. 41

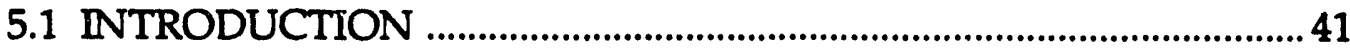

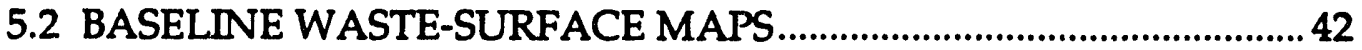

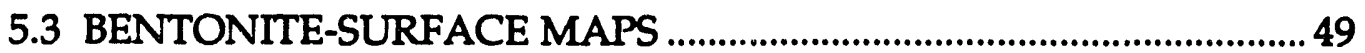

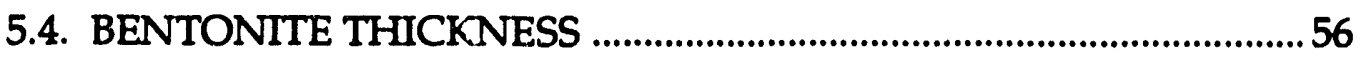

5.5. VOLUMETRIC ANALYSIS .................................................................... 72

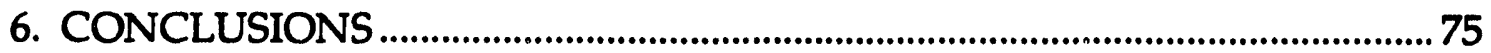

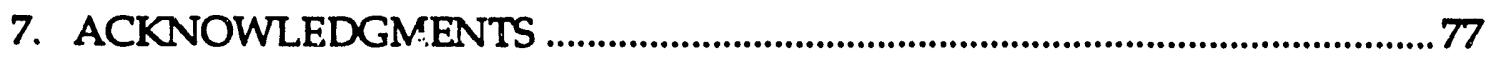

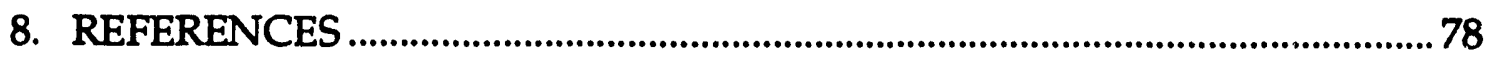




\section{LIST OF FIGURES}

Figure

Page 1.1 Cross-sectional schematic of the $\mathrm{K}-65$ silos at Fernald. ..............................3

1.2 Illustration of the hypothetical worst case camera and laser

line-of-sight angles. .........................................................................................6 6

2.1 Surface-mapping measurement system schematic. .................................... 8

2.2 Illustration of a surface-mapping measurement unit. .............................. 9

2.3 Illustration of a global reference light assembly......................................... 10

2.4 Illustration of global reference light installation. ........................................ 11

3.1 Method of two planes for camera calibration. .......................................... 17

3.2 Sighting vector determination for camera calibration............................... 18

3.3 Laser orientation relative to the camera reference frame..........................21

3.4 Camera calibration laser pitch measurement. ...............................................22

3.5 Orientation of measurement units relative to the global reference frame. ........................................................................................... 25

3.6 Relationship between global reference frame and measurement units reference frames. ........................................................ 25

3.7 Relationship between global reference frame and surface point. ............. 27

3.8 Illustration of the mapping system operator interface. ..............................29

3.9 Operator interface windows illustrating menu options.............................. 31

3.10 Operator interface display of a map in progress. .......................................... 39

5.1 Contour plot of Silo 1 baseline waste-surface data. .....................................43

5.2 Contour plot of Silo 2 baseline waste-surface data. ...................................... 44

5.3 Silo 1 baseline waste-surface map 256-color vertical dimension. .............. 45

5.4 Silo 2 baseline waste-surface map 256-color vertical dimension. .............. 46

5.5 Silo 1 baseline waste-surface map, 6 in. topographical color bands......... 47

5.6 Silo 2 baseline waste-surface map, 6 in. topographical color bands.......... 48

5.7 Contour plot of Silo 1 bentonite-surface data. ............................................50

5.8 Contour plot of Silo 2 bentonite-surface data. ............................................... 51

5.9 Silo 1 bentonite surface, 256-color vertical dimension................................52

5.10 Silo 2 bentonite surface, 256-color vertical dimension................................53

5.11 Silo 1 bentonite surface, 6 in. topographical color bands. ........................... 54

5.12 Silo 2 bentonite surface, 6 in. topographical color bands. .......................... 55

5.13 Contour plot of Silo 1 surface change (bentonite thickness) data. ...................................................................... 57

5.14 Contour plot of Silo 2 surface change (bentonite thickness) data. ........................................................................ 58

5.15 Silo 1 surface change (bentonite thickness),

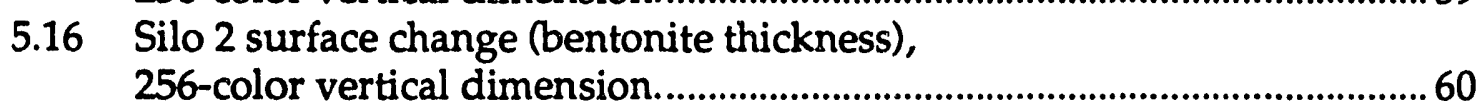

5.17 Silo 1 surface change (bentonite thickness), 6 in. topographical color bands. 
5.18 Silo 2 surface change (bentonite thickness),

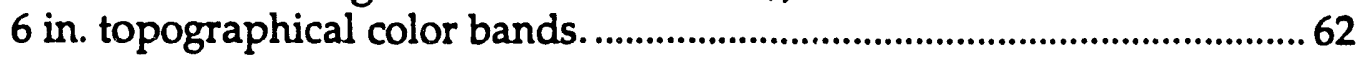

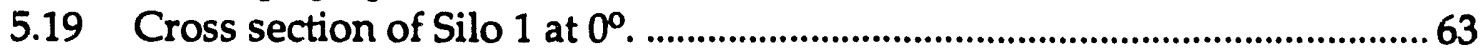

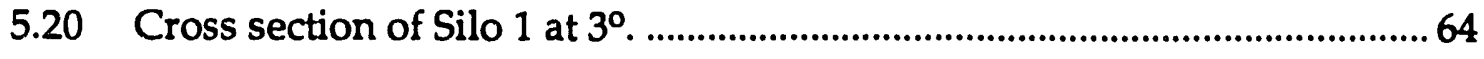

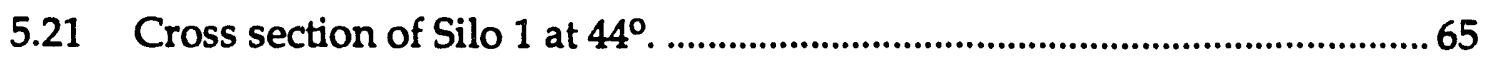

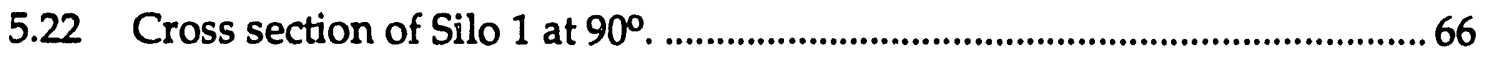

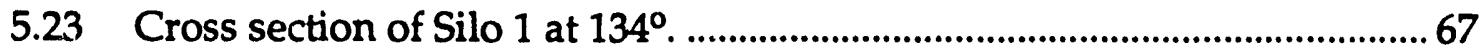

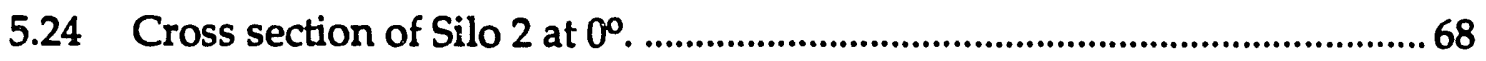

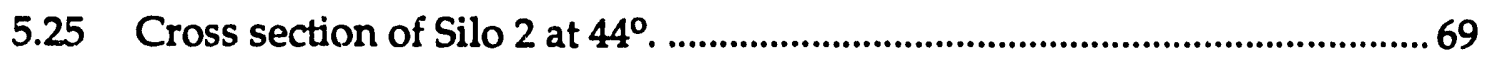

5.26 Cross section of Silo 2 at $90^{\circ}$....................................................................... 70

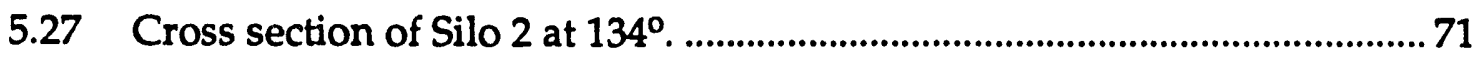




\begin{abstract}
During FY 1991, a remotely operated surface-mapping measurement system was developed by the Robotics \& Process Systems Division at Oak Ridge National Laboratory for use in the K-65 waste-storage silos at Fernald, Ohio. The mapping system used three infrared line-generating laser diodes as illumination sources and three high-resolution, low-lux, calibrated, black-and-white, chargecoupled-device video cameras as receivers. These components were combined to form structured light source range and direction sensors with six different possible emitter-receiver pairs.

A technology demonstration and predeployment tests were performed at Fernald during July and August 1991, using the empty Silo 4 into which was placed rectangular objects of known dimensions. These objects were scanned by the structured light sources to demonstrate functionality and verify that the system was giving sufficiently accurate range data in three dimensions. The tests provided a checkout of installation and operational logistics, prior to field deployment, as well as verification of accuracy and repeatability.

In September and October 1991, the structured light sources were then deployed in Silos 1 and 2 to scan the waste surfaces. The resulting data were merged to create three-dimensional maps of those surfaces. A bentonite clay cap was placed over the waste surfaces in November 1991. Surface maps were obtained in December 1991 of the be! nite clay caps. The change in surface height before and after bentonite addi . in was utilized as a measure of clay cap thickness. Verification of clay cap thickness was required to support a Department of Energy (DOE) Removal Action Milestone defined in the Amended Consent Agreement with the Environmental Protection Agency under Comprehensive Environmental Response, Compensation, and Liability Act Section 106 and 120.

This report includes final results of the surface mapping campaign as well as a description of system components. Mapping system sensors and control hardware are described. Calibration and data acquisition methodology are described as well as the operator interface that facilitated these operations. The sensor system development was sponsored by the DOE Office of Technology Development, Robotics Technology Development Program. Field deployment in the K-65 silos was funded by the DOE Office of Environmental Restoration.
\end{abstract}




\section{INTRODUCTION}

\subsection{PROJECT BA_:_GROUND}

One of the highest priority remedial action projects in the U.S. Department of Energy (DOE) complex is remediation of the K-65 silos at the Fernald Environmental Management Project (FEMP), formerly the Feed Materials Production Center (FMPC), Fernald, Ohio. The K-65 silos are bermed, aboveground, domed, reinforced concrete structures that were built in the early 1950s to store uranium ore residues from the processing activities at FMPC. Two of the four silos (Silos 1 and 2) contain a waste material that is rich with radium and, hence, generates radon gas due to natural radiological decay. Silo 3 contains primarily metal oxide wastes. Silo 4 is empty and is used as a test site to demonstrate remediation approaches planned for the three silos that contain radioactive waste. During the fall of 1991, a layer of bentonite clay was deposited over the entire waste surfaces in Silos 1 and 2. This bentonite layer acts as an attenuation barrier to mitigate emitted radon gas long enough to dissipate the radioactivity. Radon has a relatively short half-life, 3.8 days. The U.S. Environmental Protection Agency (EPA), DOE, and Westinghouse Environmental Management Company of Ohio (WEMCO) analyzed the radon generation rates from the $\mathrm{K}-65$ silos, considered the absorption properties of bentonite, and concluded that a minimum of $15 \mathrm{~cm}(6 \mathrm{in}$.) would be required to attenuate the radon emissions to desired levels. A goal was established to place a minimum 30-cm (12-in.) layer or bentonite clay in each silo.

The silos at Fernald are $24.4 \mathrm{~m}(80 \mathrm{ft})$ in diameter, with $7.9 \mathrm{~m}$-high (26-ft-high) vertical walls and a domed top rising to $11.0 \mathrm{~m}(37 \mathrm{ft}$ ) at the center (see Fig. 1.1). The walls are $\sim 20-\mathrm{cm}$-thick (8-in.-thick) concrete, and the dome tapers from $20 \mathrm{~cm}(8 \mathrm{in}$.$) thick at the edges to 10 \mathrm{~cm}(4$ in.) thick at the center. Five 0.5 -m-diameter ( 20 in.-diam.) access portals are available on the dome tops, one near the center and four at $90^{\circ}$ spacings, $7.6 \mathrm{~m}(25 \mathrm{ft})$ from the center of the dome. An array of $5-\mathrm{cm}(2-\mathrm{in}$.) sounding ports, typically spaced $4.6 \mathrm{~m}(15 \mathrm{ft})$ apart, are also located on the dome tops. Various other penetrations exist on some, but not all, of the silos. Constraints included the use of existing penetration! only, load limits of not more than $311 \mathrm{~kg}(700 \mathrm{lb})$ on the outer part of the dome, and no net loading on the center of the dome. Operation from a suspended platform was necessary to access the center access portal without loading the dome center.

Because the waste surfaces were not flat but were known to have several mounds and other surface features, the thickness of bentonite needed to be measured at points throughout the waste surfaces to ensure adequate coverage. The silos had a limited number of access portals and moderately high levels of radioactivity; therefore, remote measurements were required utilizing techniques

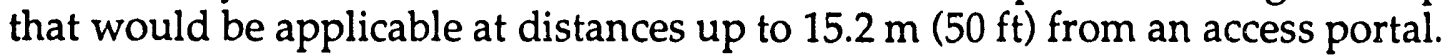




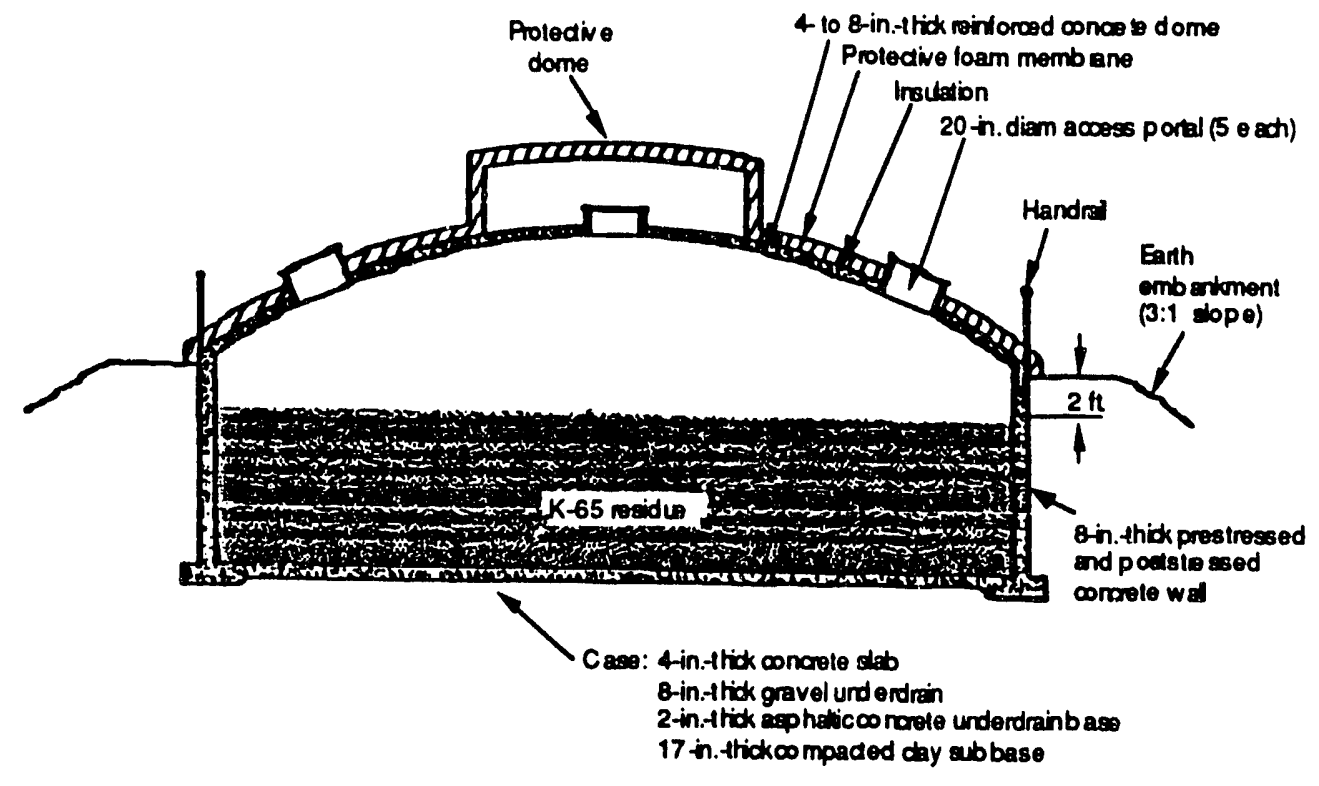

Figure 1.1. Cross-sectional schematic of the K-65 silos at Fernald.

In this report, we describe the application of a structured light source to obtain waste-surface contour data before bentonite deposition and to obtain bentonite-surface contour data after deposition. The thickness of bentonite at any point along the waste surface can be determined by the change in surface height between the two surface maps. Development of this technology and testing in Silo 4 was sponsored by the DOE Office of Technology Development (OTD) Robotics Technology Development Program. Field deployment in Silos 1 and 2 was sponsored by the DOE Office of Environmental Restoration (ER) through FEMP. Participants in the field deployment included personnel from Oak Ridge National Laboratory (ORNL), WEMCO, and Rust Engineering. During the early stages of the development phase, ORNL was assisted by Sandia National Laboratories (SNL). Much less detailed reports of this work were previously published describing the project before completion of the Silo 4 test, 1 after the baseline waste-surface mapping, ${ }^{2}$ and following completion of bentonite-surface mapping.,3

Section 2 contains a description of the measurement system hardware. Section 3 describes the data acquisition methodology and graphical operator interface. Section 4 summarizes the results of tests in Silo 4 . Section 5 summarizes the results of the field deployment in Silos 1 and 2 and shows a large number of data plots. Section 6 presents a final summary and conclusions from this development project. Section 7 acknowledges the contributions of those not represented in the author list. Section 8 provides a list of references cited in this report. 


\subsection{SELECTION OF MAPPING APPROACH}

Research and development activities related to range and direction sensing have been conducted for many years at both ORNL and SNL. Both laboratories have recently been involved in the creation of three-dimensional world models using sensor input from remotely deployed systems. Recent efforts at ORNL include the use of sonar transceivers, optical range sensors, stereo image processing, and a laser rangefinder. Similar activities at SNL have also included development of a structured light source for surface mapping. In 1990, SNL demonstrated the application of a structured light source to map simulated waste surfaces. ${ }^{5}$ This demonstration using ordinary sand as a generic waste simulant consisted of a laser line projector and a calibrated black-andwhite, charge-coupled device (CCD) video camera mounted on a gantry robot (Cimcorp XR6100) at a fixed separation and orientation typically about $1 \mathrm{~m}$ above the waste surface. This structured light system yielded range resolutions of $<5 \mathrm{~mm}(0.2 \mathrm{in}$.).

Several approaches for range measurement inside the silos were evaluated. The most promising alternatives were use of a commercial laser imaging scanner and structured light. Two commercial laser imaging scanners were considered, Odetics and Perceptron. The Odetics laser range camera was found to be too fragile to be reliable in field deplcyment based upon experience with a similar system at ORNL. The Perceptron system was found to be more rugged but failed to demonstrate the required accuracy and reliability for mapping bentonite surfaces during tests at the vendor site. Both systems were too expensive to justify procurement of multiple units and both would require repair at the vendor site in case of damage during handling or operation, hence, limiting system redundancy and options for failure recovery. A commitment to one approach or the other was required after only a couple of months of evaluation. The structured light approach was judged to be less expensive for capital equipment, more rugged, more easily designed for redundancy and failure recovery, and more likely to succeed under the geometrical, lighting, surface texture, and moisture conditions found in the silos as well as the schedule constraints. Had there been sufficient time and funding to improve a laser imaging scanner for use at Fernald, a different choice may have resulted. However, the structured light was deemed more likely to succeed in this particular application.

ORNL and SNL worked together to extend the capabilities of the structured light approach to accommodate the distances, physical constraints, and accuracies required for mapping surfaces inside the K-65 silos at Fernald. System design, fabrication, integration, and testing were performed by ORNL. Site coordination and preparation were provided by WEMCO. Equipment installation and operational support in the $\mathrm{K}-65$ area were provided by Rust Engineering. SNL provided assistance during the evaluation of alternatives such as laser imaging scanners and performed a feasibility demonstration in April 1991 that confirmed the use of a structured light to obtain range data from a wet bentonite surface. Following joint development activities in the spring of 1991, ORNL focused on development of the structured light system used at Fernald 
while SNL focused on development of a structured light system for use in a technology demonstration at the Hanford site in August 1991.6

\subsection{FEASIBILITY DEMONSTRATION}

In April 1991, a feasibility demonstration was performed by personnel at SNL. There was concern that the structured lighting sensor would have difficulty operating at low-incidence angles; i.e., at locations near the silo walls as shown in Fig. 1.2. As can be seen in the figure, laser light would reflect back to the camera at angles of approximately $20^{\circ}$. Since the bentonite slurry has water in it, the worst case surface would have a high reflectivity. It was possible that the laser light would reflect off the surface away from the camera and not enough laser light would be captured by the camera, resulting in little or no data acquisition near the silo walls. This was objectionable since the FEMP wanted to ensure proper bentonite coverage over the entire waste surface.

SNL acquired a Pearpoint CCD camera similar to the one that would be used in the K-65 waste silos at Fernald. A 24-mw, 812-nm laser with cylindrical optics to spread the laser beam into a $20^{\circ}$ fan was also obtained. This laser was from the same manufacturer that was supplying the lasers for the deployed sensor system. A bentonite slurry was mixed at proportions recommended by FEMP. This slurry was placed in a $0.6 \mathrm{~m}$ by $0.6 \mathrm{~m}$ ( $2 \mathrm{ft}$ by $2 \mathrm{ft}$ ), shallow pan to simulate the waste surface. Since the inside of the silo was not lighted, there would be little ambient background light for the camera to detect. An $812-\mathrm{nm}$ bandpass filter was placed on the 12-mm lens attached to the Pearpoint camera to simulate the lack of background light in the silos. Data were also taken at night to mimic the silo light conditions as closely as possible.

The Pearpoint camera was mounted on a gantry robot that allowed the cam sra to be positioned with six degrees of freedom anywhere in the gantry workspace, $18.3 \mathrm{~m}$ by $9.1 \mathrm{~m}$ ( $60-\mathrm{ft}$ by $30-\mathrm{ft}$ ). Mounting the camera on a large robot allowed many different sensor configurations to be tested easily. The laser was placed on two $12.7-\mathrm{cm}$ (5-in.) Daedal rotary stages mounted orthogonally to each other. The stages were controlled by Compumotor AX controllers. This pan-and-tilt system was similar to the one actually deployed in the waste silos. The pan-and-tilt system was mounted on a tripod and placed near one end of the robot work space. The bentonite mixture and the camera could be placed anywhere in the robot work space, providing maximum versatility in observing different sensor configurations.

Surface maps of the bentonite surface were generated at several different configurations, including low-incidence angles. It was confirmed from these tests that the camera could detect a sufficient amount of reflected laser light from the illuminated bentonite surface. Confidence was further bolstered by the fact that a more powerful laser $(30 \mathrm{mw}$ ) would actually be used in the waste silos. These tests proved that the structured lighting sensor could be used to map bentonite surfaces at low incidence angles and lead the way to the full scale development of the measurement system that would be placed into the waste silos. 


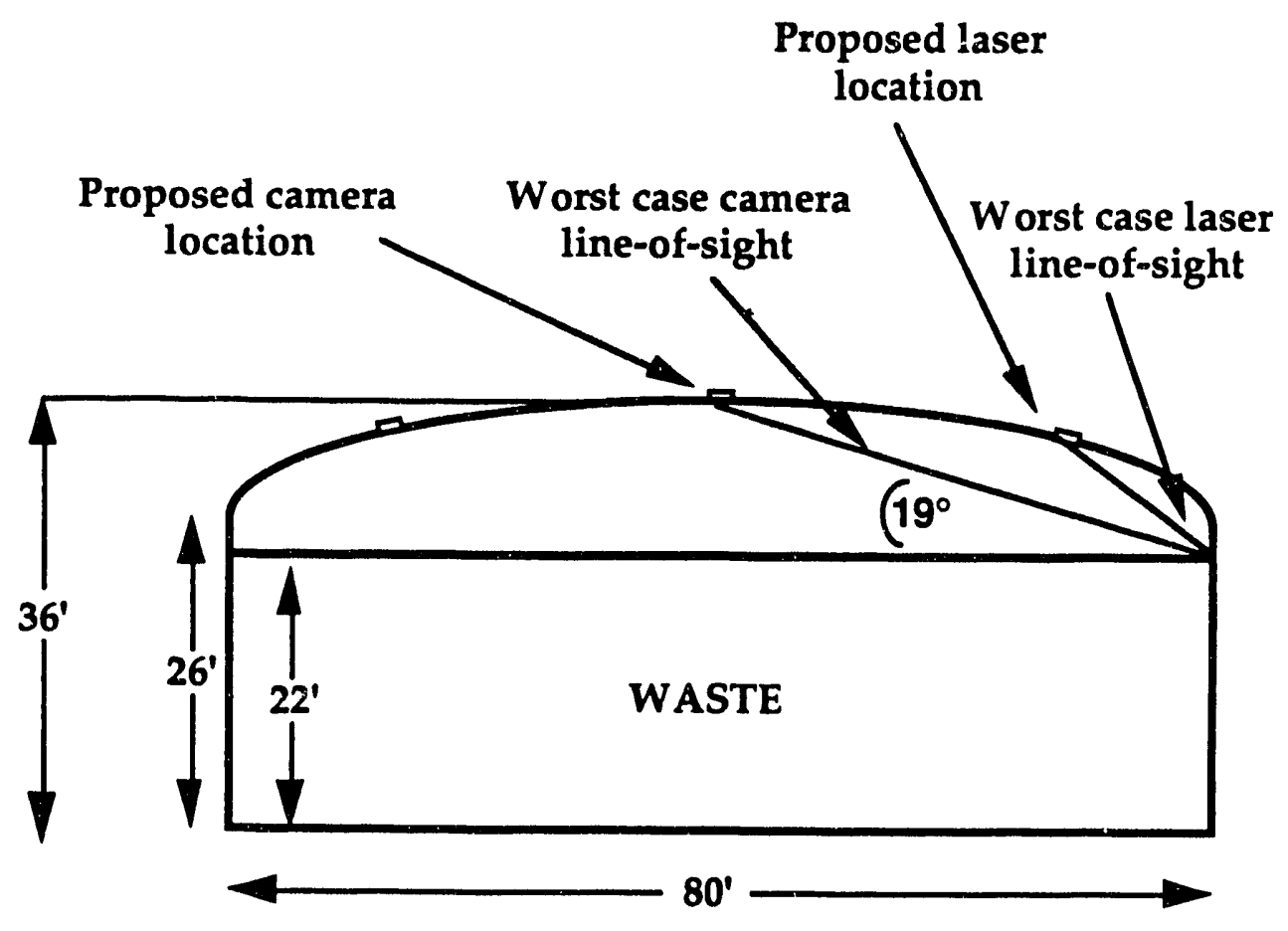

Figure 1.2 Illustration of the hypothetical worst case camera and laser line-of-sight angles. 


\section{DESCRIPTION OF MEASUREMENT SYSTEM}

\subsection{SYSTEM OVERVIEW}

The primary personnel safety hazard in the $\mathrm{K}-65$ area was radon generated by the waste material in Silos 1 and 2. A fence around these silos separated the area into regulated zones. Contamination control suits and respirators were required for personnel on the silo domes and on the berm around the silos. Requirements for respirator use in the outlying areas were determined by air monitoring. During periods of high radon concentration in the area, personnel were required to wear respirators or evacuate. The control station was located about $1 \mathrm{~m}(3 \mathrm{ft})$ outside the fence but inside the area frequently evacuated because of radon. The control station, that was located within a trailer, was connected to the apparatus inside the fence with RS-232 serial links and camera control cables. In addition, power cables were run from the control trailer to power supplies and controllers located near the silos in environmental enclosure boxes. The mapping system hardware was installed through glove bags into selected access portals. An overall wiring diagram is shown in Fig. 2.1.

\subsection{IN-SILO HARDWARE}

The in-silo hardware consisted mainly, but not exclusively, of three structured light measurement units (MUs). Each of these units consisted of a mounting base, light, camera, line laser, and spot laser. This assembly was fastened to a pan-and-tilt mechanism for azimuth and pitch alignment and adjustment. The pan-and-tilt encoders had resolution of $0.0035^{\circ}$ or $\sim 0.2 \mathrm{~min}$. of arc. To obtain that accuracy, the mechanism was custom designed with precision rotary components.

The pan-and-tilt mechanism of each MU was fastened to an aluminum pipe extending down from a flange plate mounted in one of the access portals of the silo dome. The length of pipe was chosen to provide pan-and-tilt clearance inside the dome, while also maximizing MU height above the waste surface. Electrical connectors and wiring were provided to power the pan-and-tilt motors and the electronic apparatus as well as receive and transmit data and control signals with the lasers, cameras, and rotary stage encoders. This assembly is shown in Fig. 2.2.

In addition to the MUs, three global reference light assemblies were used to define a reference plane called the global reference frame (GRF). A diagram of these assemblies is shown in Fig. 2.3. These assemblies were inserted through $5-\mathrm{cm}(2$-in.) sounding ports near the periphery of the silo. During installation of the GRF, a water balance was used to ensure that the lights were mounted in a plane level with respect to gravity. In this way, a level reference plane was established regardless of any local nonuniformity in the shape of the dome. The installation and usage of the GRF assemblies are shown in Fig. 2.4. 


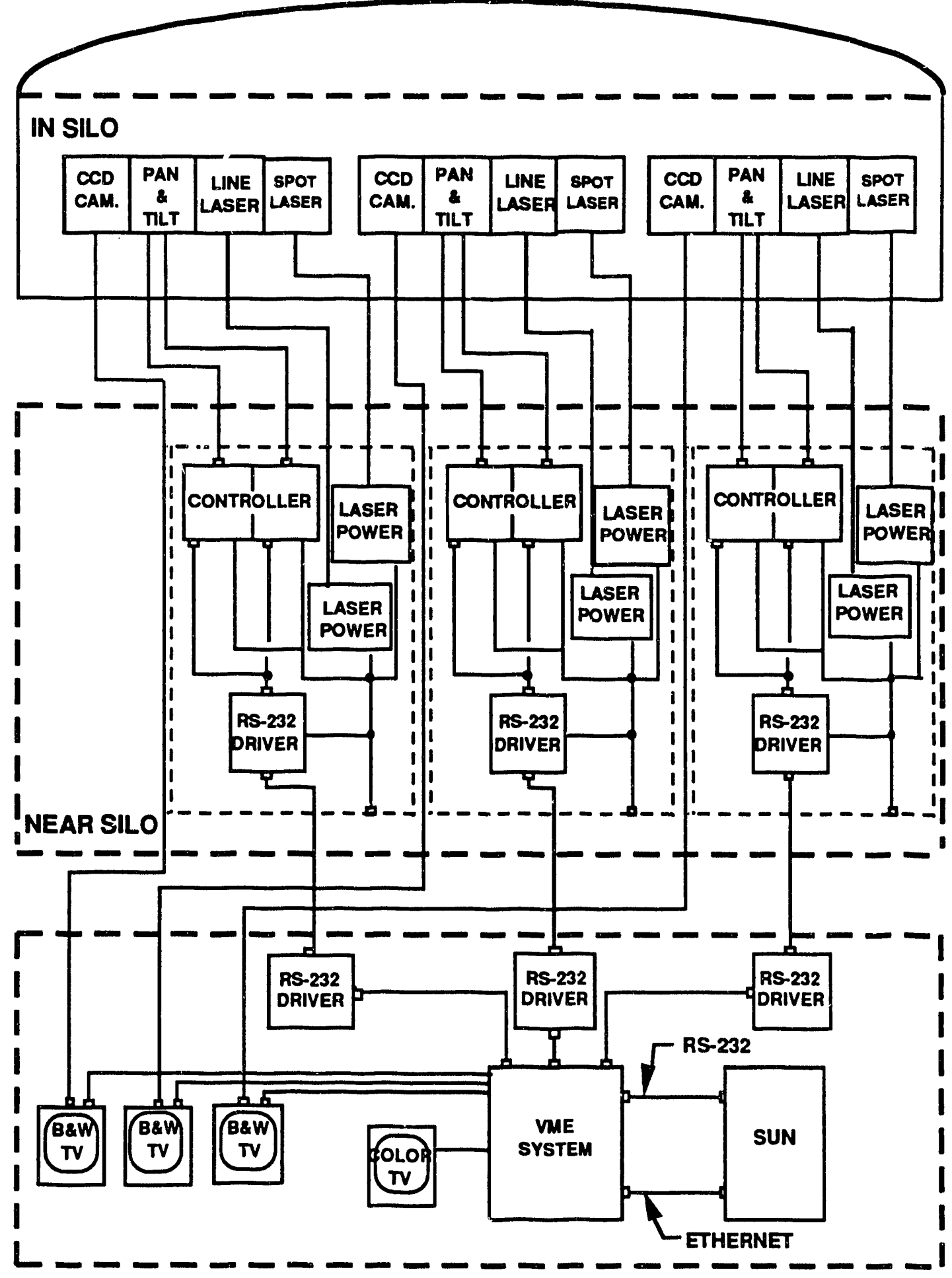

Figure 2.1 Surface-mapping measurement system schematic. 


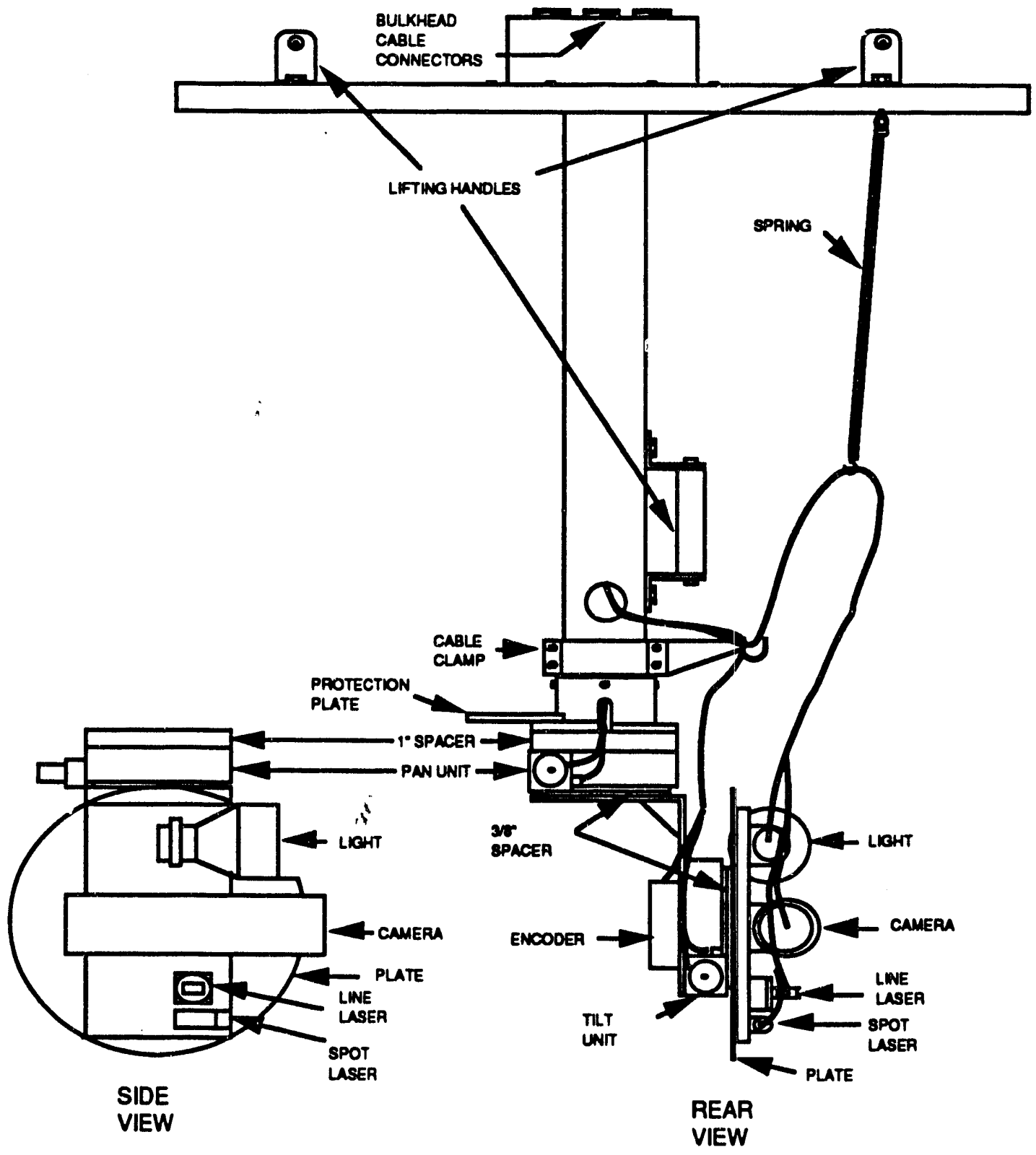

Figure 2.2 Illustration of a surface mapping measurement unit. 



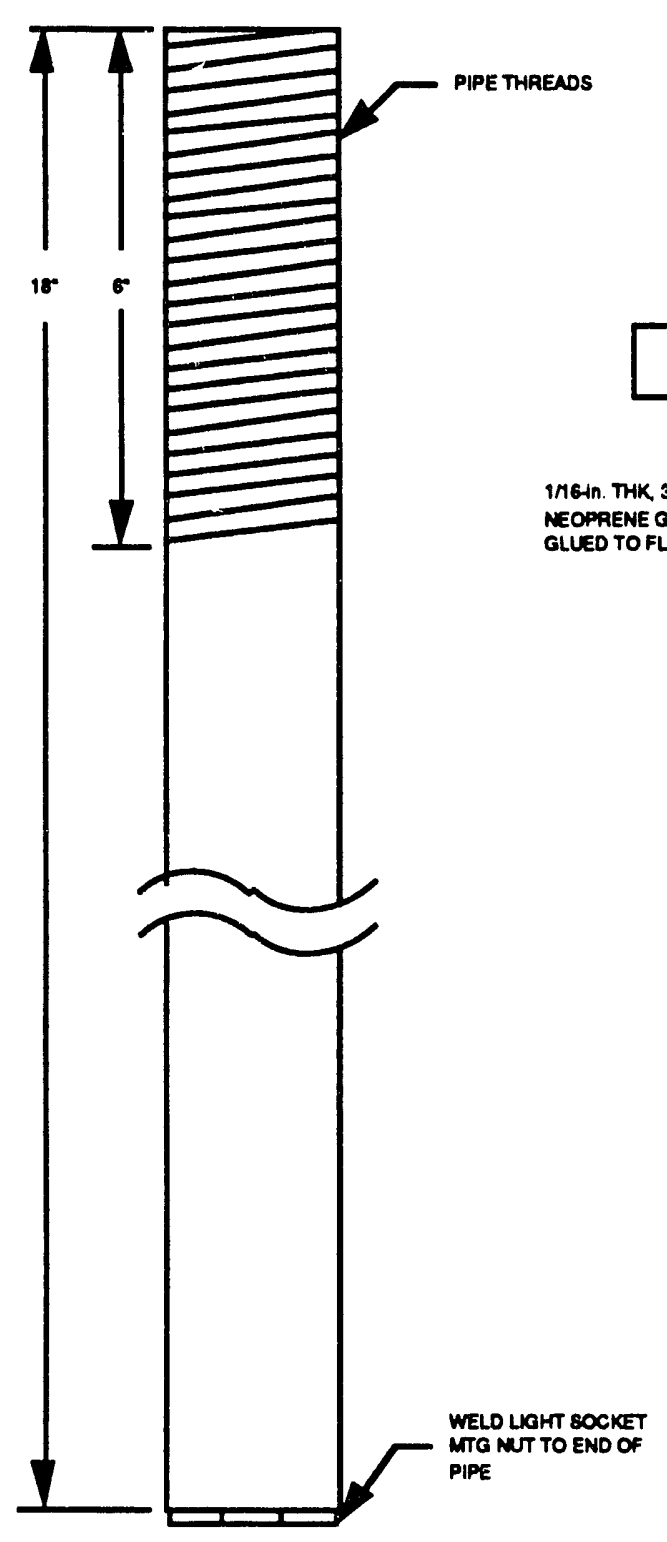

MAT'L: 1 -in. STAINLESS

PIPE 6 EA REQ'D

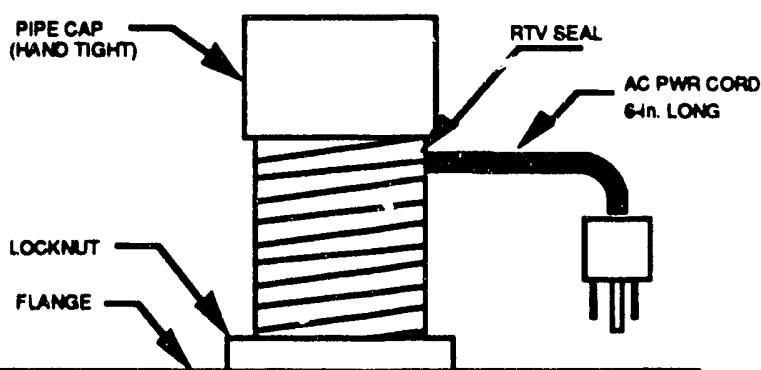

MG-1n. THK 3-1/2+1. O

NEOPRENE GAGKE

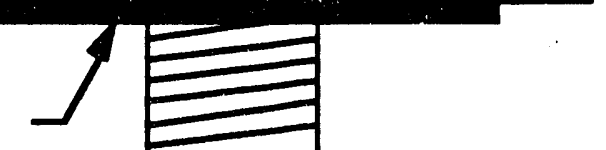




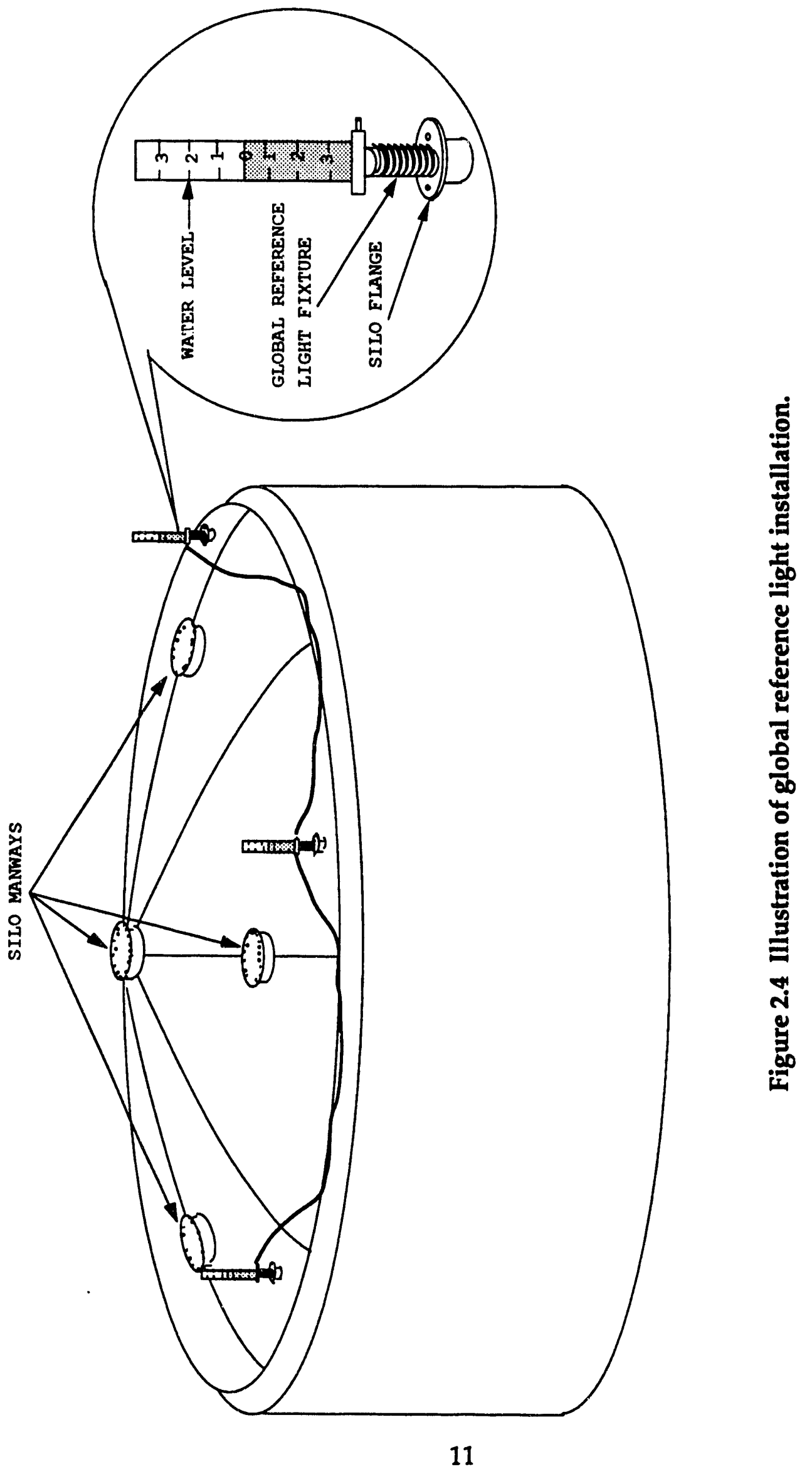




\subsection{NEAR-SILO HARDWARE}

To minimize signal loss and voltage drop for the rotary stages, it was decided to station the power control units for the servo amplifiers and the laser power supplies within $15 \mathrm{~m}$ ( $50 \mathrm{ft}$ ) of the MUs. In this way, the only long runs of power cable would be the $115-\mathrm{V}$ ac power for all of the apparatus and the RS- 232 serial links.

Items that needed to be placed close to the MUs on the silos were:

1. 6 Compumotor servo controllers,

2. 6 Analog Devices $5-\mathrm{V}$ power supplies,

3. 3 Sola $12-\mathrm{V}$ power supplies, and

4. 3 Black Box RS-232 signal conditioners/line drivers.

Item 4 above was required to recondition the serial signals and to drive the signal lines to the in-silo equipment. This equipment was installed in environmental enclosure boxes to protect them from rain and heat. Cooling fans were installed on the underside of each box. These enclosures were highly effective in protecting the equipment. No problems were encountered with this equipment as a result of heat buildup, and no problems were encountered during operations as a result of precipitation. However, careless storage of these boxes during the interim between baseline mapping and bentonite mapping did introduce rainwater into all three boxes, causing some damage and requiring replacement of a servo controller.

\subsection{CONTROL STATION HARDWARE}

The control console was situated in a trailer adjacent to the fenced enclosure surrounding Silos 1 and 2. The control system was typical of many such real-time systems that have a master computer controlling a single-board computer and other boards housed in a VMEbus computer rack (see Fig. 2.1). In this case, the master was a Sun Sparcstation 2, and the single-board computer was a Force model CPU30. To analyze the pictures coming from the video cameras, DataCube boards were used. A 'Digimax' board was used to digitize the analog video frames, and a 'Framestore' board was used to store the digitized images for analysis.

Three monochrome monitors were used for viewing the output from the three black-and-white cameras. A fourth monitor, which had color capabilities, was also part of the control setup and was used for debugging purposes and to a lesser degree for feature emphasis. The cameras were operated by using a controller from Remote Ocean Systems for zoom, aperture, and focus. After optimizing the zoom and focus for the nominal range and field of view, the camera systems were calibrated. Zoom and focus controls were then disabled to preserve the camera calibration during the measurement campaigns. The 
aperture was varied somewhat as a function of distance from the illuminated surface but normally kept small for good depth of field since sufficient light levels were available.

Because of the high accuracy needed, the pan-and-tilt controls were custom designed at ORNL by using Compumotor controllers. An operator interface was developed that allowed control of the pan-and-tilt systems from the Sun system.

During initial checkout of the sensor system in Silo 4 occasional ground fault interrupts (GFI) occurred tripping off system power. This problem was solved by using isolation transformers in the control trailer to power each MU. These same voltage differences that had occasionally triggered the GFI may also have caused the noise problems that were sometimes observed in the RS-232 signals.

A printer was included in the control station, primarily as a diagnostic aid rather than for data printouts. The color prints shown in Sections 3 and 5 were generated from off-line Sun system screen dumps using a color printer at ORNL. 


\section{DESCRIPTION OF DATA ACQUISITION}

\subsection{STRUCTURED LIGHTING METHOD}

The term structured light refers to an illumination source that emits light in some known pattern.7 In the ORNL mapping system, a line laser was used to generate a plane of light. Range data were then found by capturing images of the waste surface as illuminated by the laser plane. To map the entire waste surface, the lasers and cameras were placed on pan-and-tilt positioning platforms. The scanning process consisted of analyzing images of the laser illumination as it was incrementally advanced across the waste surface. Several calibration, initialization, and processing steps were required prior to obtaining rarige data. These steps are described below and are followed by details of the range calculation. The steps are described in the order that each came into play in the range calculation.

\subsection{LOW-LEVEL IMAGE PROCESSING}

When the laser plane intersected the waste surface, the intersection was an irregular contour line. The first stage in finding range data was to analyze images of the 'squiggly' contour line. This stage located illuminated pixels that coincided with the center of the irregular contour line. This pixel location was accomplished by using several rudimentary image processing techniques.

Some initial processing steps were required to reduce noise in the video images. One source of noise problems was marginally adequate camera cooling. Heavy equipment and radio-frequency interference were also suspected of producing intermittent noise, although these sources were never positively identified. The effects of these noise sources were to decrease the contrast of images and to introduce random intensity variations. The random noise was in the form of additive intensity spikes which changed from pixel to pixel and from frame to frame. The spikes were relatively brief and were greatly reduced by capturing four images in succession and averaging corresponding pixels in each image.

Next, an intensity threshold was applied to each pixel to form a binary image that indicated the presence or absence of the contour line. Because of the fairly low contrast images, selection of a single image-wide threshold was not a trivial matter. A poorly selected value could either result in no data at all or in completely erroneous information. Because of the potential impact on mapping operations, the threshold was tuned in an operator interactive manner during system startup. 
The application of a simple threshold tended to result in what is commonly referred to as salt-and-pepper noise, which occurred when pixels retained a sufficient noise content to exceed the threshold. This typically occurred in isolated pixels that were near the contour line. Two approaches were experimented with to eliminate this noise source. Morphological operations that erode and dilate binary images ${ }^{7}$ worked well. However, this method was not used in the final system, because an alternate approach was identified that had several other desirable benefits. This alternate method was a connected component analysis. ${ }^{7}$ This analysis was performed to isolate connected regions, or blobs, in the binary image. A filtering criterion based on minimum blob area was used to eliminate the salt-and-pepper blobs, which were typically quite small and were easily segmented from the blob(s) associated with the contour line.

Because of the divergence of the laser beam $\left(\sim 0.1^{\circ}\right)$, the contour line in the image was typically broader than one pixel. Widths ranged from $\sim 10$ to 50 pixels, depending on the geometry of a given measurement. The model of the structured light was an infinitesimally thin sheet located in the center of the laser plane. Hence, only pixels at the center of the contour line were considered for further processing in the range measurement. These central pixels represented the best approximation to the location of the laser plane. Once the binary image of the contour line had been prepared, the pixels residing at the center of the line had to be isolated. The line center was approximated by traversing the image in a direction perpendicular to the contour line and then averaging the location of the pixels at both edges of the line. A troublesome aspect of this operation was the necessity of first finding an approximation to the orientation of the irregular contour line. The connected component analysis proved to be beneficial because it could provide the orientation of the major axis of each blob. In a given image, the blob with largest area was assumed to be part of the contour line. Image slices were then generated in a direction perpendicular to the orientation of the largest blob. The spacing between each image slice was specified by the operator, thus permitting the data density of the surface points to be adjusted.

Another benefit of the connected component analysis came from the determination of the centroid of each blob. This point provided the necessary data to allow adaptive centering of the camera during mapping. Although the camera and laser were nominally aimed at the same location during surface scans, variations in the waste surface were large enough that, without an adaptive mechanism, the contour line would have become occluded from the camera view at times. Adaptive centering allowed mapping to continue across relatively long segments of the waste surface despite large variations in surface height. Centering was achieved by calculating small corrections to the camera pan-and-tilt angles. Corrections were generated by finding the displacement of the largest blob's centroid relative to the image center. The radial displacement was applied to a proportional/integral control law 8 to generate the needed angular corrections. 


\subsection{CAMERA CALIBRATION}

The end result of the low-level image processing was to find pixels at the center of the contour line. The next step in finding range data was to calculate a vector associated with each pixel that extended from the camera to an intersection point at the laser plane. The purpose of camera calibration was to determine the precise direction of incoming illumination associated with each image pixel. The result of a camera calibration was a model of the perspective effects and distortions introduced by the camera. Applying the camera model was the next step in obtaining range data. A description of the camera calibration process follows.

Many factors affected the camera model, lens distortion being the most significant. 9 A camera's image array was not typically aligned with respect to the optical axis or with respect to the camera housing to any specified degree of precision. Another effect necessitating camera calibration occurred during the digitization process for an image. The synchronization of the video to digital converter with the camera tended to vary somewhat from camera to camera. Video synchronization affected the horizontal position of each row in an image. The effects of all these factors were modeled during the camera calibration procedure.

The method of two planes was used to find the camera model. ${ }^{10}$ This technique established the relationship between image coordinates and threedimensional world coordinates located on a calibration target. A minimum of two such models were required for two targets, each located in a distinct plane. Once these relationships were known, the direction to an illumination source was determined (see Fig. 3.1). In Fig. 3.1, I_source was an illumination source at some unknown distance away from the camera. The direction to I_source was described by using points on the planes W1 and W2. This step was accomplished by first finding I_centroid, the center of the illumination pattern as seen in the camera image. Having isolated a point of interest in the image, the camera models $\mathbf{L} 1$ and $\mathrm{L} 2$ were then employed to map this image coordinate onto each of the two planes. Note, as Fig. 3.1 shows, the actual source of illumination was not located on either calibration plane.

The planes $\mathbf{W} 1$ and $\mathbf{W} 2$ were defined with respect to $C$ a coordinate frame rigidly attached to the camera. The points $\mathbf{S} 1$ and $\mathbf{S} 2$ were specified by position vectors related to frame $C$ (see Fig. 3.2). The sighting vector $S$ is a unit vector along the ray of illumination and was found by taking the difference of $\mathbf{S 2}$ and S1. Points along the sighting vector $F$ were represented in parametric form by

$$
F=S 1+t S,
$$

where $t$ was an arbitrary scalar. 


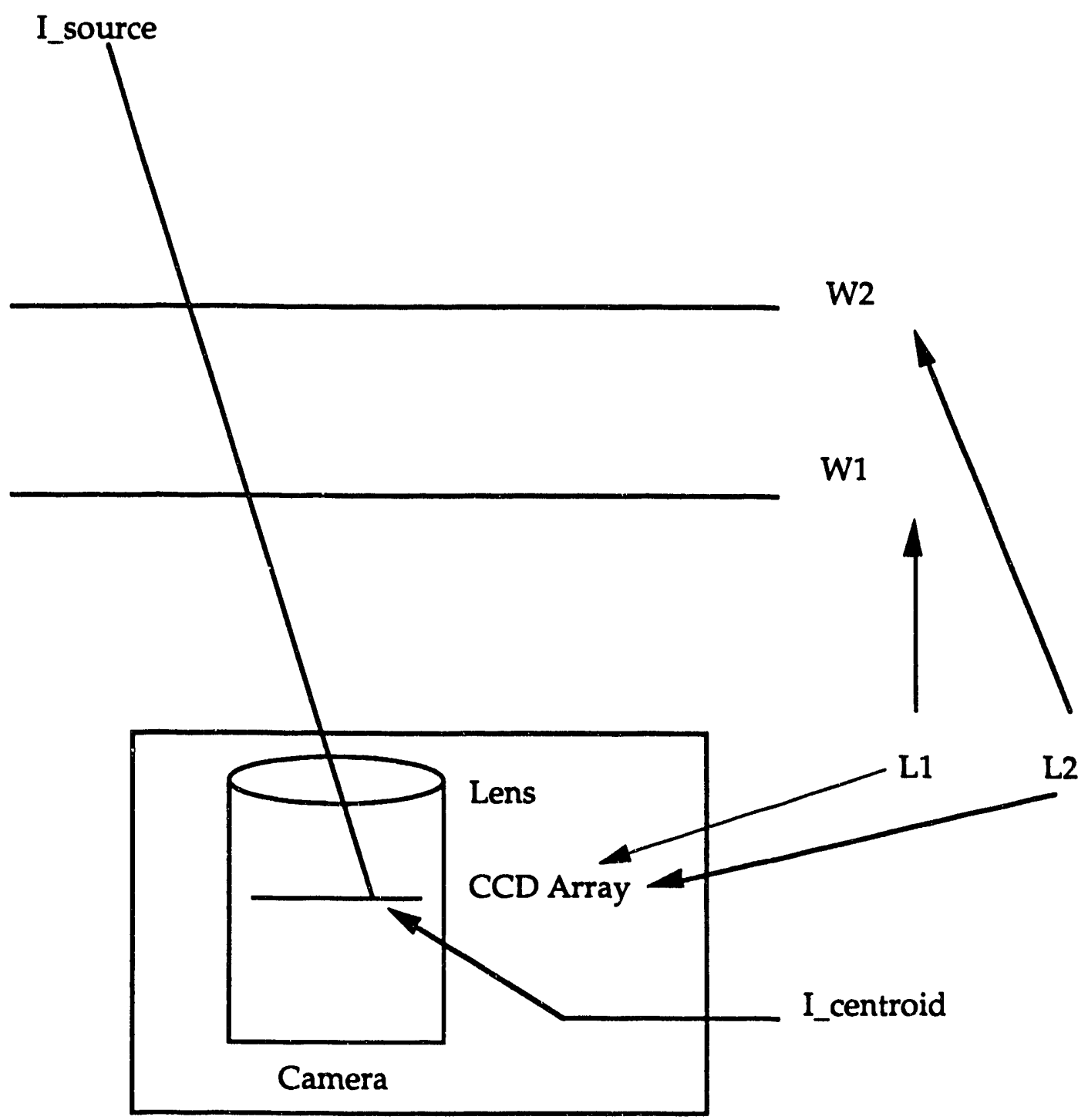

Sensor Mounting Plate

Figure 3.1 Method of two planes for camera calibration. L1 and L2 are the camera models relating planes $W 1$ and $W 2$ to pixels in the CCD Array. I_source is a light source. I_centroid is the pixel in the CCD array corresponding to the center of the image of I_source. 


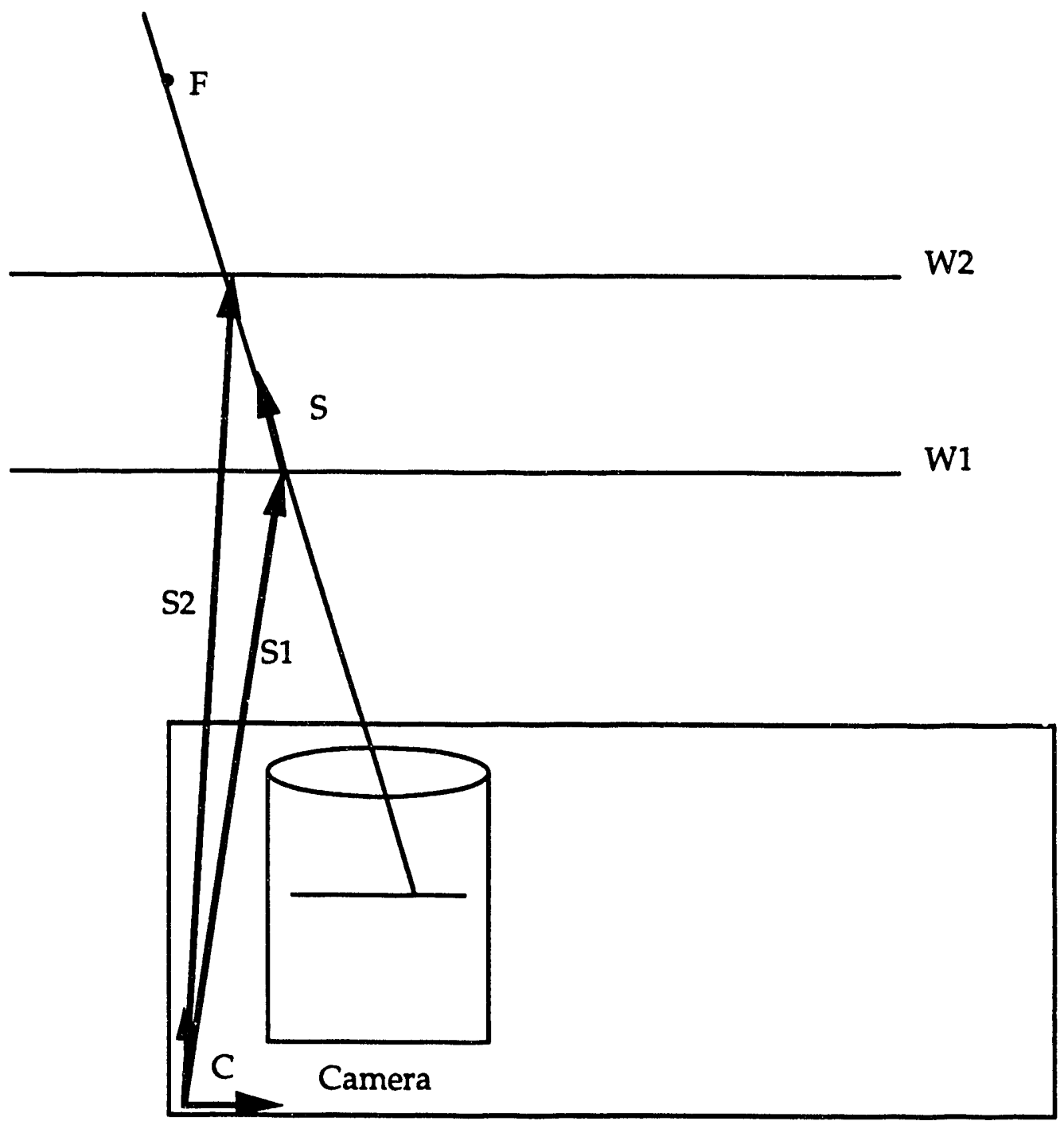

Sensor Mounting Plate

Figure 3.2 Sighting vector determination for camera calibration. $C$ is the reference frame attached to the camera. $S$ is the unit vector in the direction of the sighting vector. $S 1$ and $S 2$ are points of intersection between planes W1 and $W 2$, respectively, and the ray of illumination from I_source. $F$ is a point along the sighting vector. 
An attractive feature of the method of two planes was the ability to calibrate a camera over a wide range of distances. This calibration could be done by using multiple calibration planes $\mathrm{W} \boldsymbol{1}$ to $\mathrm{Wn}$ that spanned the needed ranges. When measurements were required ar a particular distance, the closest two planes to this range could be used. This method tended to reduce errors that would otherwise propagate when extending a sighting vector well beyond its point of origin. Four calibration planes were found in the ORNL system: 3.05, $6.10,10.67$, and $15.24 \mathrm{~m}\left(10,20,35\right.$, and $\left.50 \mathrm{~s}_{\mathrm{t}}\right)$.

To find each camera model, a calibration target was imaged that contained high-contrast features located at known positions. The target had a grid of black diamonds on a white background. The targets were printed on mylar by using a high-precision drafting plotter. Depending on the standoff to the calibration plane, a varying number of the black diamonds were placed on each target. -loser targets had 42 of the image features. More distant targets had to be constructed by using multiple E-size drawings, the largest of which contained 252 diamonds.

Image coordinates and world coordinates of the black diamonds were used to solve for the camera model $\mathrm{L}$ by

$$
\mathbf{W}=\mathbf{P} \mathbf{L},
$$

$\mathrm{W}$ was an $\mathrm{N} \times 3$ matrix with rows containing the world coordinates of the centroid of a particular target diamond. The rows of $\mathbf{P}$ contained augmented vectors of length $D$ that were formed from the image coordinates of each diamond's centroid. Experiments were performed with several forms of augmentation. Vectors containing cross terms of the row $r$ and column $c$ proved to be most effective; for example,

$$
\left[\begin{array}{lllllllllll}
1 & \mathrm{r} & \mathrm{c} & \mathrm{r}^{2} & \mathrm{c}^{2} & \mathrm{r}^{3} & \mathrm{c}^{3} & \mathrm{r}^{2} \mathrm{c} & \mathrm{c}^{2} \mathrm{r}
\end{array}\right]
$$

Hence, the dimensionality of $P(N \times D)$ and $L(D \times 3)$ varied with the type of augmentation. In general, $L$ was not square and the Moore-Penrose pseudoinverse ${ }^{11}$ had to be applied:

$$
\mathbf{L}=\left(\mathbf{P}^{\mathbf{T}} \mathbf{P}\right)^{-1} \mathbf{P}^{\mathbf{T}} \mathbf{W} .
$$

The $P^{T} \mathbf{P}$ matrix inversion was accomplished by an LU decomposition followed by back substitution. 12

The accuracy of the camera model was evaluated by reprocessing the input data. The pixel location of each black diamond was fed into the model, and the resulting three-dimensional location was compared to the actual location on the calibration plane. This fitting error in the model was used as both a measure of numerical performance and a measure of the adequacy of the form of the camera model. The above model yielded an average fit error for each of the black diamonds of $\sim 65$ mils at a target standoff of $6.10 \mathrm{~m}(20 \mathrm{ft})$. This result corresponded to a shift in the image of approximately one-half pixel. 
The difficult aspect of this calibration procedure was determining the location of the target relative to the camera frame. Calibration planes were needed at distances up to $15.2 \mathrm{~m}(50 \mathrm{ft})$ away. Because a $15.2-\mathrm{m}(50-\mathrm{ft})$ optical bench was not available, some method had to be found to accurately locate each of the calibration targets. To achieve this goal a small spot laser was fixed to the sensor mounting plate (see Fig. 3.3). The direction of the spot laser beam was iirst determined, and then the laser was used to locate the calibration target by autocollimation.

Two orientation angles were required to describe the optical axis of the spot beam. These angles were designated as pitch and yaw (see Fig. 3.3) and were the angles in the vertical and horizontal planes respectively. Throughout the calibration and modeling process, the measurement of displacements was much less critical than the measurement of orientations. This difference was due to the tendency of angular errors to be amplified because of their propagation across long distances. Hence, the displacement from the camera frame $\mathrm{C}$ to the point of emission of the spot laser was determined simply by using a ruler.

The pitch of the spot laser was found by leveling the sensor mounting plate and then measuring the change in vertical height of the beam at a distance of $\sim 15.2 \mathrm{~m}(50 \mathrm{ft})$ away. The plate was leveled with a digital clinometer that had been calibrated with an accuracy of $\pm 0.03^{\circ}$. The drop in the beam height was measured by using a water level (see Fig. 3.4). By judging the meniscus of the water to within $\pm 3.2 \mathrm{~mm}(0.125 \mathrm{in}$.), the angular change could be determined to an accuracy of $\pm 0.01^{\circ}$. The yaw of the spot beam was determined in a similar fashion, turning the mounting plate on its side. After these measurements were made, the optical axis of the spot beam was known with respect to frame $C$.

To locate the calibration target relative to frame $C_{\text {, the spot beam was }}$ autocollimated by using a mirror on the target. The orientation of the sensor plate was adjusted until the beam reflected off the target and returned to the point of emission. Because of the divergence of the beam, its center could not be precisely located, but an accuracy of $\pm 6.4 \mathrm{~mm}(0.25 \mathrm{in}$.) at a round trip distance of

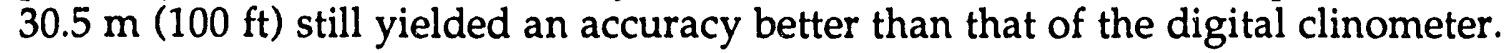
The third orientation of the target (a rotation about the spot beam) was found by leveling the sensor plate with the clinometer and then adjusting a center line on the target to be parallel to a plumb line. This alignment was the least accurate at $\pm 0.06^{\circ}$. However, the error introduced by this inaccuracy propagated much less in the final range calculation than did errors associated with the other orientations.

After the target had been aligned with the beam, the distance along the optical axis to the target could be measured. The location of the spot beam at the target was measured relative to the target's coordinate frame. After all these distances were known, the location of the calibration target's black diamonds could be described relative to the frame $C$. At this point, all the necessary data for the camera calibration was available and an image of the target was captured. 


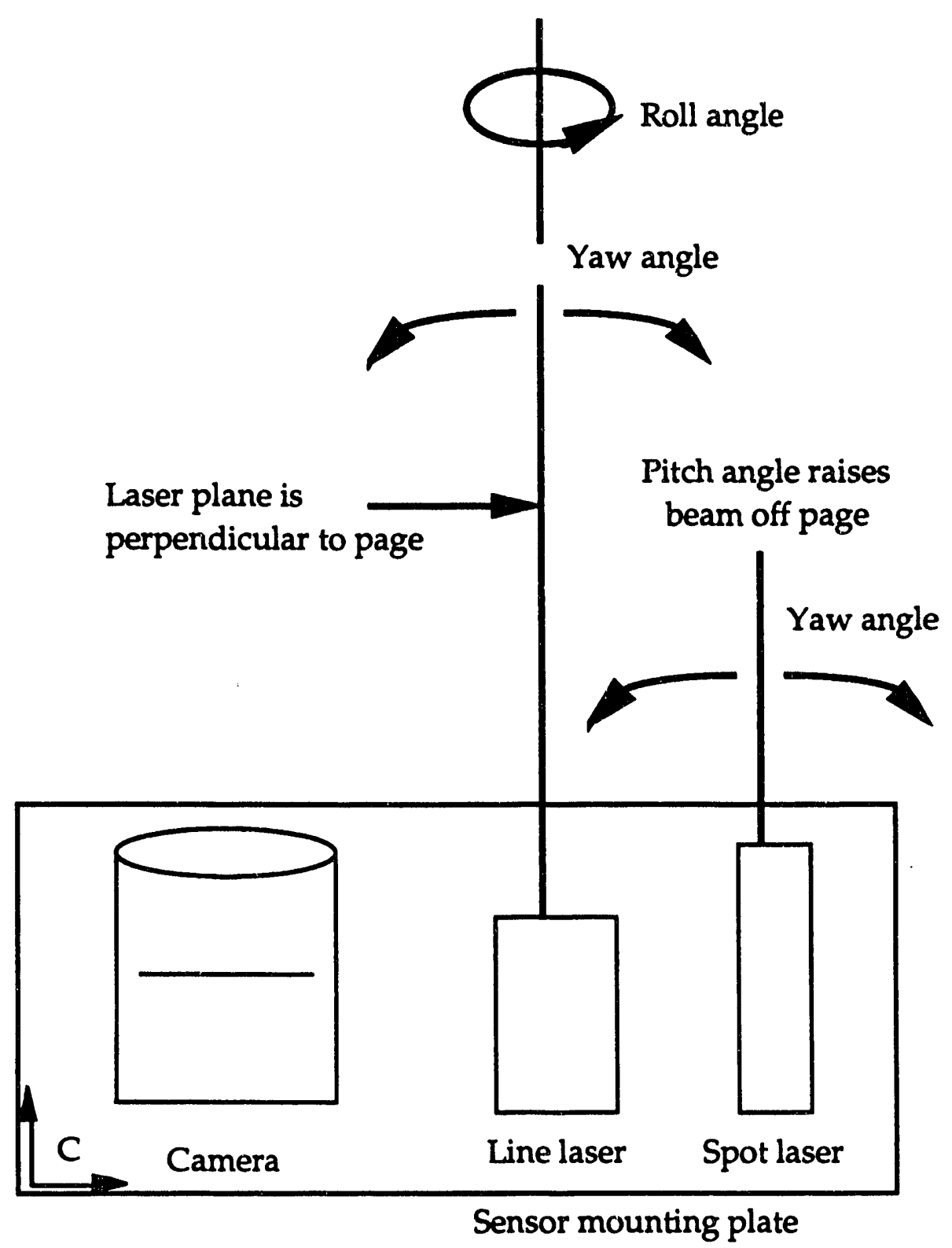

Figure 3.3 Laser orientation relative to the camera reference frame. 

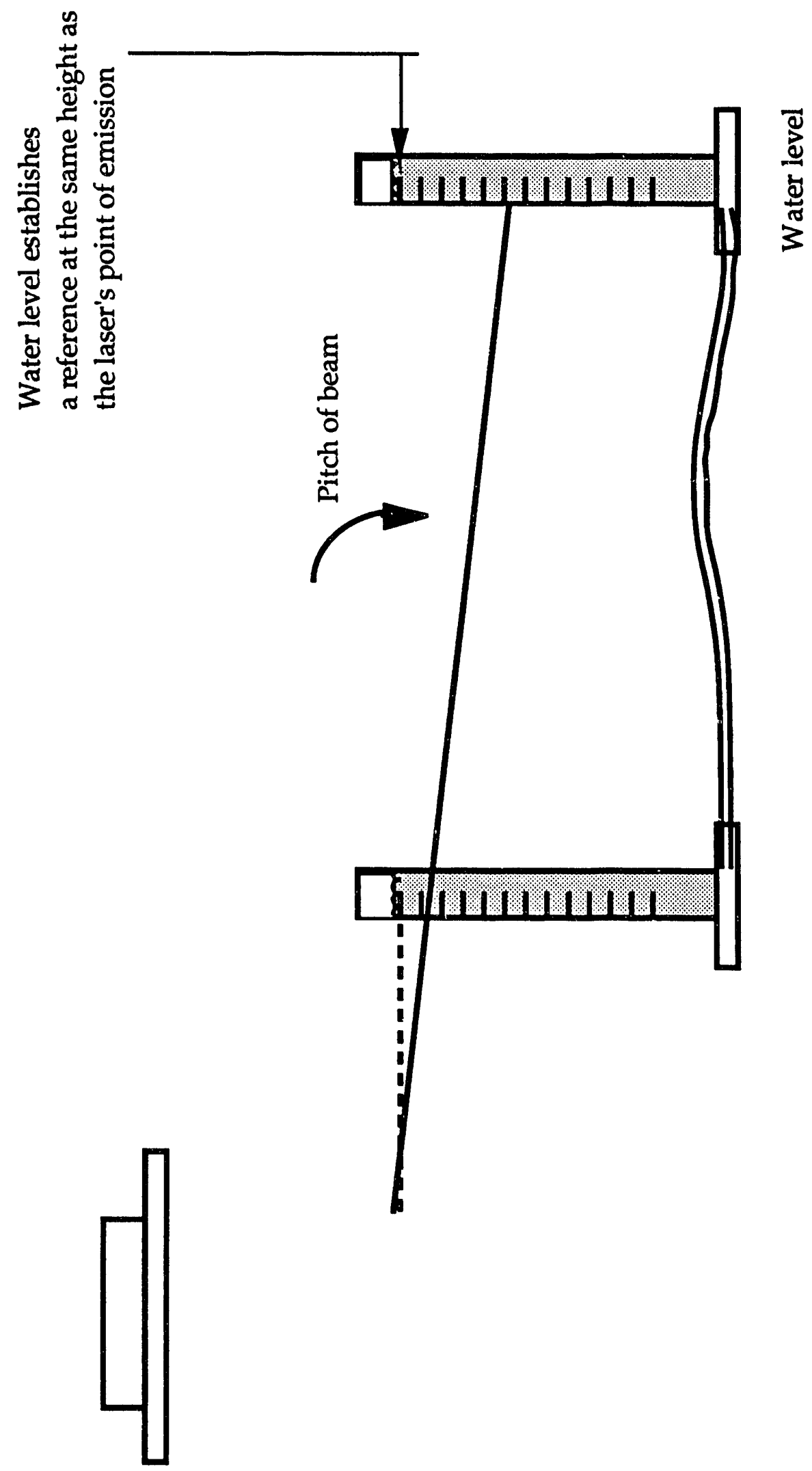

ปี 


\subsection{MEASUREMENT UNIT KINEMATICS}

The camera calibration was required to find a sighting vector associated with each of the pixels at the center of the contour line. The sighting vector then had to be transformed to be expressed with respect to a fixed coordinate frame located at the base of the MU. This transformation required kinematic (geometrical) modeling of the pan-and-tilt mechanisms. Another subject for modeling was the orientation of the plane of laser light.

The kinematics of the pan-and-tilt unit were defined by using DenavitHartenburg (DH) parameters. The dimensions needed for this type of model were obtained from vendor drawings of the rotary stages and from machinist drawings used in the fabrication of custom bracketry. Once the DH parameters had been found the geometry of the pan-and-tilt unit was described by using a homogenous coordinate transform. ${ }^{13}$

The orientation and displacement of the laser plane were measured in a manner similar to that of the spot laser. The laser plane was modeled by using two points. One point was located within the plane of light and the second was displaced a unit distance from the first in a direction along the normal to the laser plane.

\subsection{GLOBAL REFERENCE FRAME}

The kinematic model of the positioning unit allowed both the laser normal and the pixel sighting vectors to be expressed relative to fixed frames at the base of each MU. However, before ranging calculations could be made, these vectors had to be described with respect to the same coordinate frame. This coordinate transformation was determined during system initialization and is described below.

The GRF was composed of three small bulbs inserted into the silo dome in 5-cm-diam (2-in.-diam) sounding ports. The needed coordinate transform was calculated by sighting on the three GRF bulbs and then applying an iterative algorithm to find the ranges to each bulb.

The three-bulb approach used for the GRF represented a critical aspect of the system design. In particular, the design was heavily constrained because of the limited area available on the silo domes. Another factor in the design was the lack of knowledge of the precise geometry of the sounding and access ports on the silo dome. Ruggedness was also a factor because the GRF had to remain in position during the bentonite application. Initial designs focused on a GRF that was inserted into a single sounding port. This GRF insertion eliminated the need to know any interport spacings on the dome. However, a sensitivity analysis demonstrated the need for extremely high tolerances associated with the bulb spacing, and this approach had to be abandoned. A trade-off was made between the difficulty in determining the interbulb spacing versus the sensitivity to errors in sighting each bulb, and it was decided to maximize GRF spacing using the perimeter silo dome sounding ports. 
The ranges to each GRF bulb were found by using a gradient search to minimize a cost function. An initial guess of each distance was determined by using silo blueprints. At each iteration, three trial bulb locations were calculated along each sighting vector by using the current set of ranges. The cost function was evaluated by finding the sum of the squared error between the true bulb spacing and the trial bulb spacing (see Fig. 3.5). The initial guesses proved to be close enough that problems with local minima were not encountered.

Once the range to each bulb ( $r 0, r 1$, and $r 2$ in Fig. 3.6) was determined, the transform relating the MU to the GRF was calculated. The differences in the ranges to bulb 1 and 0 produced a vector parallel to the $x$-axis of the GRF,

$$
X=\mathbf{r} \mathbf{- r o} \text {. }
$$

$\mathbf{X}$ was then given unit length. The vector $\mathbf{A}$ was found in a similar manner,

$$
A=\mathbf{r} \mathbf{2} \text { ro . }
$$

The vector $\mathbf{A}$ did not lie along the $Y$ axis of the GRF, but it did define the $X-Y$ plane. $\mathrm{Z}$ and $\mathrm{Y}$ could then be found by using cross products:

$$
\begin{aligned}
& \mathbf{Z}=\mathbf{X} \times \mathbf{A} \\
& \mathbf{Y}=\mathbf{Z} \times \mathbf{X} . \quad \text { ( } \mathrm{X} \text { is the cross product ) }
\end{aligned}
$$

The vectors $X, Y, Z$, and $\mathbf{r} 0$ were then used to form the transform relating the GRF to an MU base frame,

$$
\mathrm{T}=\left[\begin{array}{c|c|c|c}
\mathrm{X} & \mathrm{Y} & \mathrm{Z} & \mathrm{r} 0 \\
\hline 0 & 0 & 0 & 1
\end{array}\right]=\left[\begin{array}{ll}
\mathrm{R} & \mathrm{r} 0 \\
\hline 0 & 1
\end{array}\right] .
$$

This transform actually has the sense opposite that required for ranging an $\mathrm{A}$ was inverted by using

$$
\mathrm{T}-1=\left[\begin{array}{c|c}
\mathrm{R}^{\top} & \mathrm{d} \\
\hline 0 & 1
\end{array}\right]_{\left(\mathrm{d}=-\mathrm{R}^{\mathrm{T}} \mathrm{r}\right)}
$$


True Bulb Spacing

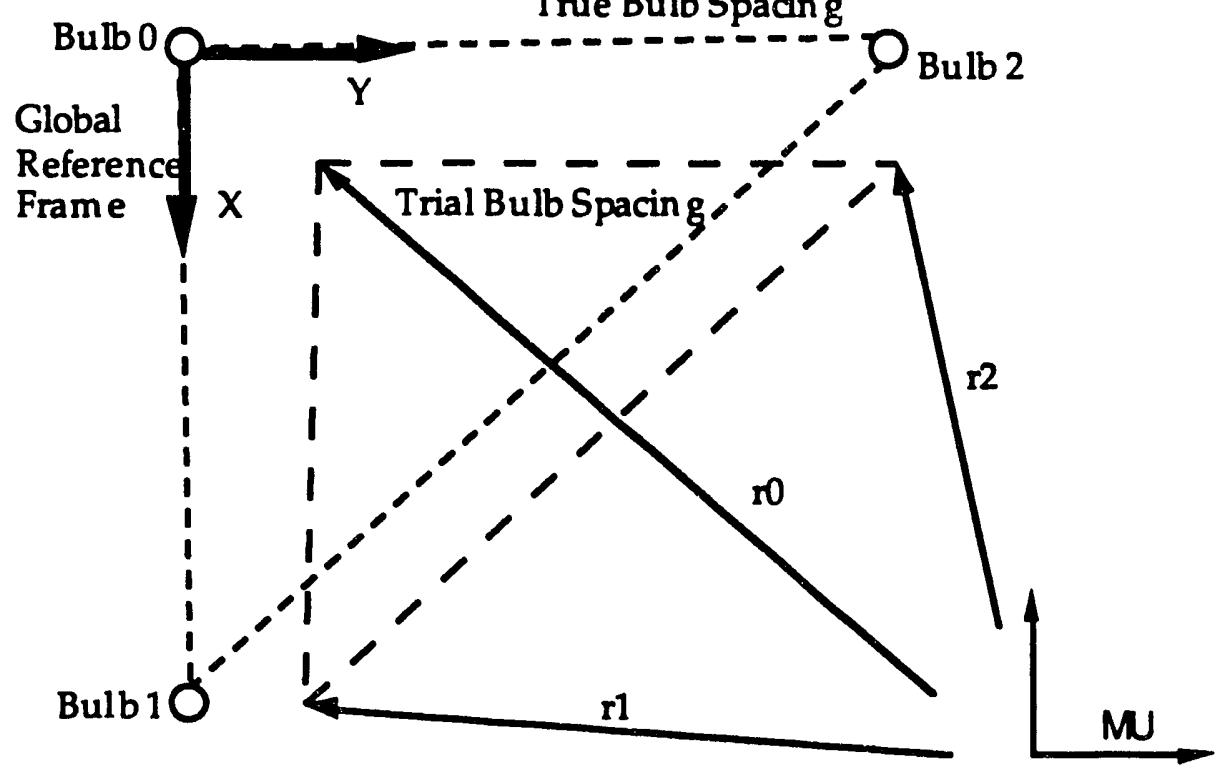

Figure 3.5 Orientation of measurement units relative to the global reference frame (GRF). The vectors $\mathrm{r} 0, \mathrm{r} 1$, and $\mathrm{r} 2$ are the sighting vectors to GRF bulbs 0,1 , and 2 respectively. The lengths of $r 0, r 1$, and $r 2$ are iterated to find a best match to the spacings.

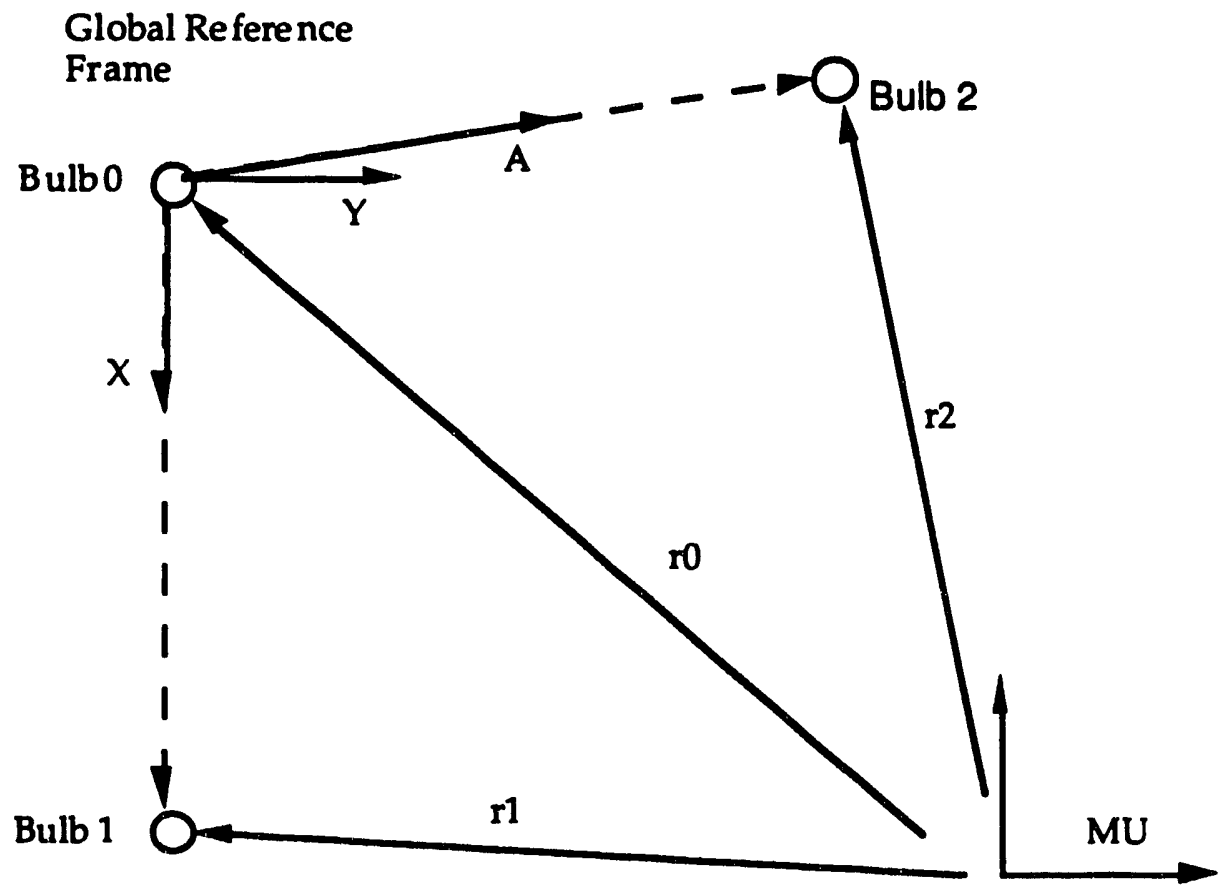

Figure 3.6 Relationship between global reference frame (GRF) and measurement units reference frame. The vectors $\mathrm{r} 0, \mathrm{r} 1$, and $\mathrm{r} 2$, are the sighting vectors fo GRF bulbs 0,1 , and 2 respectively. The unit vectors $X, Y$, $Z$ (out of page) define the GRF orientation. 
This final transform allowed the sighting vectors and the laser plane to be related to the common GRF frame. To determine the GRF sensitivity, the direction of each bulb sighting was perturbed and the effect on the MU location was examined. Changes in the MU location were ranked according to the motion of an auxiliary point that was rigidly attached to the $M U$ frame. The auxiliary point was located $\sim 18.3 \mathrm{~m}(60 \mathrm{ft})$ from the MU origin, thus providing an appropriately sized moment arm to amplify errors. The ratio of bulb displacement to the displacement of the auxiliary point was used to gauge sensitivity. As each bulb was perturbed, the sensitivity ratio varied from $\sim 0.1$ to 3.0. This sensitivity was regarded as being acceptably low, and the GRF design using bulbs spread around the rim of the silo was adopted.

\subsection{SURFACE POINT CALCULATION}

The surface point calculation was straightforward, involving only a single linear equation with one unknown. The calculation determined the distance down the sighting vector that must be traveled before the laser plane was intersected.

The data used to find a point on the waste surface were $n 1$ and $\mathbf{n} 2$, which described the laser plane; and s1 and s2, which described the sighting vector (see Fig. 3.7). The normal to the laser plane was given by

$$
\mathbf{n}=\mathbf{n} \mathbf{2}-\mathbf{n} \mathbf{1} \text {, }
$$

and the sighting vector was

$$
\mathbf{s}=\mathbf{s} \mathbf{2}-\mathbf{s 1} .
$$

The perpendicular distance from the GRF origin to the laser plane was equal to the magnitude of the vector $\mathbf{N}$,

$$
\begin{aligned}
& |\mathbf{N}|=\mathbf{n} \mathbf{1} \text { * } \mathbf{n} \text {. } \\
& \text { ( } * \text { is the dot product) } \\
& \text { ( } 1 \text { I denotes magnitude ) }
\end{aligned}
$$

All points $E$ on the laser plane must then obey the relationship

$$
n * E=|N| \text {. }
$$

The points $\mathrm{F}$ along the sighting vector were generated by using the scalar $\mathrm{t}$,

$$
F=s 1+t s \text {. }
$$




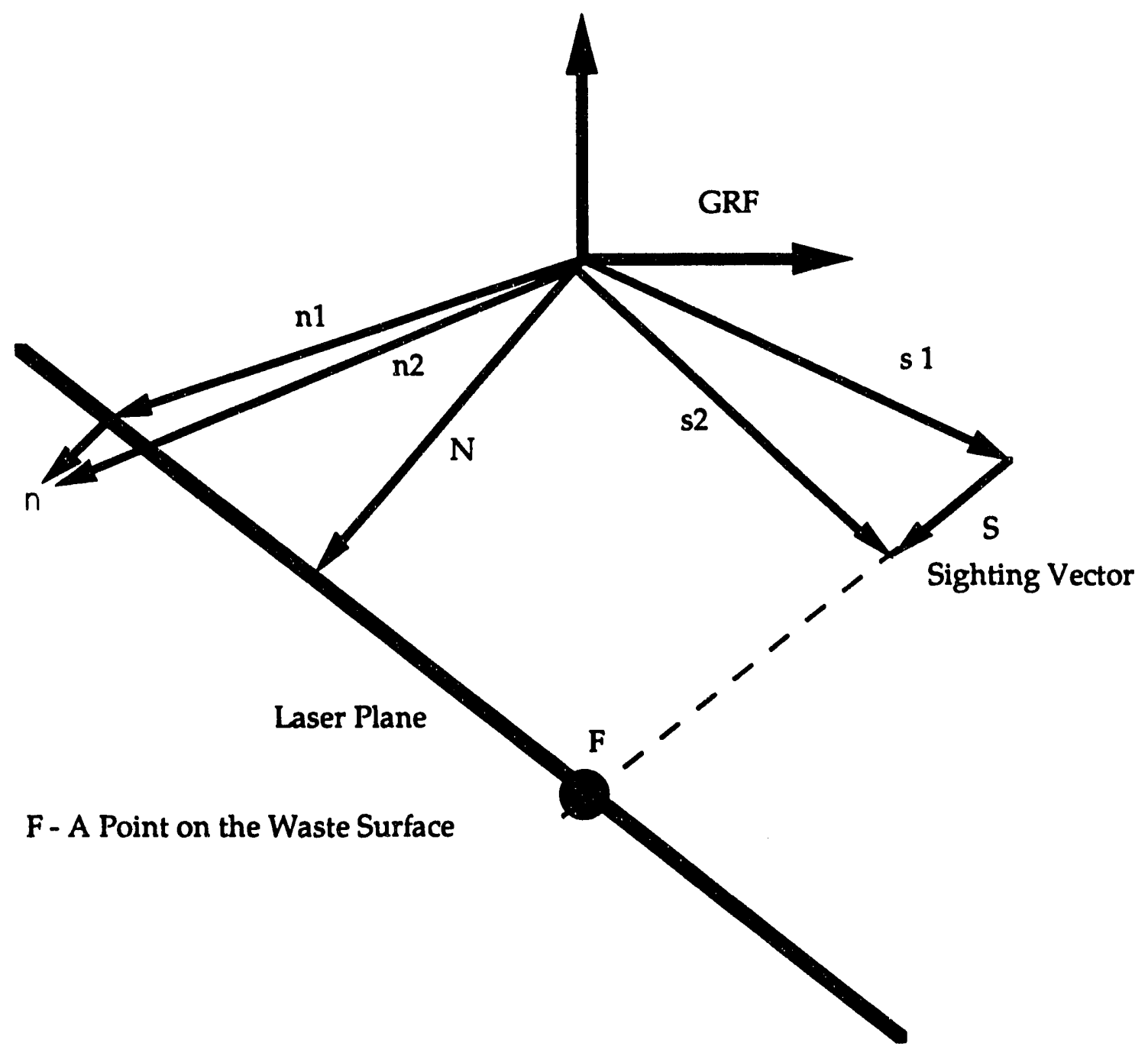

Figure 3.7 Relationship between the global reference frame and a surface point. The sighting vector $S$ from the measurement unit is expressed in terms of the vectors s1 and s2. The unit vector $n$ is the normal to the laser plane, and is expressed in terms of $\mathrm{N} 1$ and $\mathrm{N2}$. $\mathrm{N}$ represents a normal vector from the global reference frame to the laser plane.

Hence, a point that is both on the sighting vector and in the laser plane was found by replacing $E$ with the expression for $F$,

$$
n *(s 1+t s)=|N| \text {. }
$$

Equation (16) involves the single unknown $t$, which gives the distance along the sighting vector that is required to reach the laser plane. The point on the surface is then found by using the expression for $F$ above with the appropriate value of $t$ applied. 


\subsection{OPERATOR INTERFACE OVERVIEW}

The operator interface for the ORNL surface-mapping system was implemented on a Sun SparcStation 2. The configuration consisted of the SparcStation, $16 \mathrm{MB}$ of RAM, a 19-in. monitor, an internal 207- MB hard disk, an external 669-MB hard disk, and a 1/4-in. tape drive. The actual connections to the in-silo imaging hardware were provided by a VMEbus-based system running the VxWorks real-time operating system (refer back to Fig. 2.1). The VME system was used to preprocess the raw image data to generate surface points. The operator interface controlled the VMEbus system through remote procedure calls (RPCs). As the operator indicated surface points or paths along which to scan on a graphic of the silo surface, the software calculated the appropriate intermediate points on the basis of the desired point density and sent a request to the VME system for the scan. The VME system then pointed the camera and laser in the correct direction and determined the surface points at that location. The returned surface data were then plotted on the silo surface graphic, so the latest data were always displayed.

Software for the operator interface was developed by using SunOS with OpenWindows, OpenWindows Developers Guide, and PVwave. OpenWindows Developers Guide was used to develop the graphical user interface. It is a graphical tool that allows a developer to prototype user interfaces by drawing elements of the interface on the screen and then to tie the various elements to callback routines written by the developer. The callback routines and the database through which the data were stored and organized were written in the $C$ programming language under the SunOS. PVwave is a data visualization tool that was utilized to generate surface contour maps and three-dimensional representations of the data. Although PVwave was used during system development and field deployment the contour maps displayed in this report were generated using the Spyglass software package.

The mapping interface was started by typing run $\langle c r\rangle$ at the command line. Run was a shell script that executed the actual interface application code and properly positioned its main window on the screen. The PVwave code, a separate application, was started by typing wave file 1 file $2<c r\rangle$ at the command line. Files 1 and 2 were data files containing the data for two surfaces to be used.

The main window for the operator interface consisted of three primary areas (see Fig. 3.8): the menu bar along the top edge from which commands were selected; the status area on the left edge of the window that displayed current setup files and also contained sliders to adjust the color map; and a large drawing area with a graphic representation of the silo surface. Each of these areas along with their individual elements are discussed in some detail below.

In general, drop-down menus were indicated by a small triangle (with the point down) in the button menu. Clicking the right mouse button with the cursor positioned on the menu button dropped down the menu and the cursor was then dragged to the desired item. When the item was highlighted, releasing the mouse button would select that item. If the left mouse button was pressed 


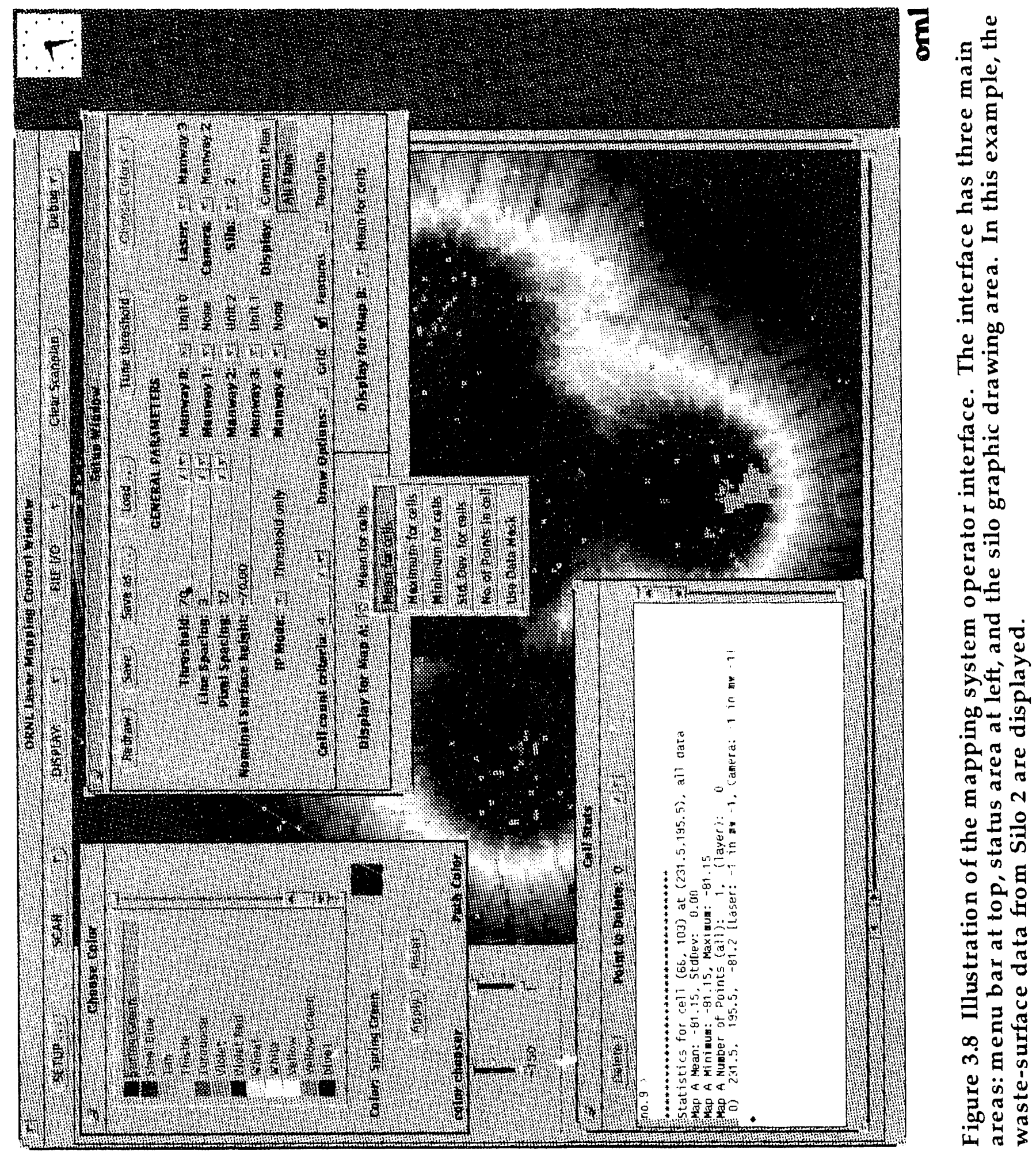


with the cursor over the menu button, then the default menu item was chosen without dropping down the menu. The default item was indicated in two ways: with the left mouse button, the text of the button changed to the default selection and was not activated until the button was released; with the right mouse button, the menu dropped down to display all the selections, but the default selection was outlined.

\subsection{OPERATOR INTERFACE, MENU BAR}

\subsubsection{MENU BAR, SETUP}

The first item in the menu bar was Setup .... Clicking the left mouse button on Setup opened a window that was used to change the current system configuration and preferences (see Fig. 3.9). Six buttons were along the top of the setup window. Redraw forced the silo graphic to be redrawn to reflect the latest changes to the system setup. Although a redraw was executed automatically when the setup window was closed, the redraw button allowed the operator to redraw and see the changes without closing the setup window. A manual redraw button was desirable because a redraw could take many seconds when a large amount of data was in the database; and, therefore, it was not desirable to automatically redraw after each change to system parameters.

The next three buttons in the setup window allowed the operator to Save the current setup to a default file, save the current setup to a specified file (Save as ...), and load the setup from a previously saved file (Load ...).

Tune threshold allowed the operator to see the results of a processed image at a specified location in the silo. The purpose was to allow the operator to adjust the intensity threshold for image processing so that the best (cleanest image, yet brightest laser line) image was available for extracting data. To use Tune threshold, a point on the silo graphic was chosen for the tuning (click with the left mouse button while the cursor was on the desired location). Then the Tune threshold button was clicked. The system aimed the camera and laser at the selected point, an image was acquired, and the image processed. The progress of the operation and the results were viewed on the $36 \mathrm{~cm}$ (14-in.) television monitor. If the results were not satisfactory, the threshold was adjusted (see below) and the process repeated until the desired result was

achieved. This procedure was also used to verify or determine an appropriate Nominal Surface height by observing how well the laser image was centered in the camera field of view. If the laser line was not centered well or not visible at all, then the nominal surface height was adjusted. Some trial and error was necessary to determine an appropriate value.

The Choose Color button allowed the user to customize the colors used for various items on the silo surface graphic. Seven items were available: the Default cell color, the Outside tank color, the Feature color, the Grid color, the Hilite color, the Path color, and the Slice color. The Path color selection was the default menu selection. 


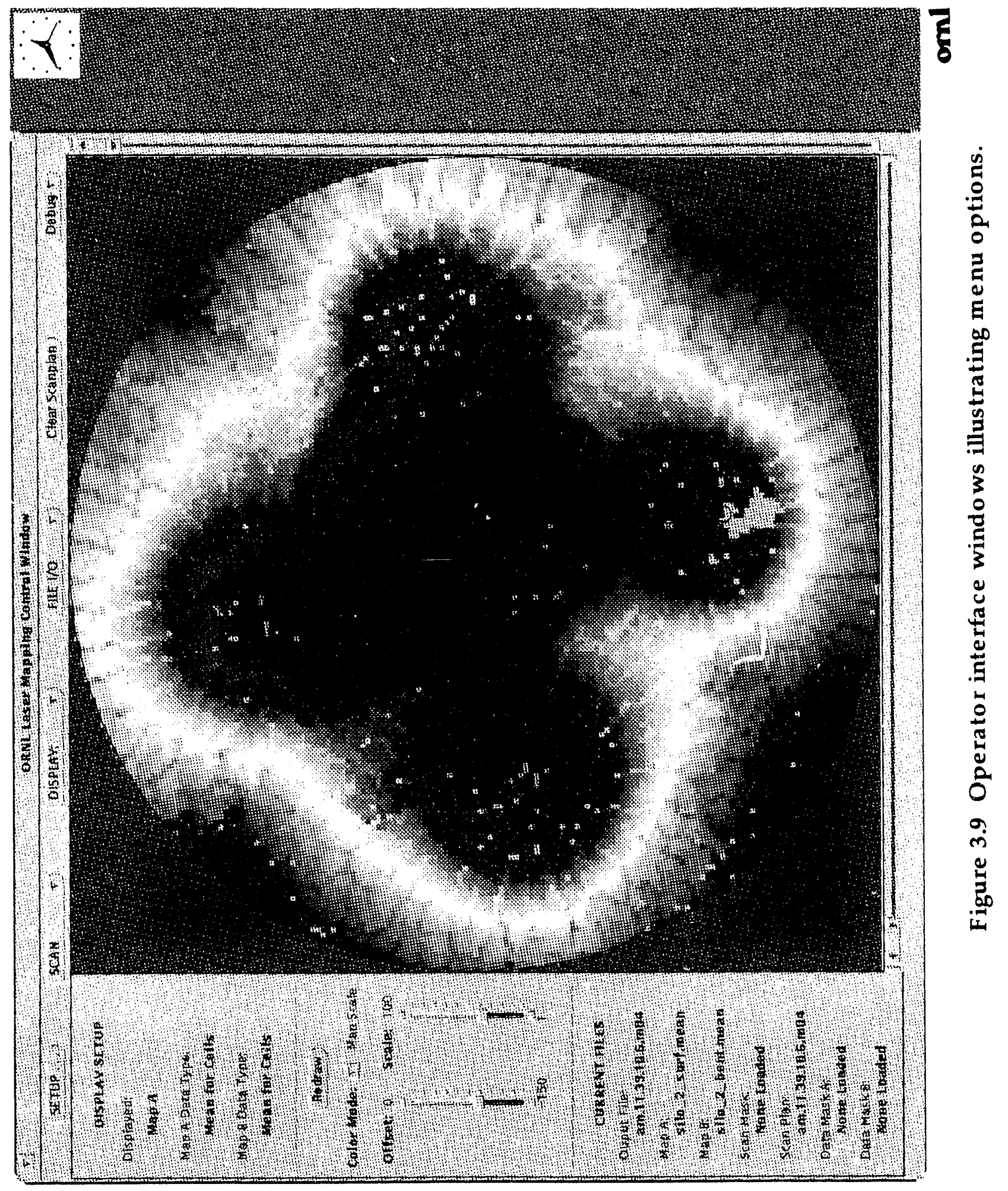


The silo surface graphic was segmented into $15 \mathrm{~cm}$ by $15 \mathrm{~cm}$ (6 by 6-in.) areas referred to as cells. The Default cell color referred to the color used to represent a cell with no surface data. The Outside tank color was the color used to draw the circle representing the tank wall. The Feature color was the color used to draw circles representing the position of the access portals over the waste surface and also the color of the scanning guidelines used as a visual aid for selecting units and areas to be scanned. The Grid color was used for the grid lines that were displayed on the silo graphic to highlight the individual cells. The Hilite color was used to indicate an individually selected cell indicated by a color dot in the center of the cell. The Path color was used for lines that were drawn on the silo surface graphic to indicate paths along which the system was to map. The Slice color was the color used to indicate all data within a specified slice through the surface data. Upon selecting an item whose color was to be changed, a Choose Color window appeared (see Fig. 3.9). Any color in the scrolling list can be selected by clicking on it and then could be changed on the silo graphic by clicking Apply.

General parameters encompassed the balance of the user-selectable preferences for the operator interface. Images were acquired in 256 gray levels and converted to a binary image ( 2 gray levels). The Threshold was the value above which a pixel was converted to white in the processed image and below which a pixel was converted to black. It was necessary to adjust the threshold value to get the best image for the lighting conditions in a particular area to be scanned. Typical values for the Fernald mapping were between 50 and 100 on a scale from 0 to 255 . The number could be typed in and followed by a carriage return, or the up/down arrows could be clicked to increment or decrement to current value. For more information, refer to the information on Tune threshold.

Line Spacing referred to the nominal distance that the system moved the laser line on the surface between image samples. This distance affects the density of surface points acquired and was in turn affected by the Nominal Surface height entered. The Pixel Spacing referred to the spacing in image pixels along the laser line at which surface data points were generated. This value affected the density of surface points generated along the line as opposed to Line Spacing, which affected density of acquired surface points perpendicular to the direction of a scan.

Nominal Surface height referred to the distance from the reference plane defined by the global reference lights to the surface to be scanned. This value was used by the system in calculations required to aim the camera and laser at a specified point on the surface. Because this value was not normally known to a high degree of accuracy, some trial and error was required to set the value.

IP Mode indicated the current image processing mode. The mode could be changed through the drop-down menu indicated by the small triangle. Three modes were available: Threshold only, Absolute difference, and Erode/Dilate. Threshold only was the fastest and most common choice. The other modes traded-off better image noise reduction with reduced speed. 
Cell count criteria referred to the number of surface points required in a cell before the system considered the cell complete. If a single cell was selected for a scan rather than a path to scan along, then the system would not remove the cell from the scan plan unless the number of surface points equaled or exceeded the Cell count criteria. Therefore, the system tried to scan the cell again in any subsequent scan.

The Manway 0 through Manway 4 items allowed the user to specify to the system where the MUs were located. The available selections through the dropdown menus were None, Unit 0, Unit 1, and Unit 2. The Laser and Camera items allowed the user to specify which access portals contained the MU to use as the laser and camera, respectively. These designations were used on subsequent scans. The current silo to be scanned was identified with the Silo item. Four choices were available: ORNL, 1, 2, or 4. ORNL referred to the test site at ORNL.

The balance of the items in the setup window controlled the appearance of the display and the data selected for display. The Display item had two options: Current Plan and All Plans. Current Plan caused the system to display only those surface points generated with the currently selected pair of units. Data in the database generated with any other MU would not be displayed. Selecting All Plans caused all surface data to be displayed no matter which units generated the data. The Draw Options were Grid, Features, and Template. These options were used to turn on (checked) or off (unchecked) the options. Clicking on the check box for each toggled the check mark on or off. The remaining two controls, Display for Map A and Display for Map B, allowed the user to specify exactly what type of data was to be displayed on the silo graphic. Two surface maps, map A and map B, could be loaded into the database simultaneously to facilitate the calculation and display of the differences between two maps. Several types of displayable data could be selected from the dropdown menus: Mean for cells, Maximum for cells, Minimum for cells, Std. Dev. for cells, No. of points in cell, and Use Data Mask. The first four choices caused the selected statistic for data within each cell to be displayed as a color based on the magnitude of the statistic. Red corresponded to the minimum value, and purple corresponded to the maximum value in the range specified. The mapping of specific values to specific colors was controlled by the sliders in the main window and will be described later. The No. of points in cell item allowed the user to visualize the density of surface data on the silo graphic by mapping the number of data points in each cell into a range of colors. The Use Data Mask item was intended to allow the user to specify data masks that would allow different types of data to be displayed in different areas of the same map. As it turned out, the feature was not necessary and, therefore, was never implemented. It could be eliminated from the interface.

\subsubsection{MENU BAR, SCAN}

The Scan menu button and associated drop-down menu were used to initiate a scan of the surface to collect surface data. Three items were in the dropdown menu: Start Scan, Cancel Scan, and Choose Output File. The default choice was Start Scan. When selected, it initiated communications with the VME 
system and sent MU positions calculated from scan plans drawn on the silo graphic. The VME computer then collected the appropriate data and returned them to the SparcStation for entry into the database and for display on the silo graphic. The Cancel Scan item would stop the system from completing a scan plan involving multiple paths and cells, but it would do so only at the end of the current path. Choose Output File allowed the operator to specify a file into which the system would write subsequent surface data. This file provided not only a backup to the main database in memory but a means of breaking the data into smaller incremental files. The full database in memory could be manually written to a file with the file input/output $(\mathrm{I} / \mathrm{O})$ menu described below.

\subsubsection{MENU BAR, DISPLAY}

The Display menu button and associated drop-down menu allowed the user to choose the current map to be displayed on the silo graphic. Display Map A was the default choice, followed by Display Map B, Display Layer B-A, Display Layer B-A slice, and Display Data Mask. Display Map A, Display Map B, and Display Layer B-A displayed either the data loaded as map A, map $B$, or the difference between maps A and B. Display Layer B-A slice caused the difference between maps $A$ and $B$ to be displayed, not as a continuous color map related to the surface height, but as a three-color map. Everything above $30 \mathrm{~cm}$ (12-in.) was blue, everything below $15 \mathrm{~cm}$ (6-in.) was red, and the surface heights within the slice 15 to $30 \mathrm{~cm}$ (6 to $12 \mathrm{in}$.) were displayed in yellow. As pointed out earlier, the Display Data Mask item was found to be unnecessary and was never implemented.

\subsubsection{MENU BAR, FILE I/O}

The File I/O drop-down menu controlled the loading and saving of map data to files. The five major items, each with its own hierarchical drop-down menu, were Map A, Map B, Scan Mask, Scan Plan, and Data Mask. Scan Mask and Data Mask were not required and were never made functional. The Map A and Map B items allowed the user to Load, Save, Save Displayed Data, and Clear the respective databases in memory. Map A and Load were the default selections. Load and Save bring up an additional dialog that allowed the user to enter the name and path of a file to load or save. Loading a map from file added the data from the file into the current database in memory rather than overwriting the existing data, so the current map was cleared before loading if that is not desirable. Save Displayed Data allowed the user to save whatever data were currently displayed for the map in a file with only one data point per cell. This feature results in a much smaller file that could be loaded into memory much faster. The saved data could be the mean, maximum, minimum, standard deviation, or number of points in a cell, depending on the current setup. Clear just removed the data for the map from the database in memory (erased the map). The Scan plan item utilized only Load, Save, and Clear, but otherwise was identical to Map A and Map B. This item was used to clear scan plans, save 
scan plans, or load previously saved scan plans. Scan plans were drawn on the silo graphic and were utilized to communicate to the system where to map.

\subsubsection{MENU BAR, CLEAR SCANPLAN}

The Clear Scanplan button was provided to make it more convenient to clear scan plans from memory. It was identical in function to the Scan plan Clear function under the File I/O menu.

\subsubsection{MENU BAR, DEBUG}

The Debug menu provided some convenient features for development and debugging, but it was not useful for general mapping. The three selectable items in the drop-down menu were Database Status, Kill Meas. Task, and Shell window. Database Status returned statistics about the database, (e.g., the number of entries in the database). Kill Meas. Task terminated the mapping task on the VME system, and Shell window was not implemented.

\subsection{OPERATOR INTERFACE, STATUS AREA}

The status area along the left edge of the main window (see Fig. 3.8) was used to indicate the current display setup, the color mapping, and the current files in use. The Display Setup area indicated which map was currently displayed (Map A, Map B, Layer B-A, etc.) and, for the two possible maps in memory, which type of data was displayed in the cells (mean, max., etc.).

A color map control area was in the center of the status area that not only indicated the current offset and scaling to be applied to the color map but allowed the user to vary the values while viewing the silo graphic. Redraw, of course, caused the screen to be redrawn if desired. Color Mode had two possible values: Man scale (manual scale) and Auto scale. Man scale utilized the values of offset and scale, set with the sliders, to generate the color mapping of surface data. Offset allowed the user to adjust the value of height to which the red (the bottom of the color map) color was mapped. Scale allowed the user to adjust the range of heights over which the color map was spread for display purposes. In other words, the color map from red to purple is mapped to a band of heights of which offset was the minimum. Scale was then related to the width of the band. Anything below the band or range was mapped to red, and anything above the range was mapped to purple, with a continuous color map in between. The units were nominally in inches. With the auto scale option, the system attempted to spread the color map over the full range of data currently in the database.

The Current files area indicates which files are currently in use. The Output file is the file to which new data was written as they were acquired by the system. Map A and Map B files were those files that were currently loaded into the database representing map $A$ and map B. The Scan Plan file was the name of the currently loaded scan plan, if loaded from file. The other files were not utilized and should indicate none loaded. 


\subsection{OPERATOR INTERFACE, SILO GRAPHIC}

The silo graphic was used not only for display of mapping progress and data but to input mapping requirements to the system. By clicking on an individual cell with the left mouse button, the cell was highlighted with a color dot in the center. If not cleared, the system would attempt to map that cell on the next scan initiated. A highlighted cell could be cleared by clicking the cell again with the left mouse button to toggle it off. Multiple cells could be selected for a scan and would constitute what was referred to as a scan plan.

Scan paths could also be entered into a scan plan. A path on the surface was indicated by highlighting a single cell with the left mouse button, then clicking in another cell somewhere on the surface by using the center mouse button. A line was drawn between the two cells indicating the path along which the system would attempt to scan (see Fig. 3.10). A single scan path could be cleared by clicking on one of the end points using the right mouse button. An entire scan plan could be cleared by clicking the Clear Scanplan button in the menu bar. Using a number of short lines was better than lorig lines for a scan plan to facilitate canceling the scan or changing the scan as the operator saw the data coming in. In general, drawing the scan paths somewhat radially frum the unit acting as the laser was advisable. This selection caused the laser to move perpendicular to the direction the line was drawn on the surface and made the generation of data more efficient.

Detailed information on an individual cell was obtained by holding down the shift key while clicking on the cell with the left mouse button. This action brought up a Cell Stats window (see Fig. 3.9). In the window, the cell position was detailed in cell coordinates and in $x$-y coordinates (in inches) relative to the GRF. Cell statistics were also listed including mean, standard deviation, minimum, maximum, and number of surface data points in the cell. Each individual data point was then listed in $x-y-z$ coordinates (in inches) relative to the global reference frame. Also listed for each point was the unit used as the laser to generate that point, the unit used as the camera to generate that point, and the access portals in which each unit was located.

Because reflections, plastic bags, or other adverse scanning conditions could sometimes result in bogus surface data, a Delete button was added at the top of the window to allow such points to be removed from the database. The number of the point was entered followed by a carriage return, and then the Delete button clicked. Such points usually differed widely from the normal points and, thus, significantly impacted the mean and standard deviation for a cell. Because of this large deviation, bogus data were readily identified. Cells for which no surface data were obtained appeared as small squares the color of the silo graphic background (see Figs. 3.8 and 3.10). 


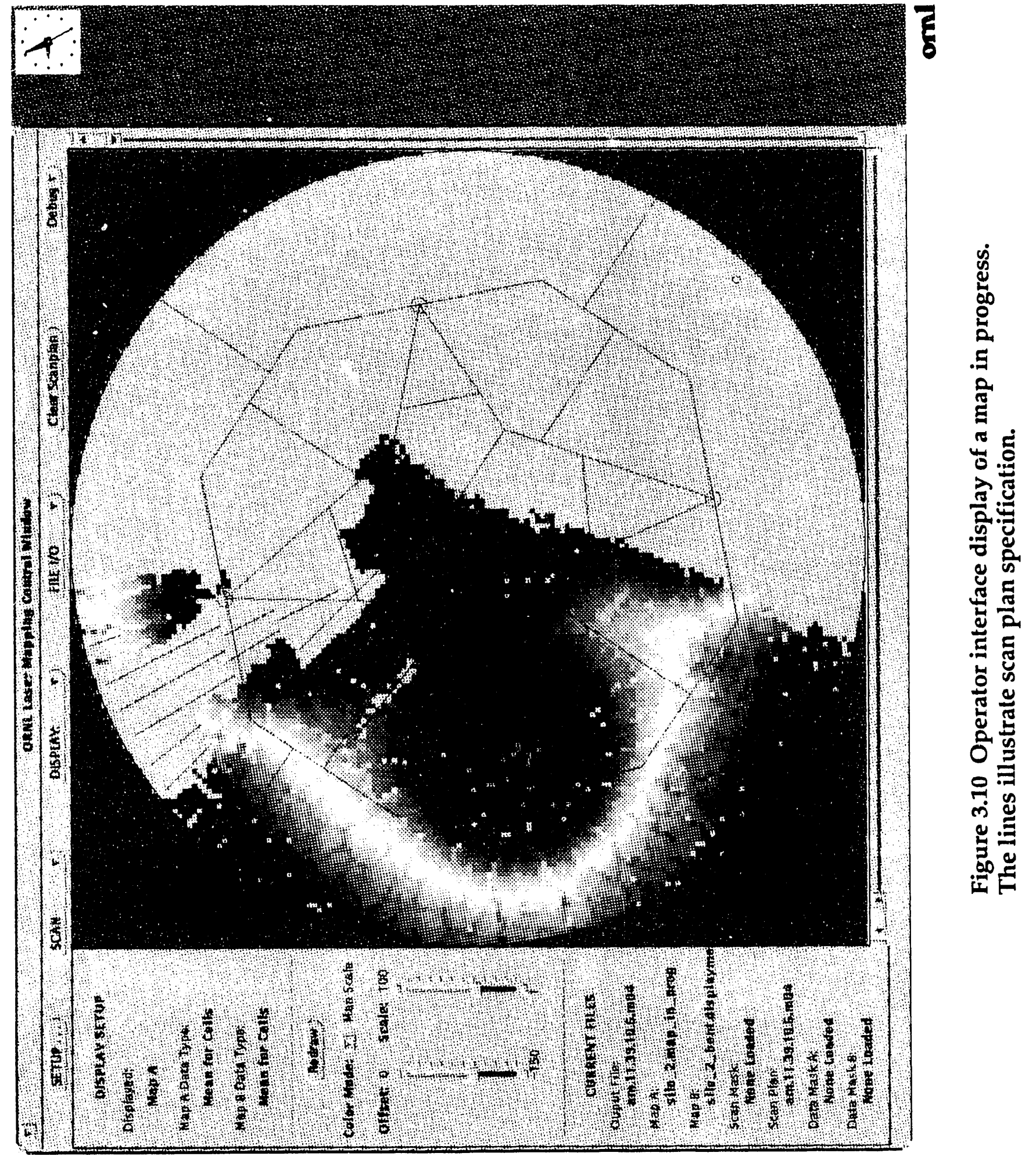




\subsection{OPERATOR INTERFACE SUMMARY}

The functions described above were combined to provide the operator with a powerful yet user-friendly tool for initiating data acquisition, data storage, and analysis. The operator did not need to understand the most intricate details of the ineasurement system to successfully acquire and analyze surface data. The interface allowed rapid, highly automated determination of setup parameters as well as quick and simple data acquisition. Original attempts to use the PVwave software package as part of the operator interface were not satisfactory, because data could not be displayed in real time. With the custom operator interface developed by ORNL, data was acquired, displayed and analyzed simultaneously. The ability to queue multiple scans increased data acquisition efficiency tremendously because it allowed data acquisition to continue during evacuations due to radon levels above threshold and other activities that prevented full-time operator attention to data acquisition. The system was sufficiently user friendly that operators with no previous experience on UNIX operating systems or VxWorks operating systems could be competent system operators in less than one day of supervised operations at the controls. ORNL successfully trained WEMCO staff members to operate the system during the field deployment campaigns. 


\section{SUMMARY OF SILO 4 TEST}

Prior to field deployment in the waste storage silos, the surface mapping system was operated in a technology demonstration and test in Silo 4 at Fernald during July and August 1991. For these tests, a wooden box $2.5 \times 0.3 \times 0.3 \mathrm{~m}$ $(8 \mathrm{ft} \times 12.5 \mathrm{in} . \times 12.5 \mathrm{in}$.) was placed on the floor of Silo 4 as a standard target. ORNL demonstrated the ability to determine the height of the box to within $6 \mathrm{~mm}(0.25 \mathrm{in}$.) for a number of test circumstances including changing emitterreceiver pairs and scanning the box in two different locations on the silo floor (below a manway and between two manways). The variations in box height measurements along the length of the box were consistently within $\pm 2.5 \mathrm{~mm}(0.10$ in.) of the average value. In principle, the $x$-y horizontal accuracies should be equivalent to the $z$ accuracy. However, because of data display limitations during the Silo 4 test, $x-y$ data were binned in $5-\mathrm{cm}(2$ in.) or greater bins; therefore, measured accuracies in the $x-y$ directions were limited by the data quantization. The width and length of the box were consistently measured correctly to within one bin dimension, $\pm 5 \mathrm{~cm}$ ( 2 in.).

Because the exact height of the global reference lights above the Silo 4 floor could not be easily determined, only relative accuracies could be tested convincingly. The dominant source of uncertainty in the absolute measurement of surface height was lack of an accurate determination of the location of the GRF with respect to the silo vertical walls. The GRF location could be calculated from silo blueprints but these calculated values could not easily be verified empirically. In retrospect, lowering a plumbed line through these sounding ports to measure height above the surface in the Silo 4 test would have been useful but the emphasis at the time was on accurate measurements of surface height change. The GRF lights were mounted $\sim 15 \mathrm{~cm}(6 \mathrm{in}$.) above the top of the vertical walls with an uncertainty of $\pm 7.6 \mathrm{~cm}(3 \mathrm{in}$.), based on camera inspection of the location of the GRF with respect to the silo vertical walls. This uncertainty was an order of magnitude larger than the uncertainty in measured box height. The primary objective of this development project was to determine with high accuracy the change in surface height; therefore, a more accurate measurement of absolute surface height was not pursued in Silo 4.

The measurement system performed well during the cold test, and data quality ( $6 \mathrm{~mm}$ accuracy, $2.5 \mathrm{~mm}$ repeatability, $25 \mathrm{~cm}^{2}$ data density) far exceeded the minimum requirements of the site which were as follows: surface height change accuracies of $\pm 5 \mathrm{~cm}\left(2 \mathrm{in}\right.$.) and data density of at least one point per $0.1 \mathrm{~m}^{2}$ $\left(1 \mathrm{ft}^{2}\right)$. However, a number of areas were identified that could be improved prior to the field deployment. These deficiencies were primarily related to mapping throughput, improved automation in the data acquisition and display process, camera heating, and improved cable handling. During the afternoons of the Silo 4 tests when ambient temperatures reached above $32.2^{\circ} \mathrm{C}\left(90^{\circ} \mathrm{F}\right)$, camera contrast degradation was observed as a result of internal heating and insufficient thermal gradient with the ambient air. After the Silo 4 tests were completed, small fans were installed inside the camera housings to help with cooling. Many 
of the MU cable connections were combined on bulkhead connectors to simplify cable handling for the gloved operations required during field deployment of the MUs.

In addition to the functionality demonstrated during the Silo 4 test, the project team practiced glove bag installation, cable routing, cable connection, and installation of the GRF light assemblies. Many improvements resulted from practice under the on-site logistical constraints, (e.g., a modified glove bag design). Another benefit of the predeployment test was that the Rust Engineering and WEMCO participants had a chance to become familiar with the equipment and installation requirements. One reason for performing the Silo 4 tests with RUST and WEMCO personnel was to reduce the time required on the domes of Silos 1 and 2, therefore, reducing the dose rates to the workers, especially for the prebentonite baseline mapping.

During the interim between the Silo 4 test and field deployment, greater emphasis was placed on development of automated functions to reduce operator interaction with the control system. In addition to automating much of the setup procedure and data acquisition, ORNL also partitioned the code in a more efficient manner, reducing the calculation load on the VME system. With these improvements, mapping throughput was reduced from about two weeks for Silo 4 in the predeployment test to two days for Silo 2 waste baseline surface mapping. The mapping efficiency improvements identified during the Silo tests and implemented thereafter along with enhancements implemented during the baseline mapping campaign allowed the mapping to be completed within the allotted time prescribed by the overall schedule for meeting the Silos 1 and 2 Removal Action Milestone. 


\section{SUMMARY OF FIELD DEPLOYMENT}

\subsection{INTRODUCTION}

Installation of the surface mapping system in the K-65 silos began on September 24, 1991. Mapping began in Silo 1, where a number of tests were performed including reversal of emitter-receiver units and mapping from selected combinations of access portals. After verifying that all MUs were operating reliably, the mapping began in earnest. Many small improvements were incorporated in the system software during the early part of the campaign.

Frequently, the control station was evacuated because of high radon concentration in the immediate area. Because this was the first attempt to install the system in a radioactive silo, lessons were learned along the way, and installation seemed to take much longer than anticipated. A steel basket was suspended and anchored over the center entry portal of each silo during MU installation to eliminate live loads on the center $6 \mathrm{~m}(20-\mathrm{ft})$ section of the dome. During removal of the center entry portal protective dome covering, cross beams were discovered that necessitated sawing and hinging the flange on the MU that was installed in the center entry portal MU. Even with this modification, it was a difficult task to position the center manway. The difficulty was primarily related to the fact that the small door through the bottom of the steel basket limited the access of installation personnel. Also, the access portal was several feet below the bottom of the steel basket so the workers were required to reach down and through the doorway while handling various tools and the $36 \mathrm{~kg}(80 \mathrm{lb}) \mathrm{MU}$ and the access portal flange.

The baseline mapping completion deadline given the team was October 12, 1991. This date was chosen to allow sufficient time to install and test the bentonite-emplacement equipment. Waste surface mapping of both silos was completed in the early morning of October 11 . As a result of the learning process on Silo 1, mapping of Silo 2 required only 47 hours from start of mapping to completion even though this surface was much more irregular. Data for each silo was stored in 15- by $15-\mathrm{cm}$ (6- by 6-in.) bins to provide a factor of frur greater data density than requested (one point per square foot). In addition to the surface maps, videotapes were made of the silo interior. To assist with data verification before and after bentonite emplacement, a series of digitized images were acquired at $10^{\circ}$ to $15^{\circ}$ intervals using the center MU camera facing horizontally out to the silo perimeter walls. Discussions of the mapping results and data plots are presented in the next section.

The MUs and other equipment installed inside the K-65 area fence were slightly contaminated and were left at Fernald in the interim between baseline mapping and bentonite mapping. Most of the control station hardware was shipped back to ORNL for off-line data analysis and plotting. Black-and-white contour maps and wireframe plots were generated immediately. Color plots of the silo graphic data required some data analysis and reduction as well as software preparation. 


\subsection{BASELINE WASTE-SURFACE MAPS}

Results of the waste-surface mapping included some surprises (see Figs. 5.1 through 5.6). The surfaces were not as smooth and flat as previous videotapes had indicated. The waste surfaces were littered with deep cracks and crevices and were very craggy, with hundreds of small puffy areas surrounded by cracks. The surfaces strongly resembled dried mud flats. The surfaces were nominally crown shaped with dropoffs of 0.6 to $1 \mathrm{~m} \mathrm{(2} \mathrm{to} 3 \mathrm{ft}$ ) from the center to the walls. Large mounds were located near all five access portals of Silo 2 and near the southeast access portal of Silo 1. The mound in Silo 1 was about $6.5 \mathrm{~m}$ $(21.5 \mathrm{ft})$ wide and about $0.8 \mathrm{~m}(2.5 \mathrm{ft})$ high and peaked at about $2 \mathrm{~cm}(0.8 \mathrm{in}$.

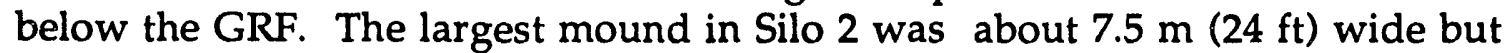
reached a height of nearly $2 \mathrm{~m}(6.5 \mathrm{ft})$. The top of this mound was about $5 \mathrm{~cm}$ ( 2 in.) above the GRF. Because the GRF was located about $15 \mathrm{~cm}(6 \mathrm{in}$.) above the top of the vertical walls, the peaks of the highest mounds in each silo were above the top of the vertical walls. The waste-surface data were used to plan for the bentonite emplacement and also as a baseline for bentonite-thickness measurements. Volumetric analyses were also performed to determine the volume of waste in each silo (see Section 5.4).

A number of methods can be used to display the three-dimensional data that were gathered in Silos 1 and 2. Presented here are surface-contour maps generated by using Spyglass software (see Figs. 5.1 and 5.2) and also color plots obtained by using the silo graphic portion of the operator interface (see Figs. 5.3 and 5.4). The operator interface color plots use 256 colors in a continuous blend from purple to red to indicate the vertical dimension (surface height). As a result of this color resolution, features like the crevices are retained in the surface data in spite of the coarse binning ( 15 by $15 \mathrm{~cm}$ ). Maximum and minimum surface heights are indicated in the figures, but intermediate heights are difficult to associate with specific colors. Therefore, in addition to the 256 color plots, we have included surface maps displaying the data in fewer colors by using $15-\mathrm{cm}$ (6-in.) topographical depth contours (see Figs. 5.5 and 5.6). The resolution of the 256 color maps is sacrificed; however, each color can now be readily associated with a surface height.

Some areas in the silos were difficult to map because either the laser or the camera view was occluded. These areas tended to be inside the crevices, behind sharp mound tops, or where the core drilling campaign had chopped up the mounds into highly irregular shapes. Bins for which no data were obtained appear as white squares in the color plots or as an outlined area in the contour plots. Where only one or two bins were missing data, the contour plots have been smoothed to eliminate the misleading information that blank regions would present. Efforts were made on-line to fill in the missing data, but because of the occlusion geometries, some small isolated areas remained unmapped. 


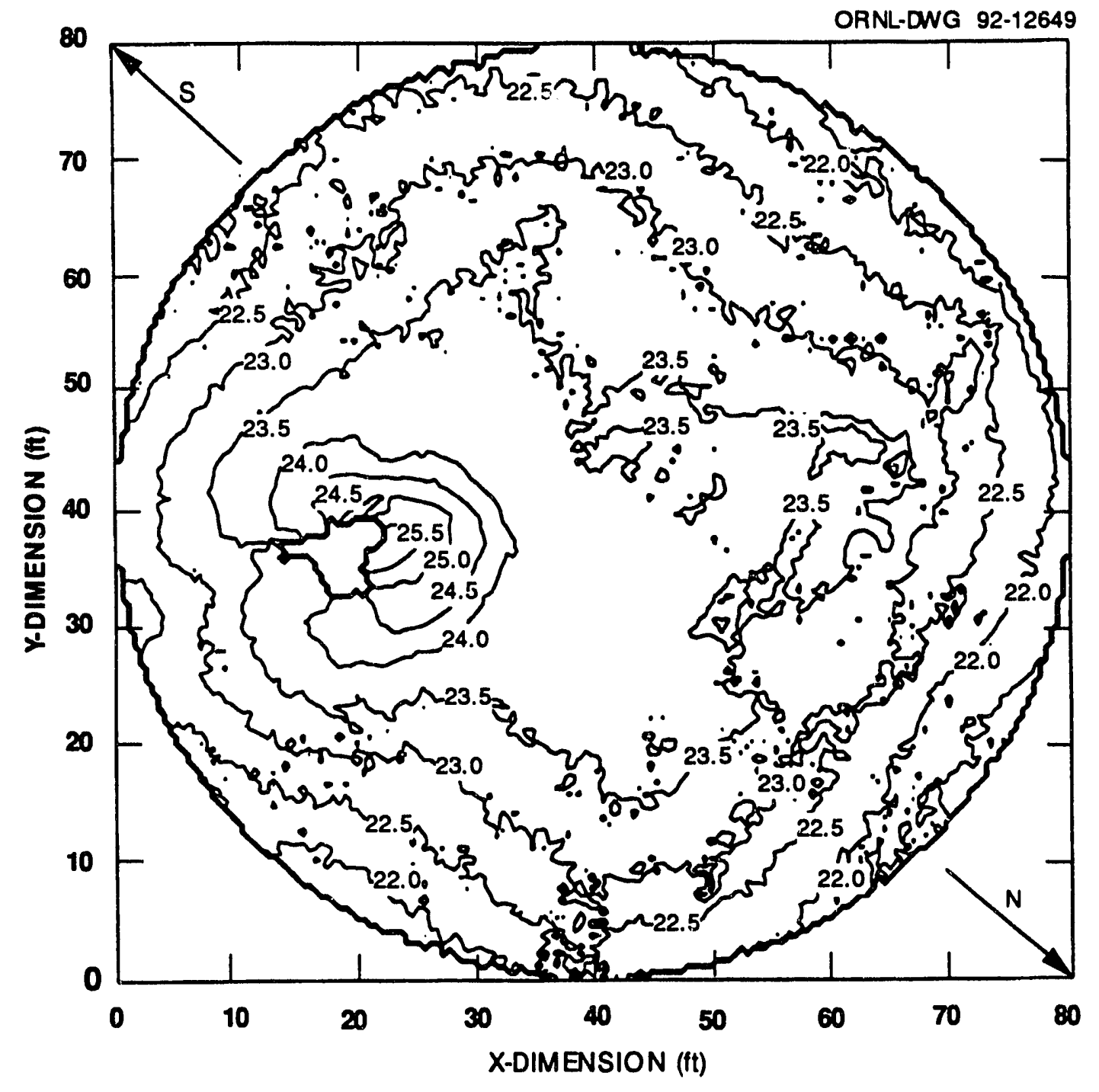

Figure 5.1 Con tour plot of Silo 1 baseline waste-surface data (6 inch contours). 


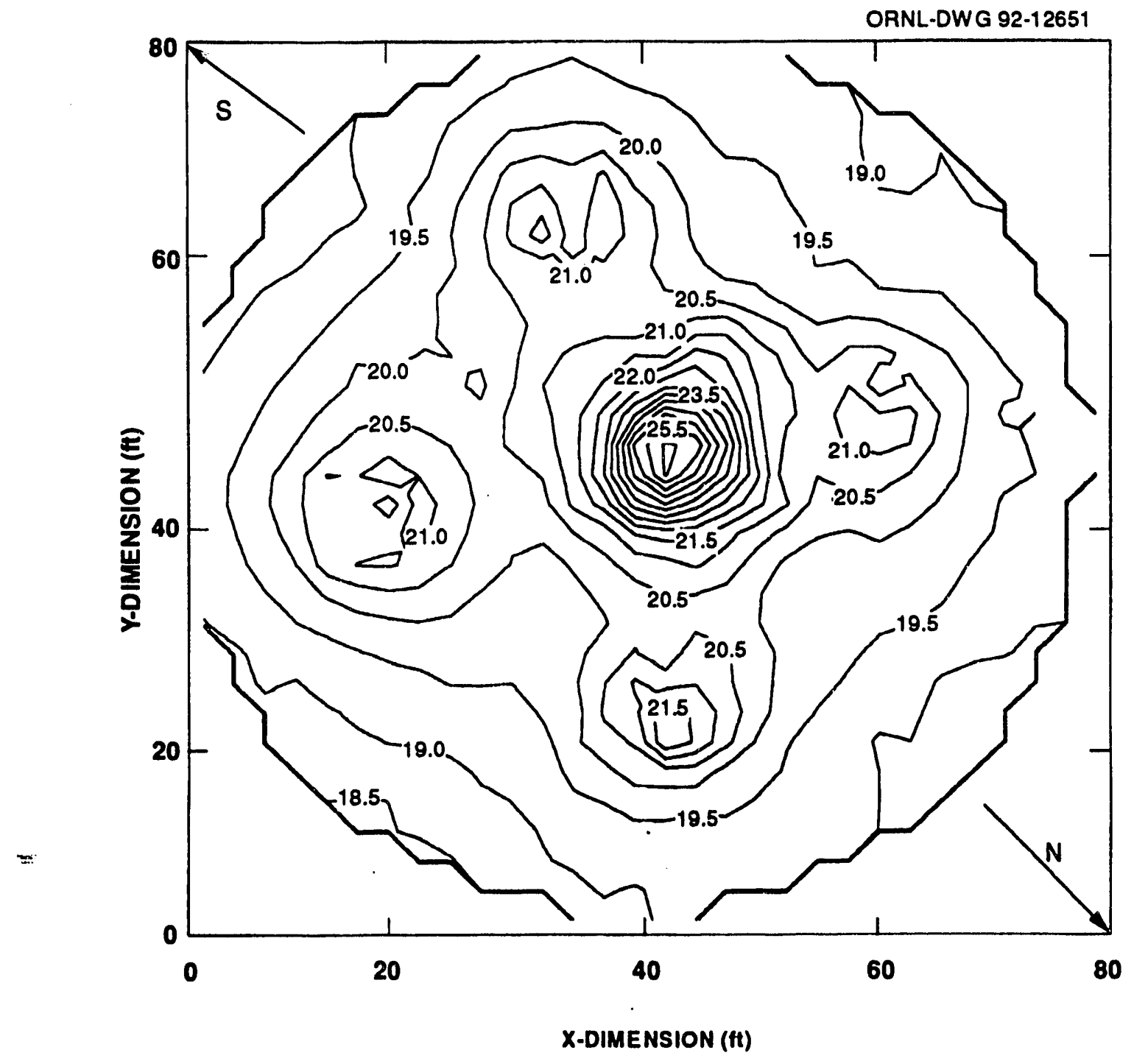

Figure 5.2 Contour plot of Silo 2 baseline waste-surface data ( 6 inch contours). 


\section{K-65 Silo \# 1 ORNL-DWG 92-8155 Waste Surface Map - Oct. 91}

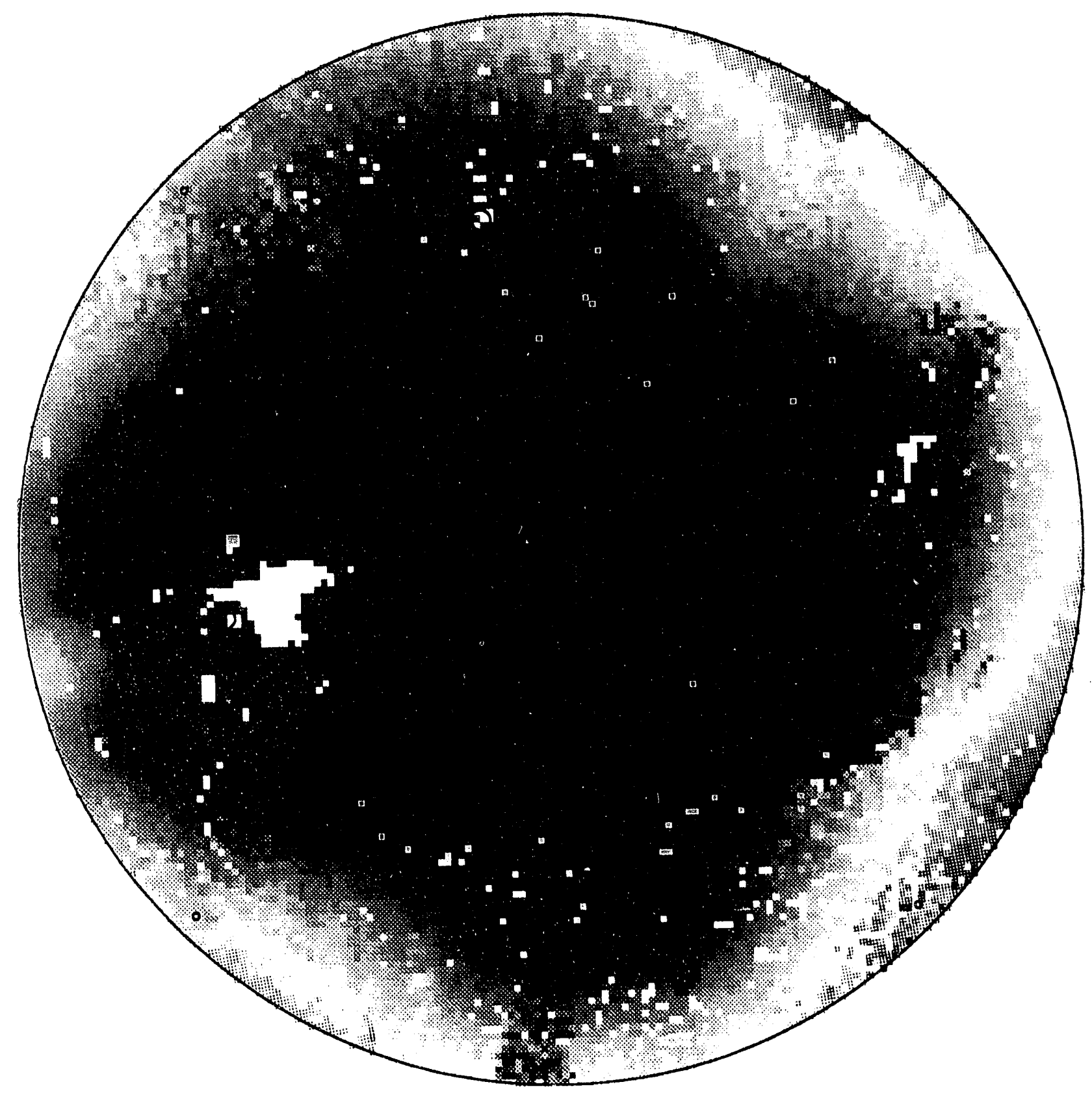

Distance below ORNL Global Reference Frame Minimum (red) $=-67^{\prime \prime} \quad$ Maximum (indigo) $=-1 "$

Figure 5.3 Silo 1 baseline waste-surface map, 256-color vertical dimension. 


\section{K-65 Silo \# 2 ORNL-DwG 92-8163 Waste Surface Map - Oct. 91}

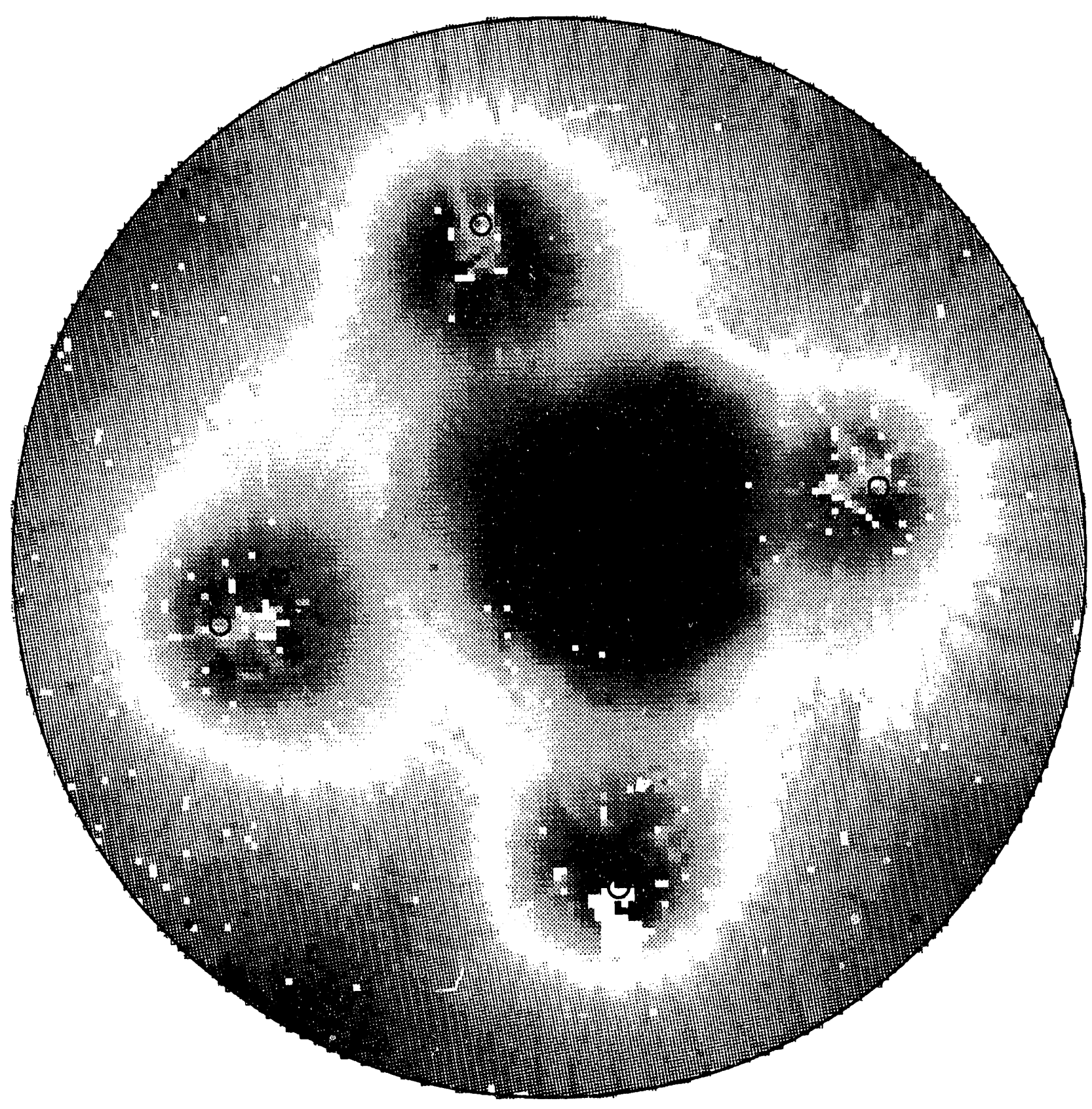

Distance below ORNL Global Reference Frame

$$
\text { Minimum (red) }=-100^{\prime \prime} \quad \text { Maximum (indigo) }=+2 "
$$

Figure 5.4 Silo 2 baseline waste-surface map, 256-color vertical dimension. 


\section{K-65 Silo \# 1 \\ Waste Surface Map - Oct. 91}

ORNL-DWG 92-8153

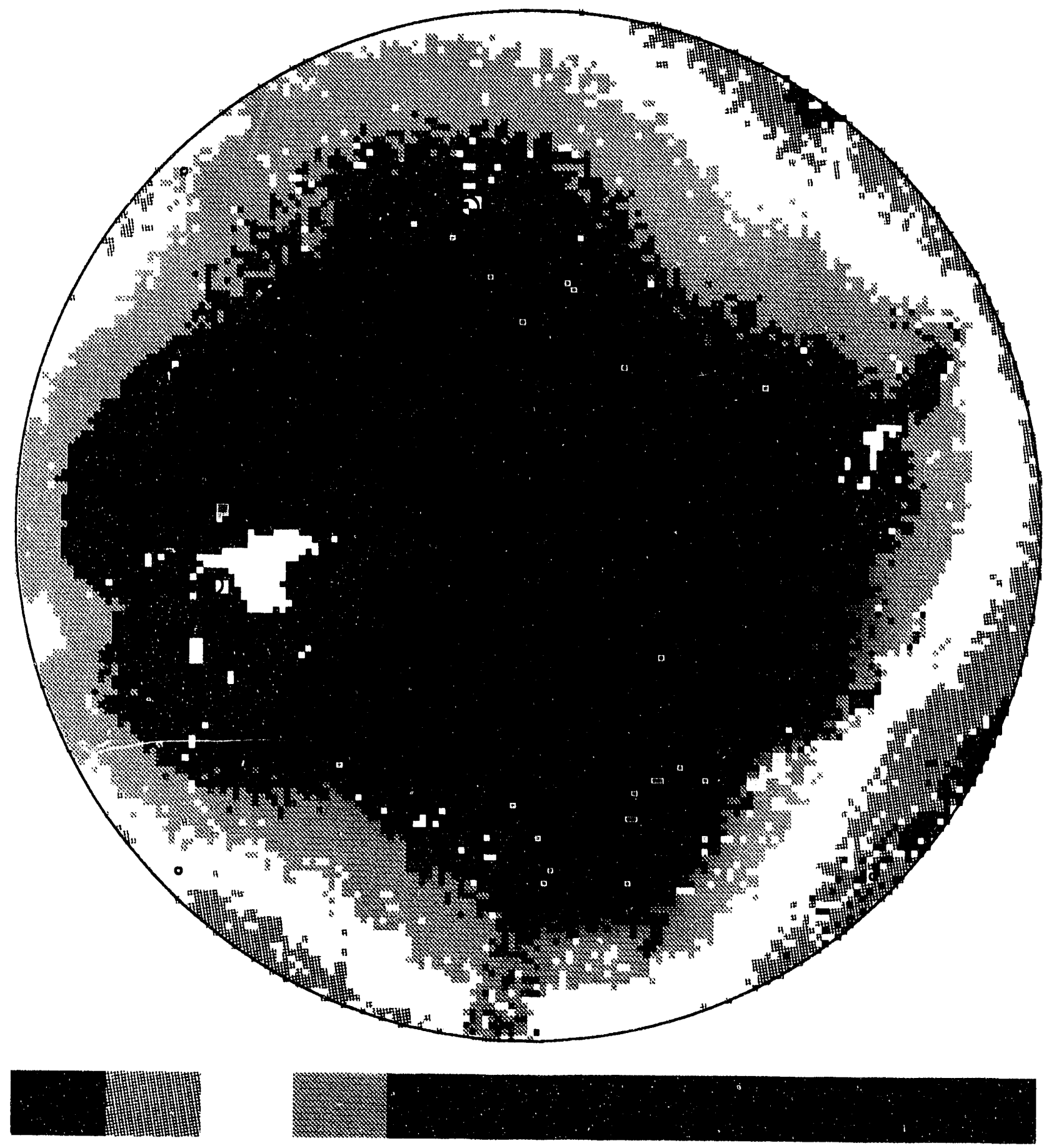

Distance below ORNL Global Reference Frame (6" steps) Minimum (red) $=-67^{\prime \prime} \quad$ Maximum (indigo) $=-1^{\prime \prime}$

Figure 5.5. Silo 1 baseline waste-surface map, 6-in. topographical color bands. 


\section{K-65 Silo \# 2 Waste Surface Map - Oct. 91}

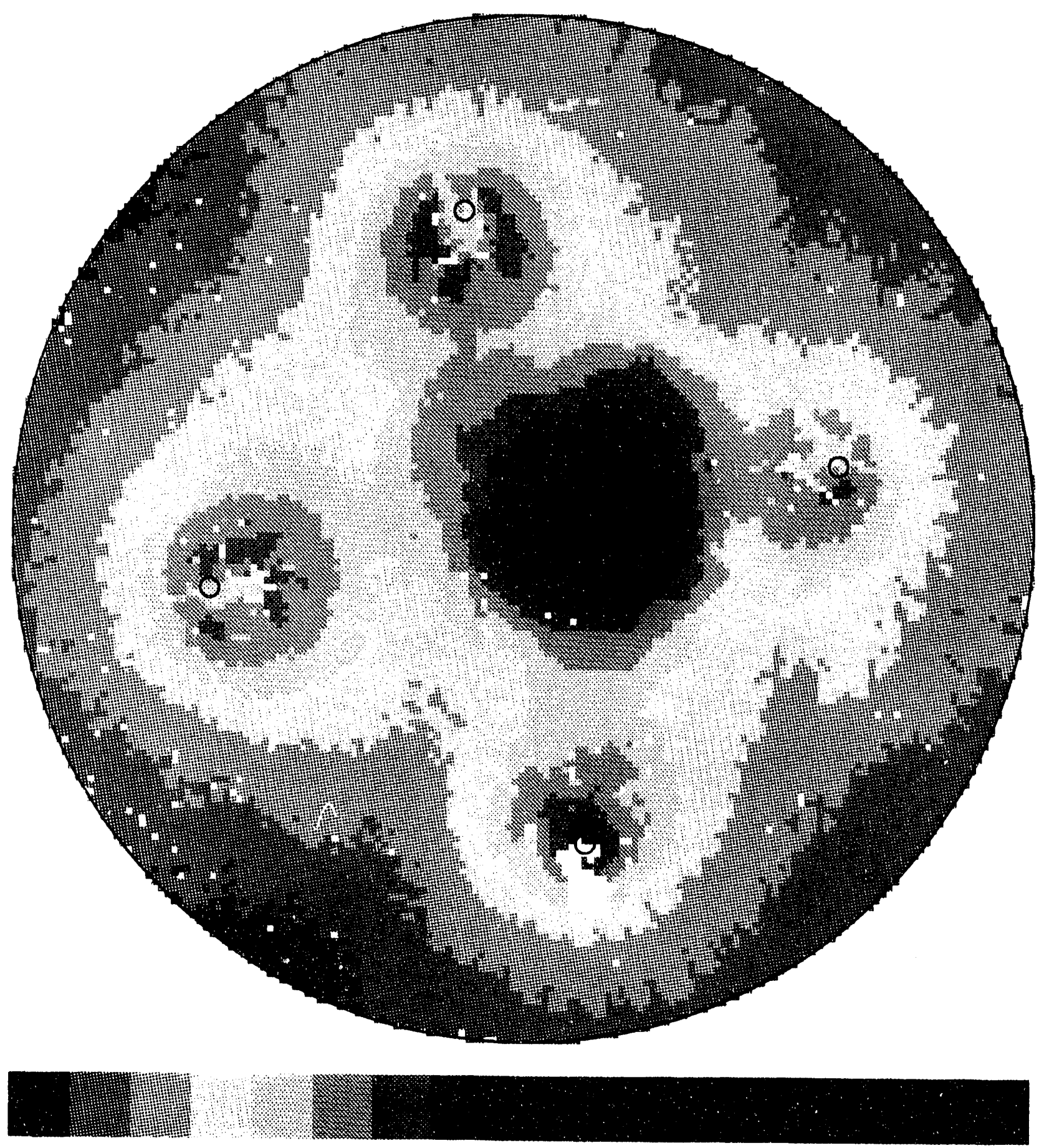

Distance below ORNL Global Reference Frame (6" steps) Minimum (red) $=-100^{\prime \prime} \quad$ Maximum (indigo) $=+2^{\prime \prime}$

Figure 5.6. Silo 2 baseline waste-surface map, 6-in. topographical color bands. 


\subsection{BENTONITE-SURFACE MAPS}

After bentonite emplacement, the surfaces were much higher, resulting in even more challenging data acquisition geometries than the worst case hypothesis described in Fig. 1.3. Bentonite was deposited by irserting a spray head into the center access portal and spraying bentonite into the silos from a pair of nozzles aiming in opposing directions. Bentonite in slurry form flows easily and tends to self level. The plan was to cover the lower portion of the waste surface with the slurry and then to thicken the bentonite slurry and deposit the thicker clay slurry in the vicinity of the large mounds, in particular, the center mound in Silo 2. As the bentonite slurry was applied, a pool of liquid formed at the walls from excess water in the slurry. This pool appeared to be about $0.3 \mathrm{~m}(1 \mathrm{ft})$ wide and made data acquisition in the vicinity of the walls more difficult because of multiple reflections of the laser beam on the water surface. This problem was accentuated by the severity of incident angles of the beam on the wet surface. The worst case laser and camera line-of-sight angles in Silo 1 were $9^{\circ}$ from the center access portal and $4^{\circ}$ for the outer four access portals. These angles were much smaller than anticipated in the feasibility demonstration ( see Section 1.3). In spite of the wet surface, data were obtained out to the edge of the pool and, in some cases, on the pool surface. Even with the excess liquid, the slurry was thick enough that the bentonite surface did not become perfectly flat but instead was slightly higher in the area underneath the application point. The drop off from center height to height at the walls in Silo 1 was about $0.5 \mathrm{~m}(1.5 \mathrm{ft})$. In Silo 2, the drop off ranged from $0.5 \mathrm{~m}(1.5 \mathrm{ft})$ on the northern side of the silo to $0.8 \mathrm{~m}$ ( $2.5 \mathrm{ft}$ ) on the south side (see Figs. 5.7 to 5.12 ).

To save on bentonite applied (and, hence, waste to be removed later), the center mound in Silo 2 was not completely submerged in the bentonite. Attempts were made to thicken the bentonite slurry and to heap additional bentonite on the top of the center mound in Silo 2. This approach caused the top of the mound to erode. Because the top of this mound was eroded by bentonite, the final height of the crown was below prebentonite levels. However, an $\sim 2.8-\mathrm{m}$

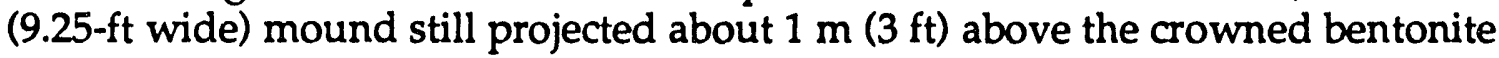
surface (see Figs. 5.8, 5.10, and 5.1.2). From the glistening appearance of the mound, it clearly was also covered with bentonite. The surface data displayed in Figs. 5.7 through by 5.12 were generated by using the same approach shown in Figs. 5.1 to 5.6 and discussed previously. 


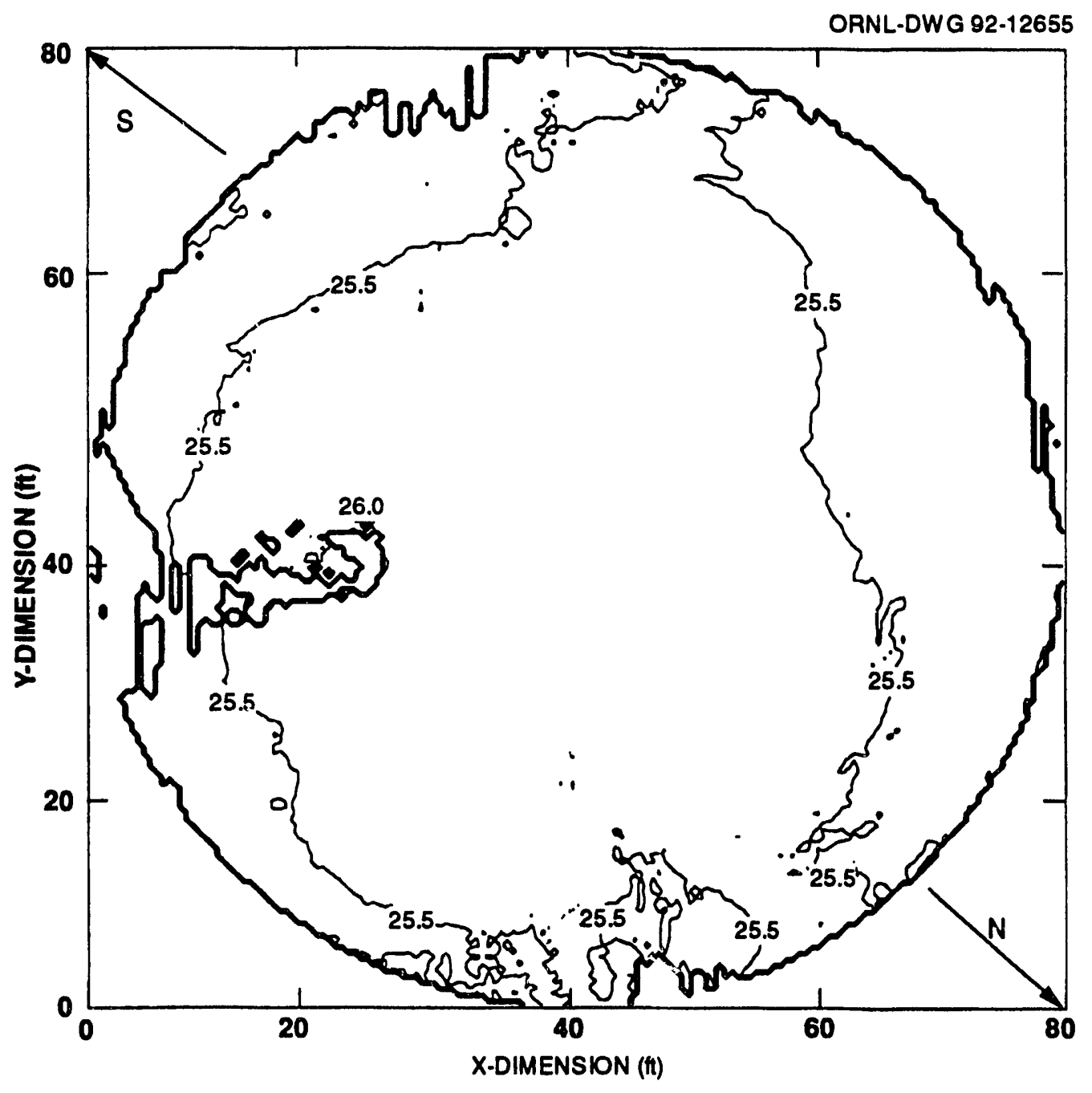

Figure 5.7 Contour plot of Silo 1 bentonite-surface data. (6 inch contours). 


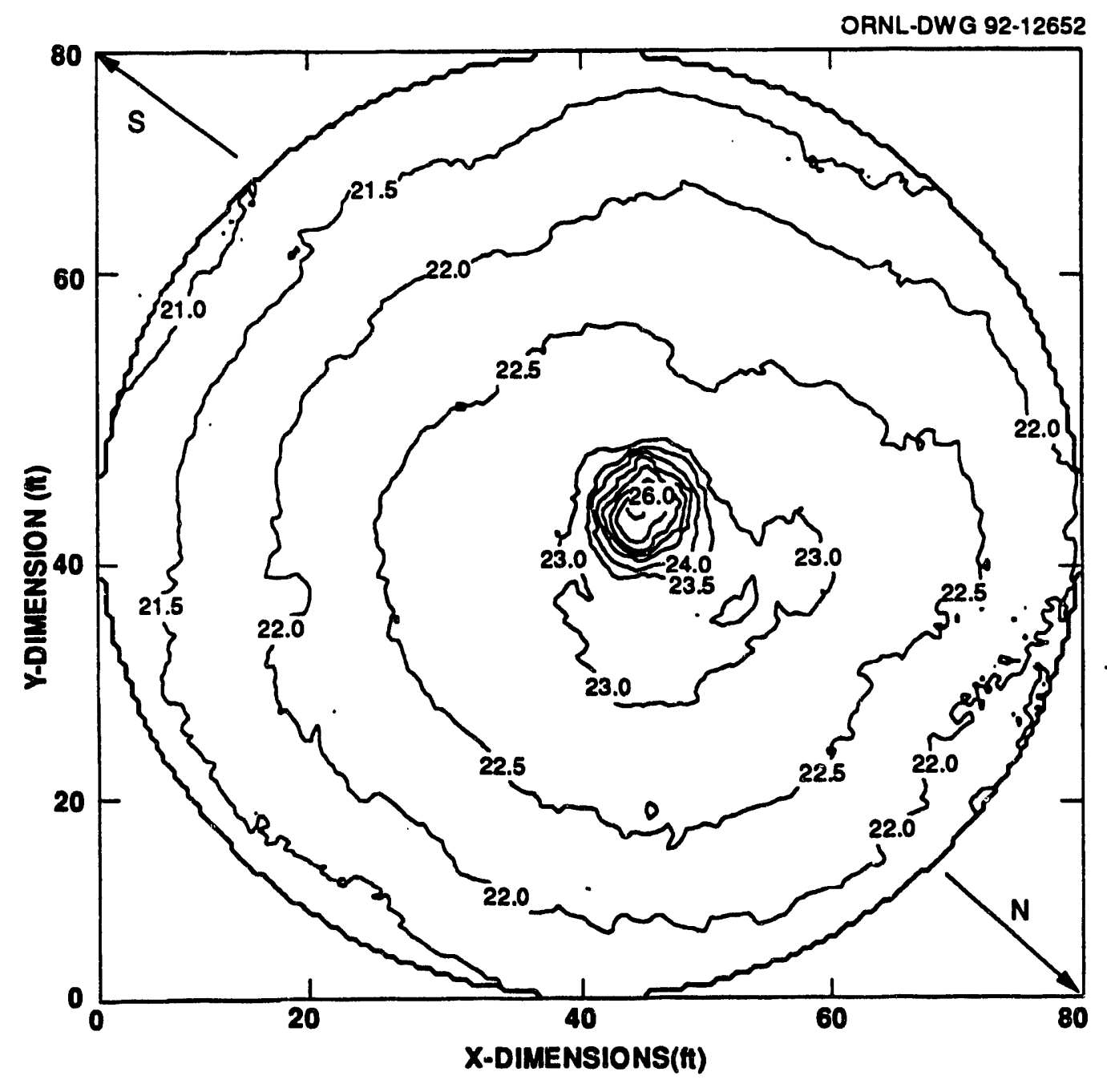

Figure 5.8 Contour plot of Silo 2 bentonite-surface data. (6 inch contours). 


\section{K-65 Silo \# 1 ORNL-DWC 92-8162 Waste Surface Map - Dec. 91}

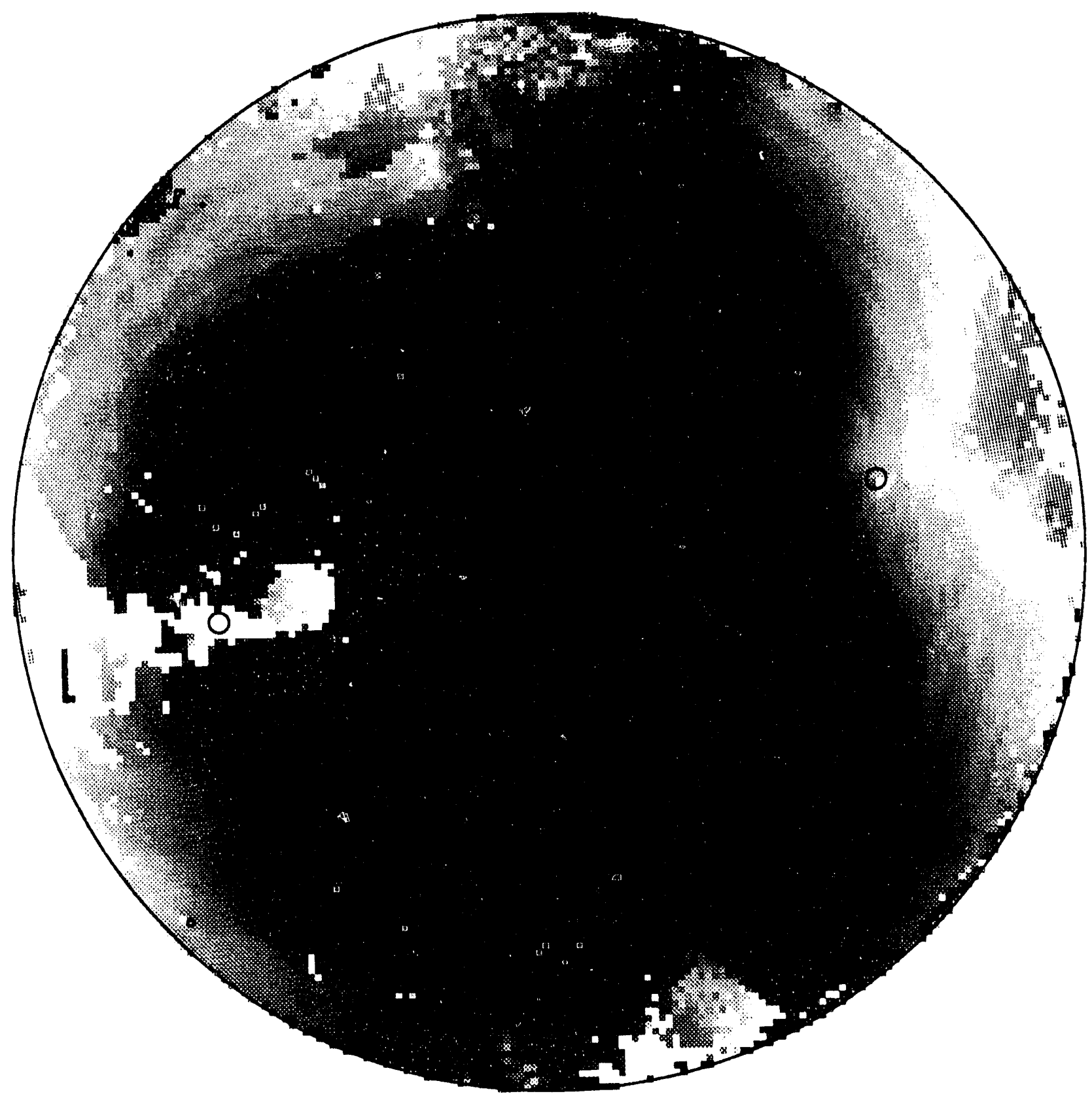

Distance below ORNL Global Reference Frame

Minimum (red) $=-18^{\prime \prime} \quad$ Maximum (indigo) $=+0^{\prime \prime}$

Figure 5.9 Silo 1 bentonite surface, 256-color vertical dimension. 


\section{K-65 Silo \# 2 ORNL-DWG 92-8154 Waste Surface Map - Dec. 91}

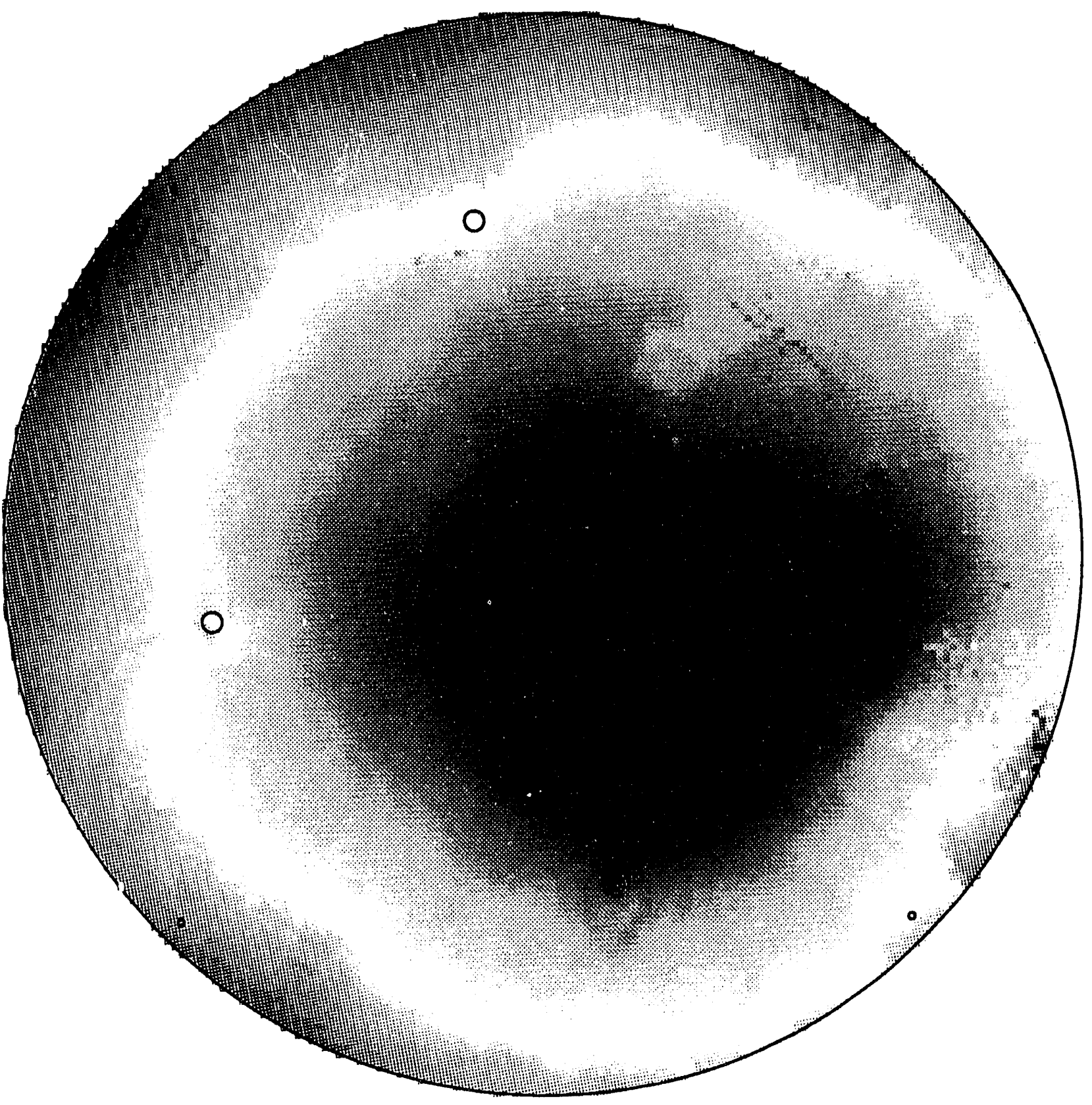

Distance below ORNL Global Reference Frame

Minimum (red) $=-70^{\prime \prime} \quad$ Maximum (indigo) $=+2^{\prime \prime}$

Figure 5.10 Silo 2 bentonite surface, 256-color vertical dimension. 


\section{K-65 Silo \# 1

Bentonite Surface Map - Dec. 91

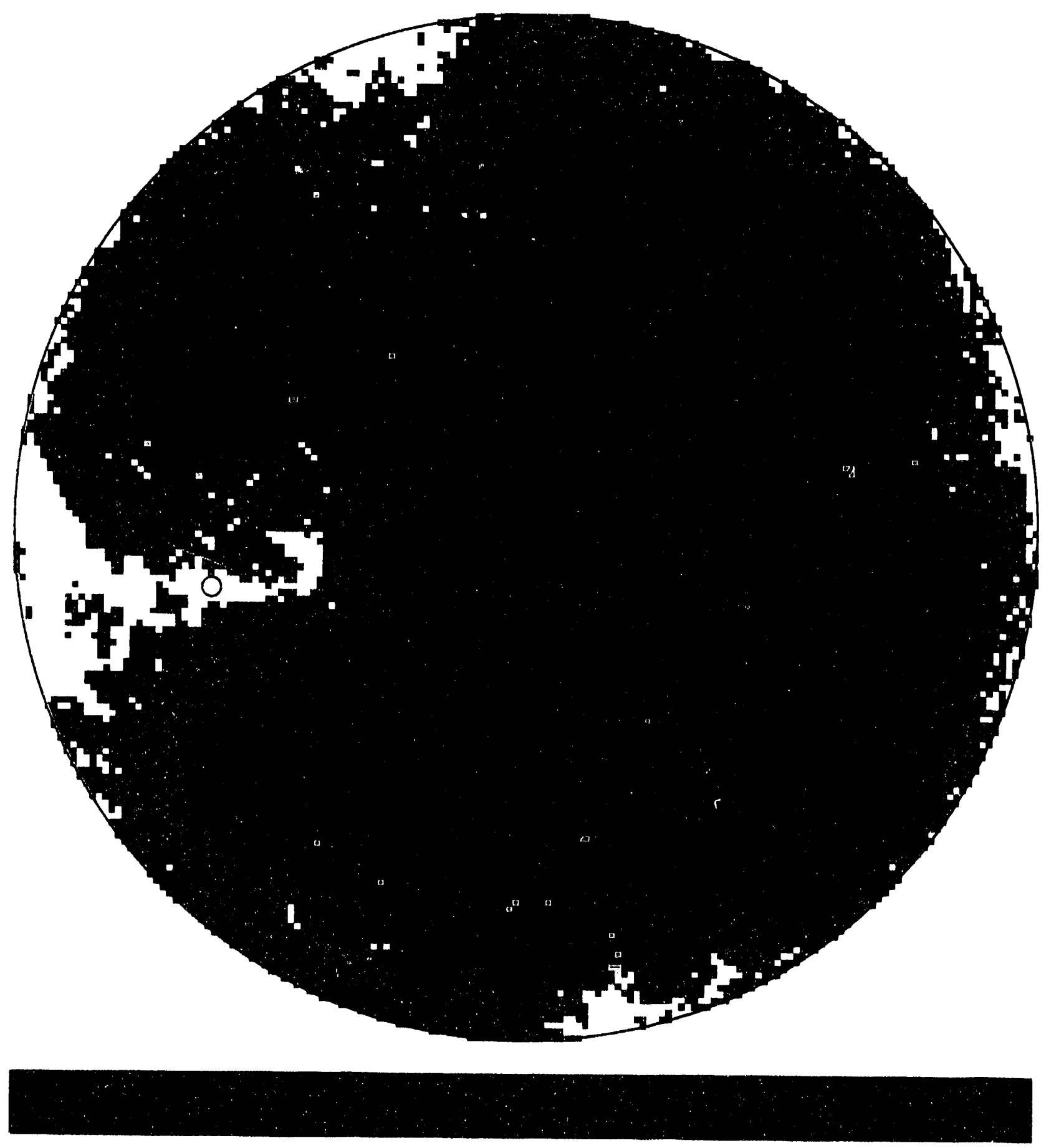

Distance below ORNL Global Reference Frame (6" steps)

Minimum (red) $=-18^{\prime \prime} \quad$ Maximum (purple) $=+0^{\prime \prime}$

Figure 5.11 Silo 1 bentonite surface, 6-in. topographical color bands. 


\section{K-65 Silo \# 2 ORNL-DWG 92-8156 \\ Bentonite Surface Map - Dec. 91}

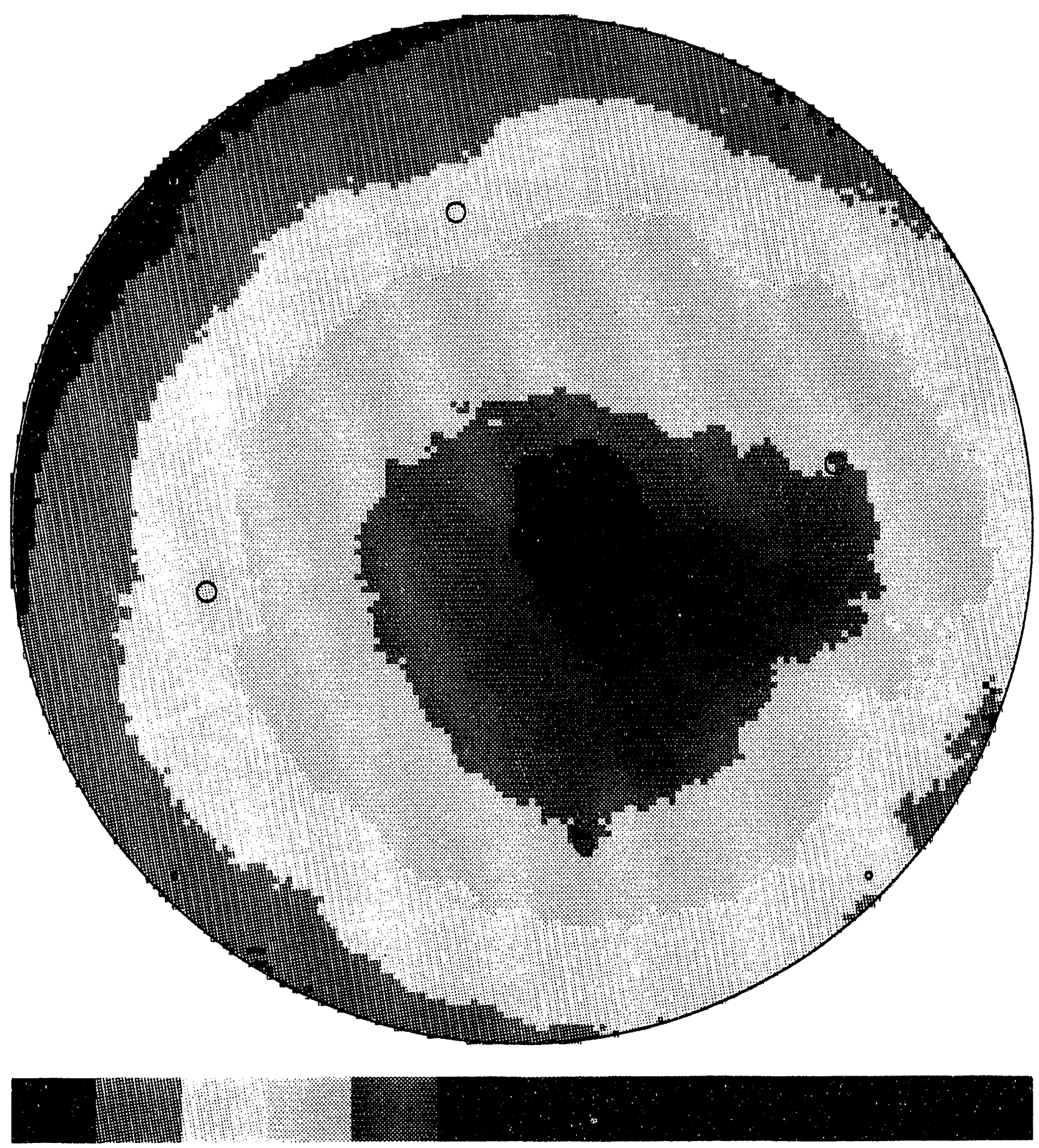

Distance below ORNL Global Reference Frame (6" steps)
Minimum (red) $=-70^{\prime \prime} \quad$ Maximum (indigo) $=+2^{\prime \prime}$

Figure 5.12 Silo 2 bentonite surface, 6-in. topographical color bands. 


\subsection{BENTONITE THICKNESS}

When this project was proposed, the primary objective was to provide a safe and accurate means of determining the bentonite thickness throughout the silos rather than relying on "dipstick"-type measurements that could only be made directly under access portals. Although the mounds tended to be near access portals openings, the mound peaks were not always directly under the access portals. For example, only one large mound existed in Silo 1 and that peaked about $2.3 \mathrm{~m}(7.7 \mathrm{ft})$ northwest of the southeast access portal. The surface directly under the access portal was about $0.9 \mathrm{~m}(3 \mathrm{ft})$ below the peak height. A dipstick approach to placing bentonite in Silo 1 would have resulted in a significant uncovered portion of the mound unless some additional approach was taken as, for example, with the large center mound in Silo 2. Deployment of the ORNL structured light surface mapping system provided extensive data needed to plan the bentonite emplacement and ensure compliance with the Amended Consent Agreement Removal Action Milestone. As a result of the baseline surface mapping data analysis, it was determined that an insufficient amount of bentonite had been ordered. Additional bentonite was obtained in time to meet the Amended Consent Agreement Removal Action Milestone.

Except for the eroded area on the top of the center mound in Silo 2, the surface mapping data offered a good measure of bentonite cap thickness. The thickness for Silo 1 varied from $122 \mathrm{~cm}(48$-in.) at the silo walls to $5 \mathrm{~cm}$ (2-in.) at the top of the highest mound, with an average cap thickness of $76.5 \mathrm{~cm}$ (30-in.). The surface height change for Silo 2 varied from $76 \mathrm{~cm}$ (30-in.) at the silo walls to $-1 \mathrm{~cm}(\sim 0.4-\mathrm{in}$.) at the top of the highest mound, with the average cap thickness of $67.4 \mathrm{~cm}$ (26.5-in.). Contour maps of Silos 1 and 2 surface change data are shown in Figs. 5.13 and 5.14. The surface height change is shown in Figs. 5.15 through 5.18 in color maps similar to those shown in Sections 5.2 and 5.3. Using the change in surface height to verify bentonite thickness is dependent on the assumption that the bentonite addition does not significantly compress the waste and that the underlying surface was not significantly altered during the bentonite application. The first assumption seems reasonable on the basis of the resulting measurements, that is, no evidence of significant compression was observed. The application of bentonite almost certainly did affect the underlying surface where sharp features were concerned. The crevice edges and mounds were no doubt partially eroded during the bentonite application. Nonetheless, the change in surface height measured by the structured light mapping system is still a far superior approach to simpler single-point dipstick techniques.

Because the contour plots and color topographical plots are more difficult to comprehend for some readers, vertical slices of the data at a few select angles were plotted in cross-sectional maps (see Figs. 5.19 through 5.27). The angles indicated in plots correspond to the counterclockwise rotation of a line through the center of the silo graphic portion of the operator interface. In this case, $0^{\circ}$ refers to a line drawn horizontally across the silo graphic and $90^{\circ}$ refers to a line drawn vertically across the silo graphic. Both the baseline waste surface and bentonite surface are plotted. The thickness of bentonite along these crosssectional cuts can readily be discerned from these plots. 


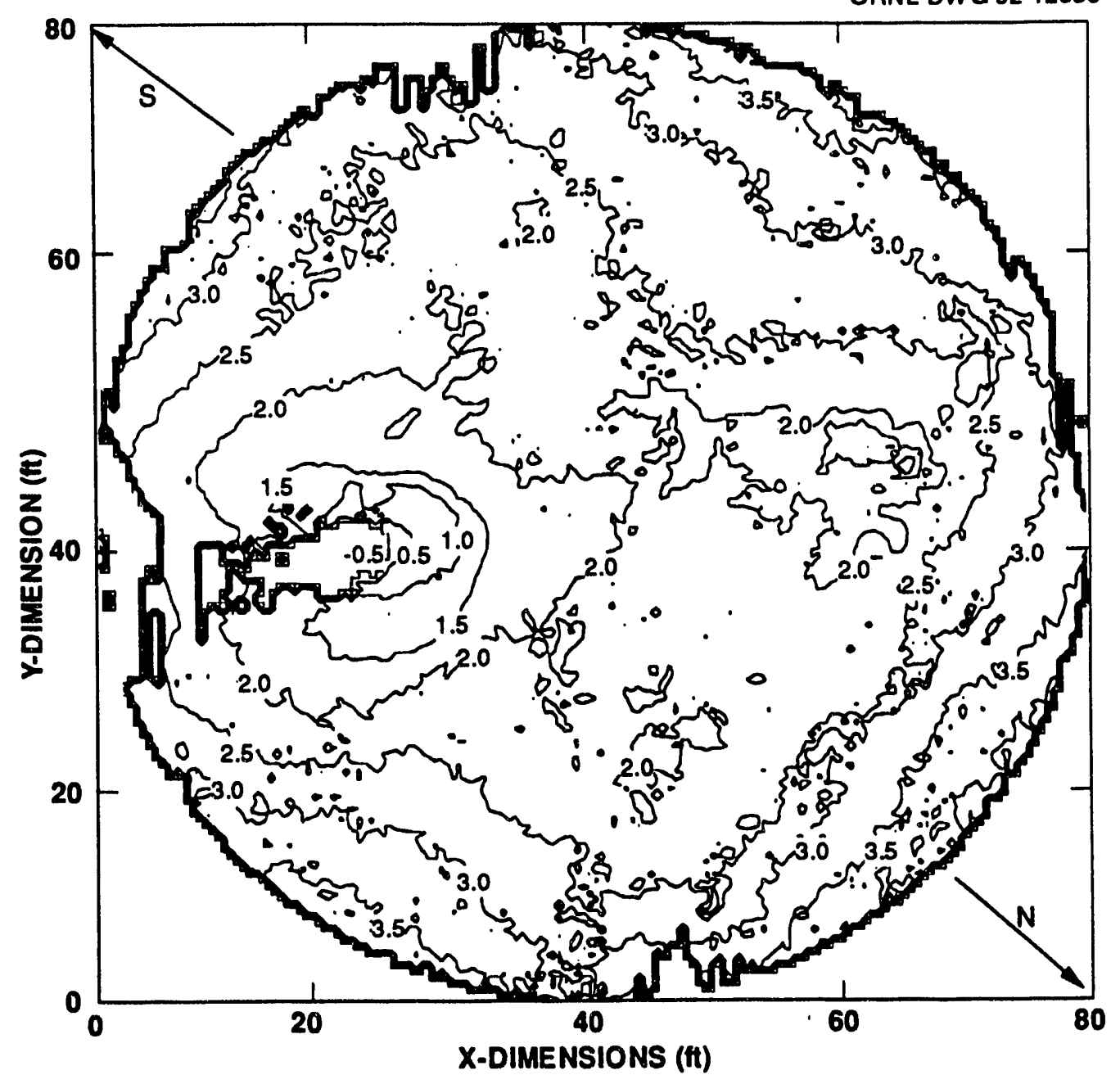

Figure 5.13 Contour plot of Silo 1 surface change (bentonite thideness) (6 inch contours). 


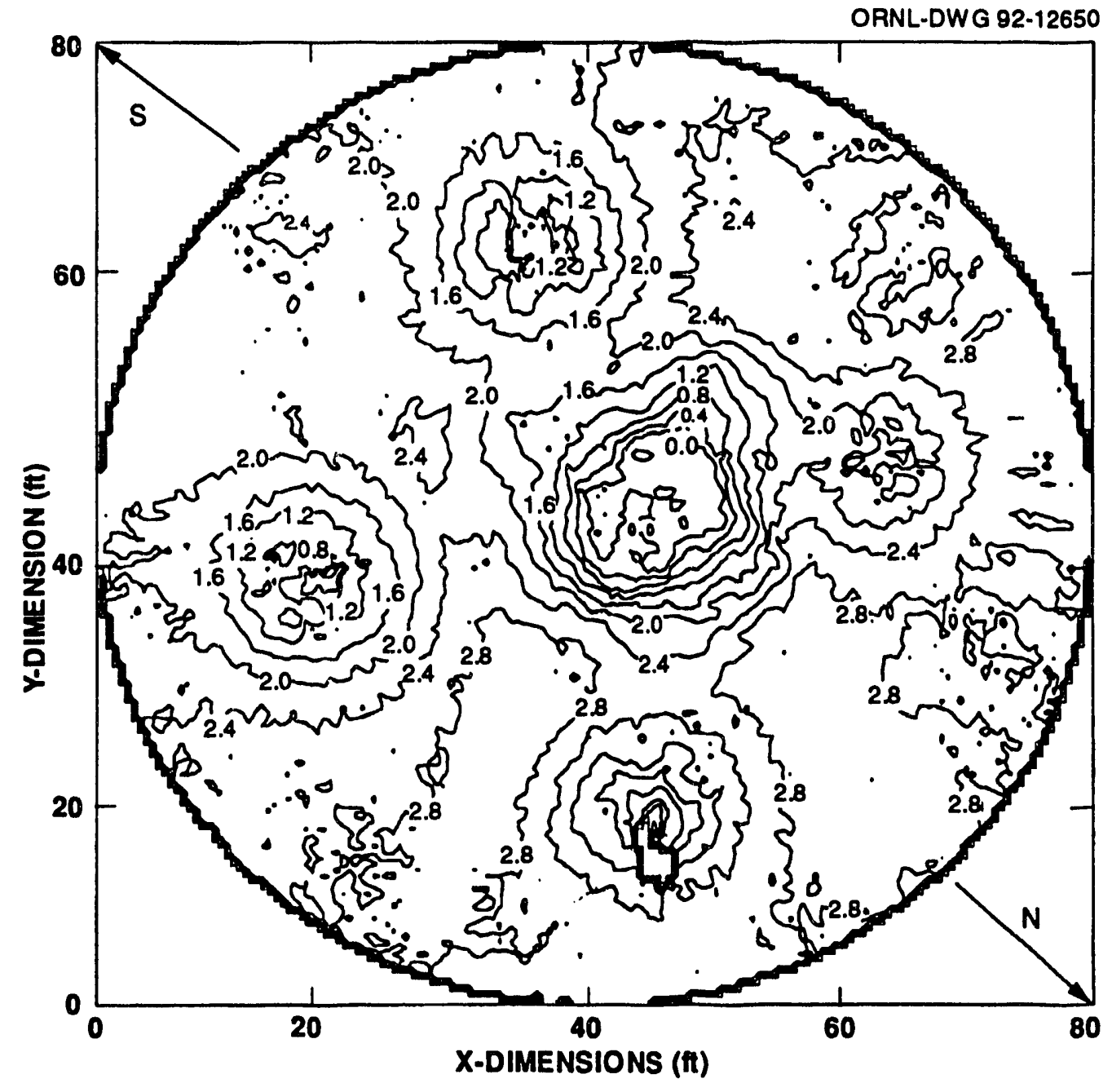

Figure 5.14 Contour plot of Silo 2 surface change (bentonite thickness). 


\section{K-65 Silo \# 1 \\ ORNL-PHOTO 6830-92 \\ Measured Surface Change (Oct. - Dec. 91)}

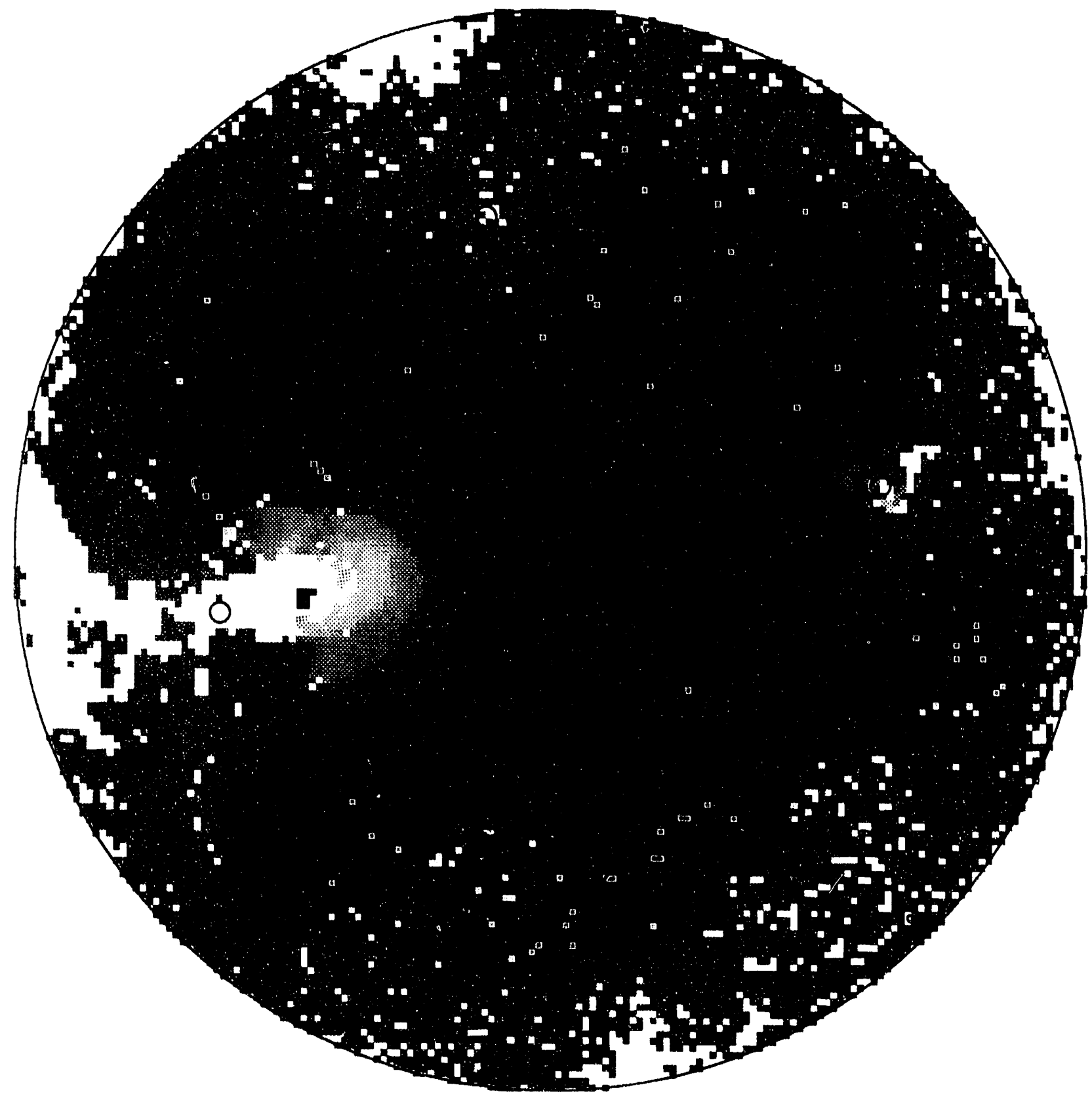

Measured Surface Change

Minimum (red) $=-9^{\prime \prime} \quad$ Maximum (indigo) $=+57^{\prime \prime}$

Figure 5.15 Silo 1 surface change (bentonite thickness), 256-color vertical dimension. 


\section{K-65 Silo \# 1 \\ Bentonite Thickness - Dec. 91}
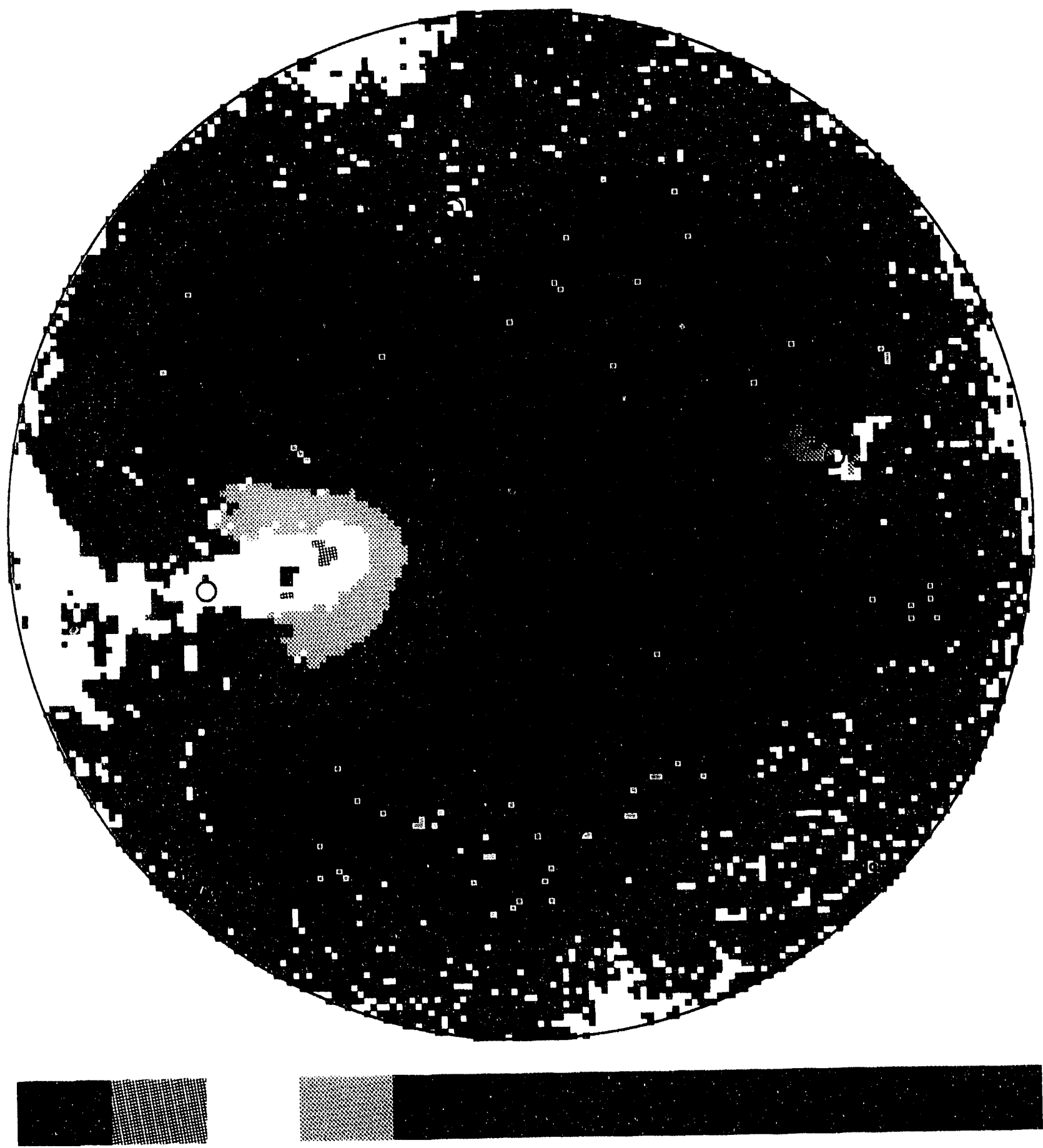

Bentonite thickness (6" steps)

Minimum (red) $=-9^{\prime \prime} \quad$ Maximum (indigo) $=+57^{\prime \prime}$

Figure 5.16 Silo 2 surface change (bentonite thickness) data, 256-color vertical dimension. 


\section{K-65 Silo \# 2 \\ ORNL-PHOTO 6831-92 \\ Measured Surface Change (Oct. - Dec. 91)}

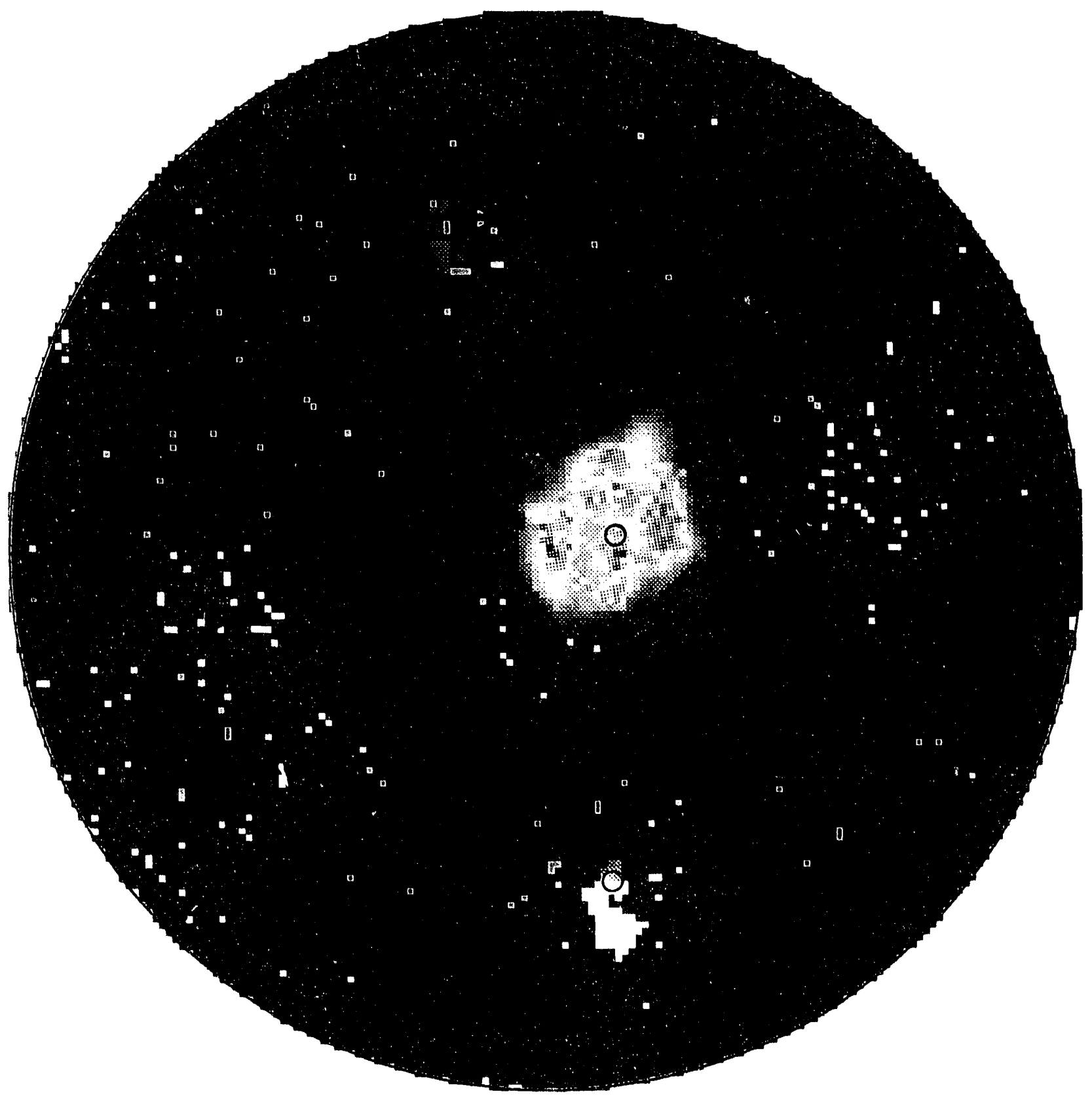

Measured Surface Change

Minimum (red) $=-11^{\prime \prime} \quad$ Maximum (indigo) $=+43^{\prime \prime}$

Figure 5.17 Silo 1 surface change (bentonite thickness), 6-in. topographical color bands. 


\section{K-65 Silo \# 2 ORNL-DWG 92-8160}

Bentonite Thickness - Dec. 91

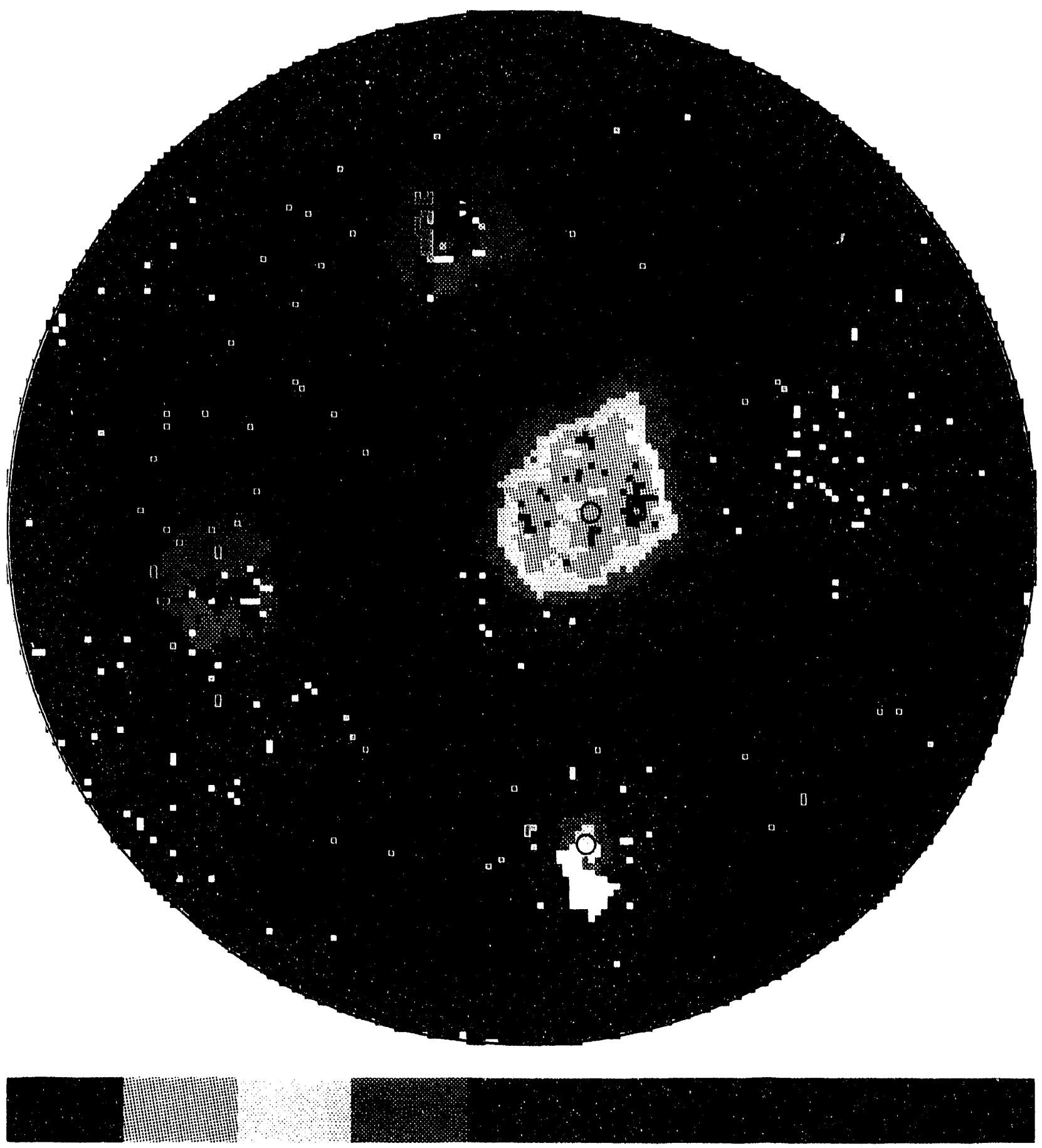

Bentonite thickness (6" steps)

Minimum (red) $=-11^{\prime \prime} \quad$ Maximum (indigo) $=+43^{\prime \prime}$

Figure 5.18 Silo 2 surface change (bentonite thickness), 6-in. topographical color bands. 


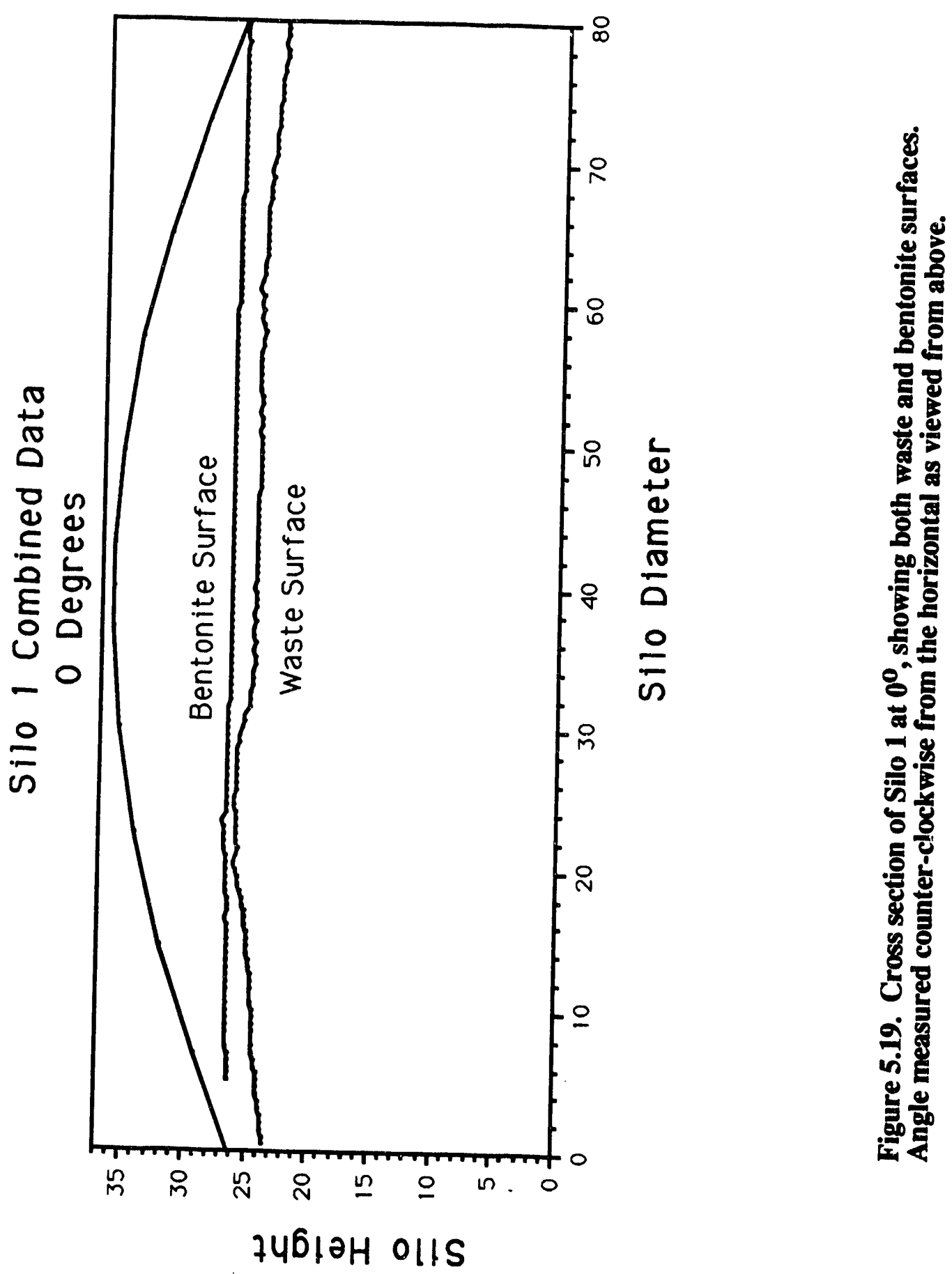




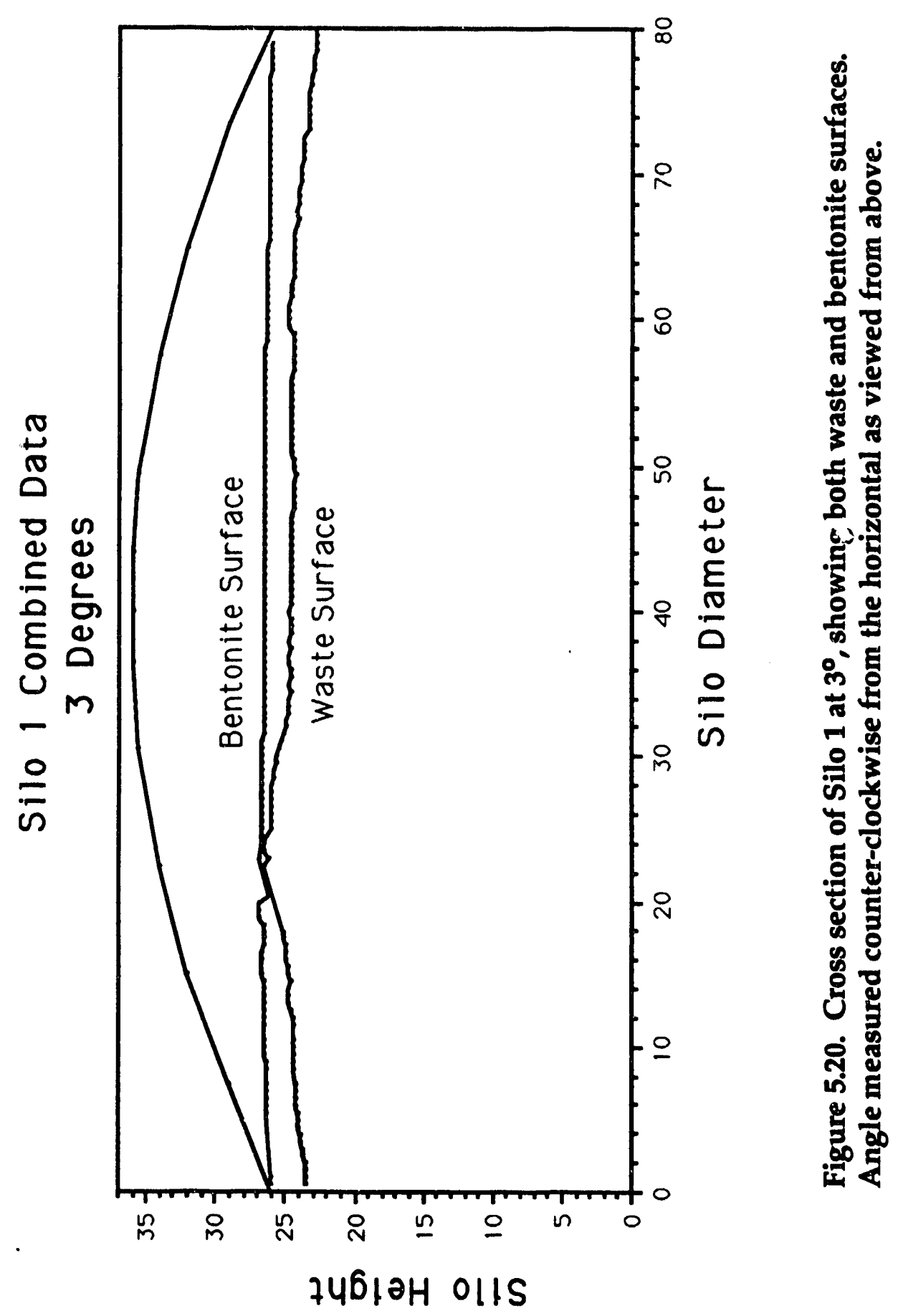




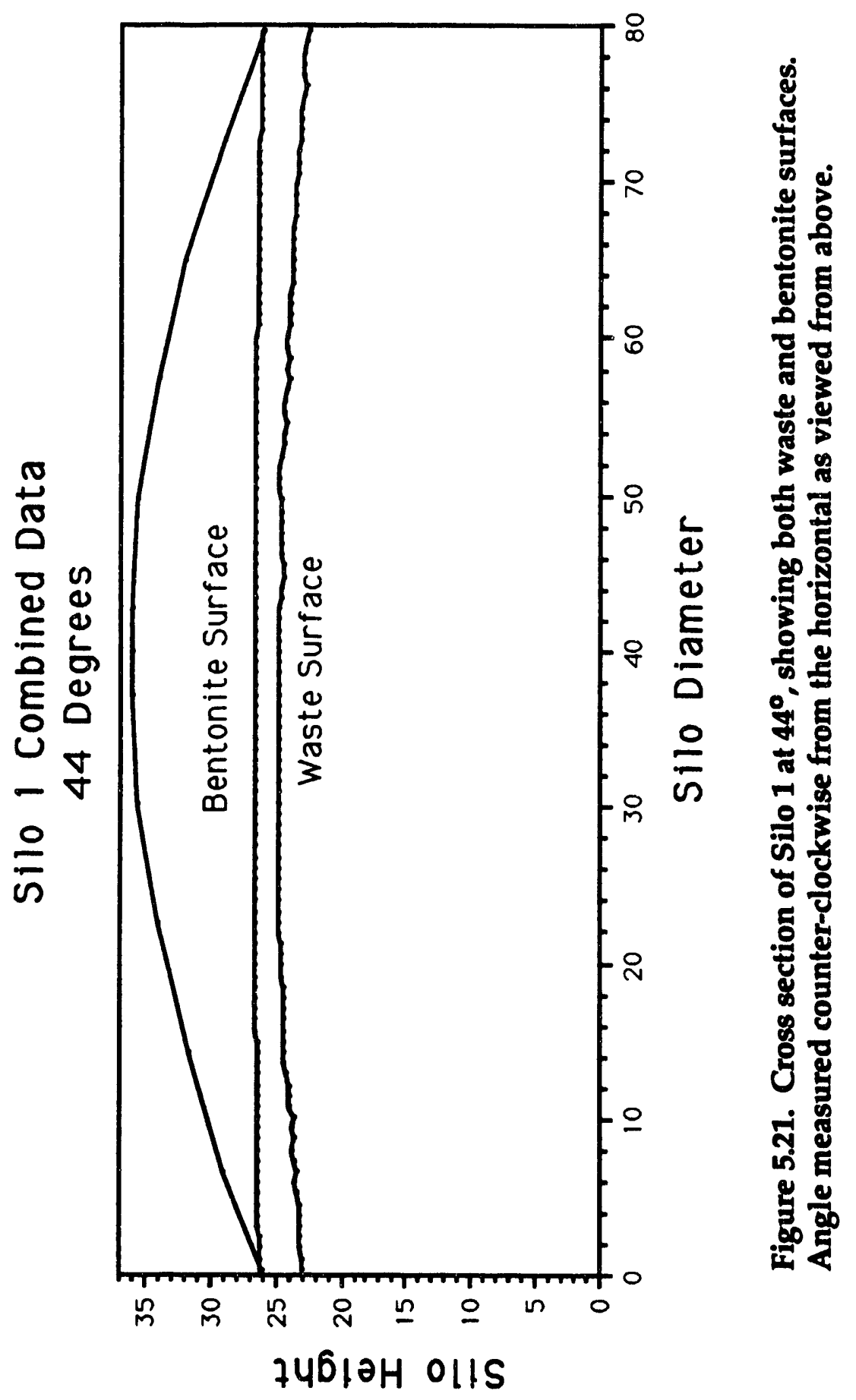




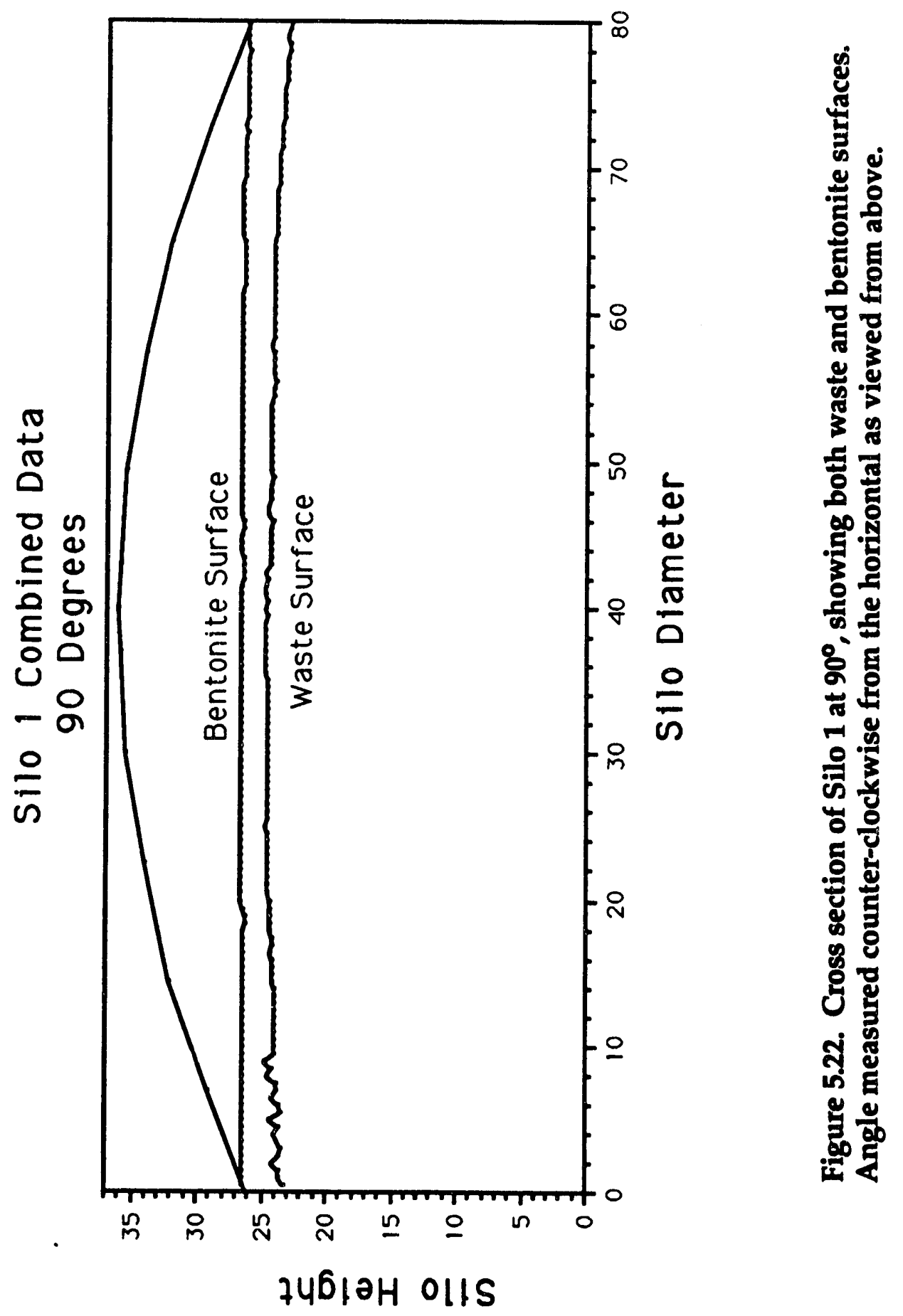




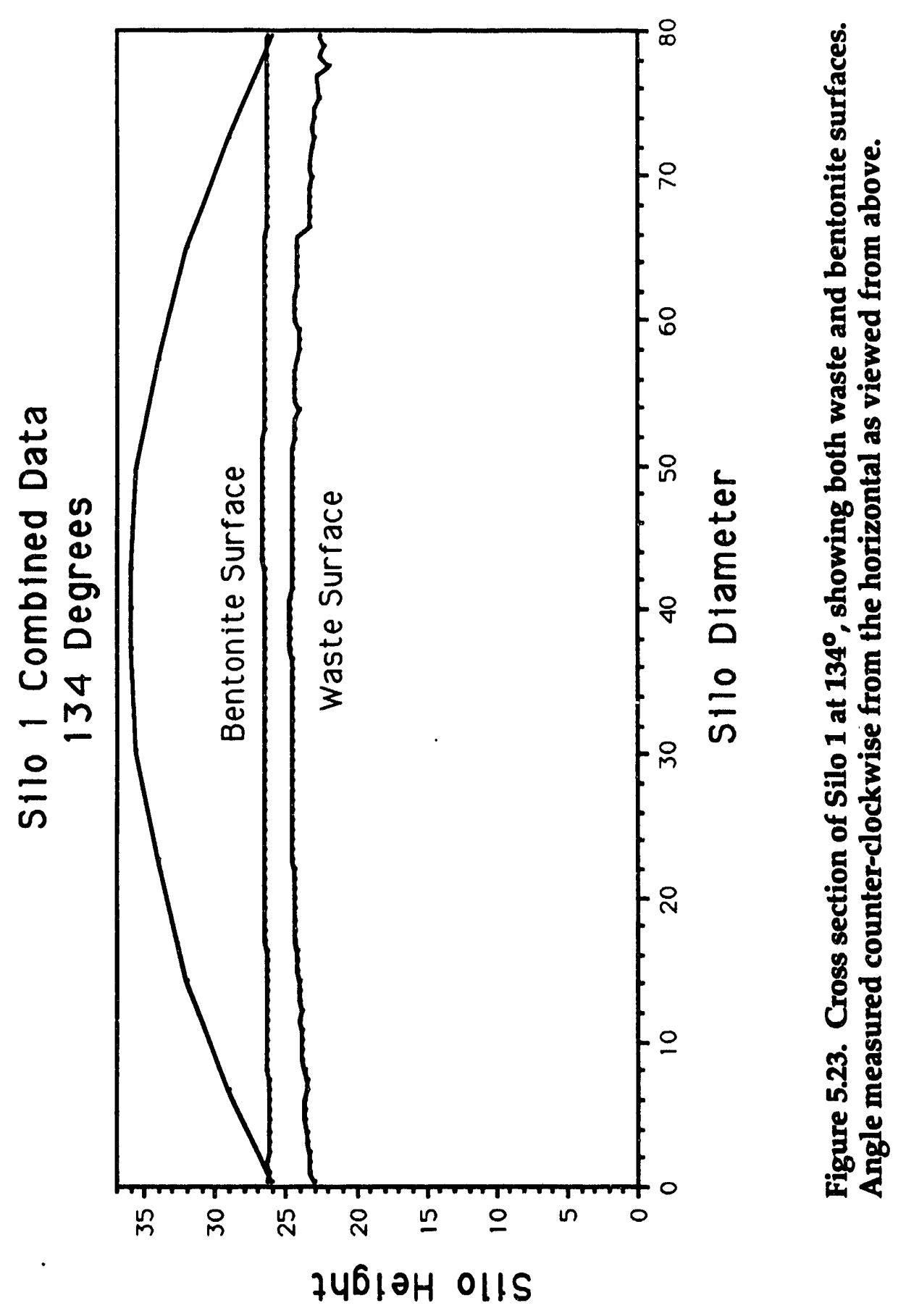




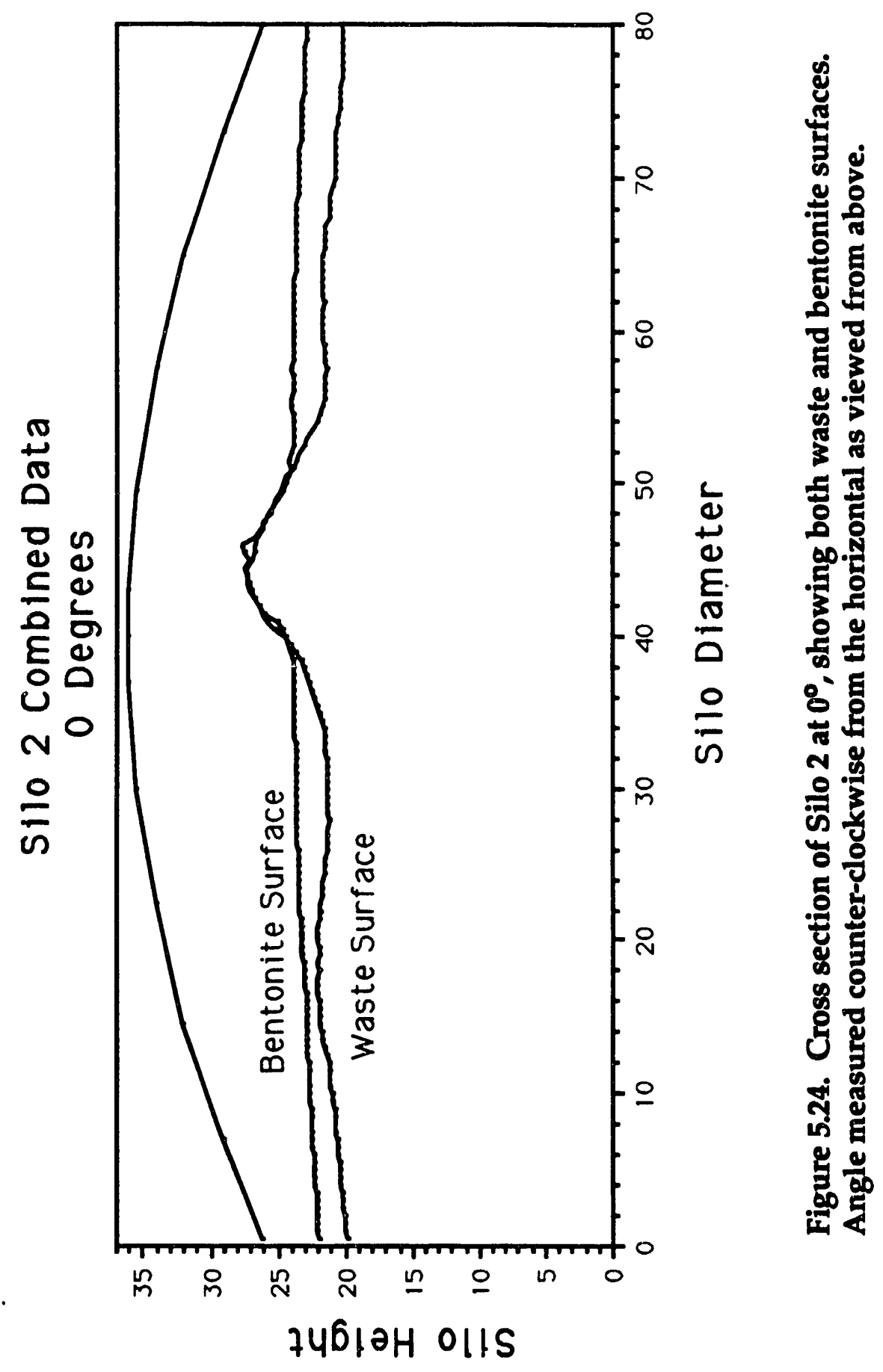




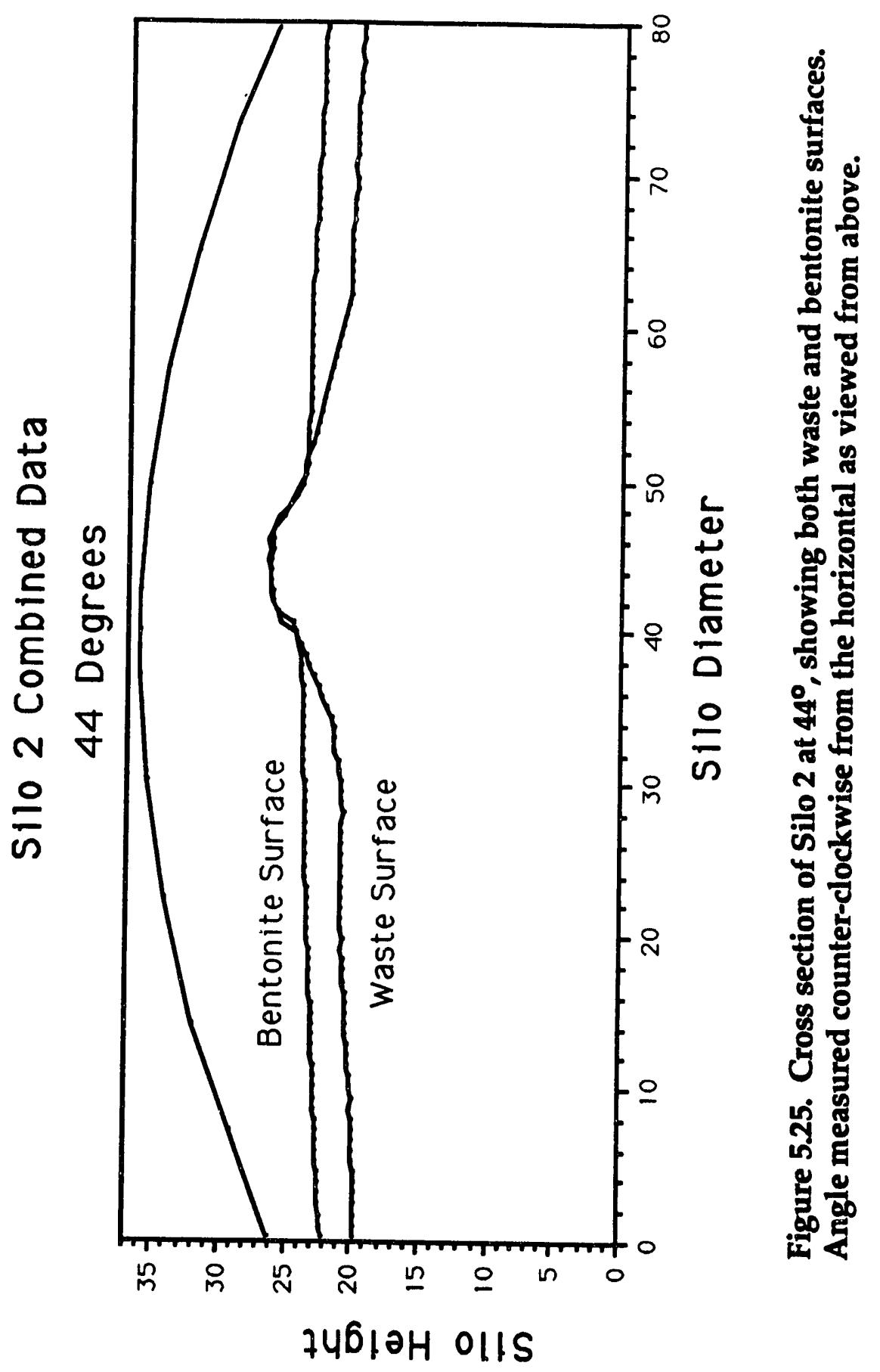




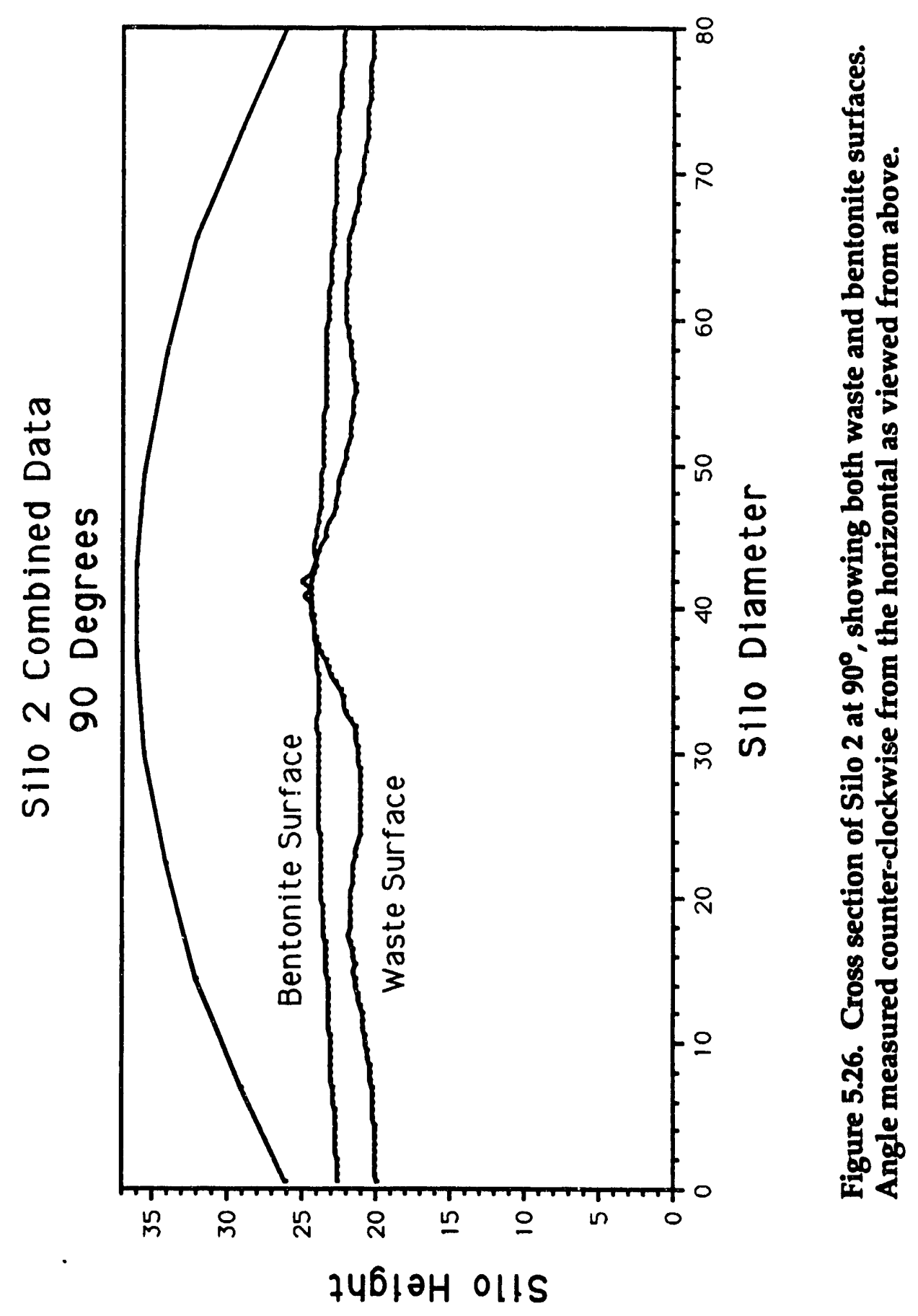




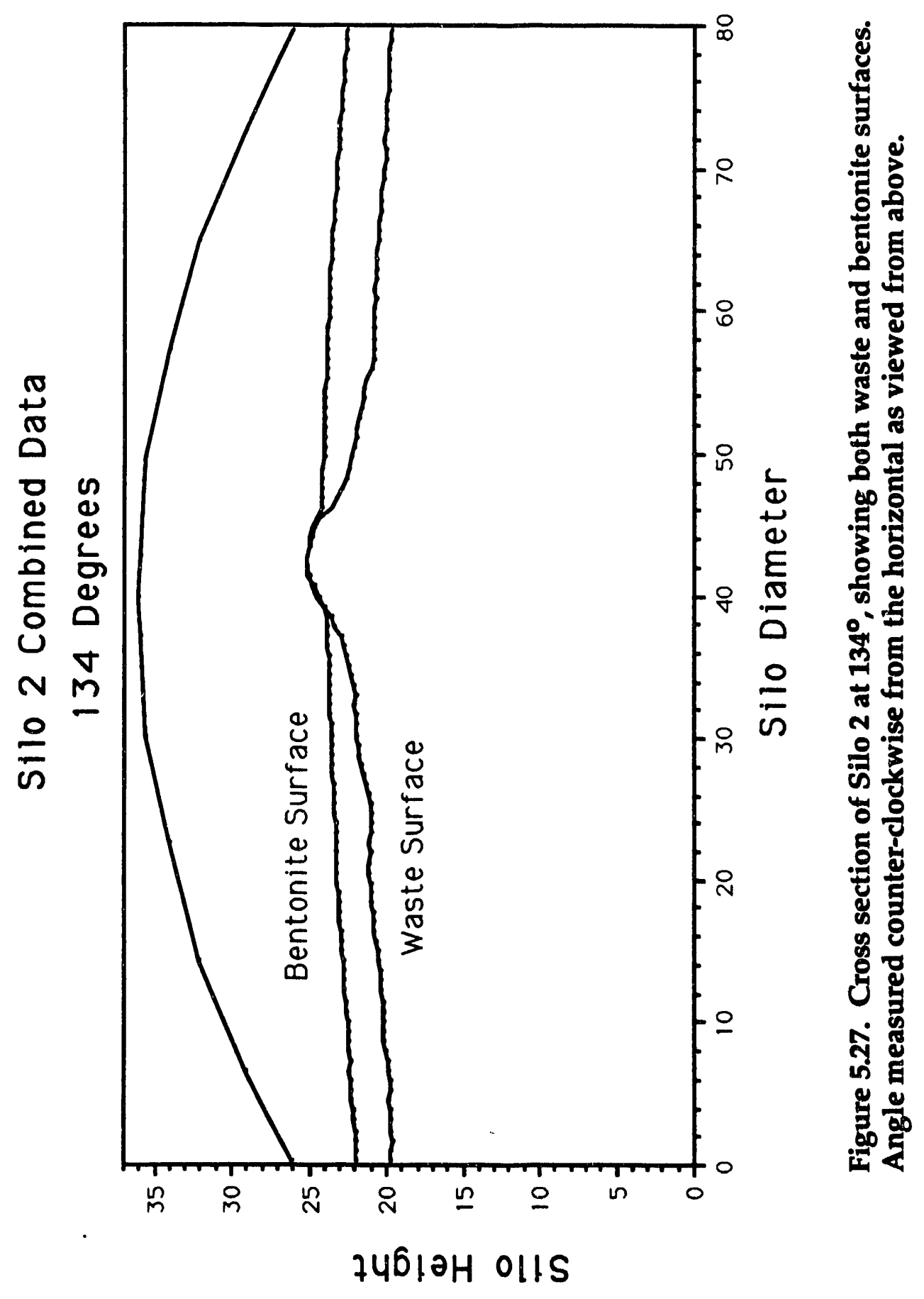




\subsection{VOLUMETRIC ANALYSIS}

To support planning for the bentonite application and to assist in the postbentonite analysis, ORNL performed volumetric analyses of the surface data. The surface data were integrated to determine the volume of waste prior to bentonite application. The headspace remaining was also calculated. After bentonite application, similar calculations were performed to determine the volume of total waste including bentonite and, hence, the volume of bentonite added to each silo. To perform these calculations, several assumptions were made and are listed below.

1. The ORNL GRF was assumed to be $15 \mathrm{~cm}$ (6-in.) above the intersection of the tank walls and the dome top. (This is assumed correct to within \pm 2 in.)

2. The tank diameter was assumed to be $24.4 \mathrm{~m}(80 \mathrm{ft})$.

3. The tank wall was assumed to be $8.1 \mathrm{~m}(26.7 \mathrm{ft})$ high. This includes the thickness of the floor, $20 \mathrm{~cm}$ ( $8 \mathrm{in}$.$) .$

4. A radius of curvature was assumed for the dome of $25.9 \mathrm{~m}(85 \mathrm{ft})$. Actually, the radius of curvature did not enter the volume calculation directly. The more important parameter was the height of the dome above the wall. A value of $3.05 \mathrm{~m}(10 \mathrm{ft})$ was assumed.

5. Surface voids narrower than $15 \mathrm{~cm}$ (6-in.) were smoothed over by the 15 by $15 \mathrm{~cm}$ ( 6 by $6 \mathrm{n}$.) binning of the data; therefore, the volume of cracks and crevices was for the most part ignored.

Because of the primary intent to measure a change in surface height (waste baseline vs bentonite), the measurement system was designed for selfconsistency and repeatability. Inside the silos were few references that could be used to verify the absolute measurements. The GRF bulbs were calculated to be about $15 \mathrm{~cm}$ (6-in.) above the silo walls and visual inspection confirmed that this was a reasonable assumption. However, the GRF height above the silo wall was not measured directly and the visual inspection was only reliable to within a couple of inches. Therefore, an uncertainty of $\pm 7.6 \mathrm{~cm} \mathrm{(6} \mathrm{in.)} \mathrm{was} \mathrm{assigned} \mathrm{to} \mathrm{the}$ absolute measurement of surface height. The calculation of bentonite volumes was less sensitive to the absolute accuracy of the measurement and more sensitive to the relative accuracy of the system; hence, a smaller uncertainty is quoted. During the Silo 4 test, the surface height change of the test objects was determined with accuracy of $\pm 6 \mathrm{~mm}(0.25$-in.). During the Silos 1 and 2 field deployment, the decant valve spacings were used to check the surface height change measurements. The measured surface height change at the wall and the value obtained by comparing before-and-after bentonite installation images of the surface at the wall were consistent within the resolution of the images. 
Therefore, an uncertainty of $\pm 3 \mathrm{~cm}(0.1 \mathrm{ft})$ was assigned to the measurement of surface height change in the field deployment. The calculated volumes are shown in Table 5.5.

Because the bentonite emplacement equipment offered limited options for selectively depositing the bentonite, several scenarios were considered for minimizing the amount of bentonite deposited. The minimum volume of bentonite required for a $30-\mathrm{cm}$ (12-in.) layer in a silo was $142.4 \mathrm{~m}^{3}\left(5,000 \mathrm{ft}^{3}\right)$ an excess of a factor of two to three was unavoidable given the limitations of the bentonite emplacement equipment and the surface shape of the waste baseline. ORNL analyzed the baseline waste-surface data and provided some guidelines for the amount of bentonite required for the various scenarios. These are listed below.

\section{$\underline{\text { SILO } 1}$}

The total volume of bentonite required to fill the low portions with $1.22 \mathrm{~m}$ (48-in.) and then place $30 \mathrm{~cm}$ (12-in.) above all areas not already covered by at least $30 \mathrm{~cm}\left(12-\mathrm{in}\right.$.) was calculated to be $280.3 \mathrm{~m}^{3} \pm 14.2 \mathrm{~m}^{3}$ $\left(9,900 \pm 500 \mathrm{ft}^{3}\right)$.

The total volume of bentonite required to fill the low portions with $1.37 \mathrm{~m}$ (54-in.) and then place $30 \mathrm{~cm}$ (12-in.) above all areas not already covered by at least $30 \mathrm{~cm}\left(12-\mathrm{in}\right.$.) was calculated to be $345.5 \pm 14.2 \mathrm{~m}^{3}$ $\left(12,200 \pm 500 \mathrm{ft}^{3}\right)$.

The total volume of bentonite required to fill the low portions with $1.52 \mathrm{~m}$ (60-in.) and then place $30 \mathrm{~cm}$ (12-in.) above all areas not already covered by at least $30 \mathrm{~cm}$ (12-in.) was calculated to be $416.3 \pm 14.2 \mathrm{~m}^{3}$ $\left(14,700 \pm 500 \mathrm{ft}^{3}\right)$.

\section{$\underline{\text { SILO } 2}$}

The total volume of bentonite required to fill the low portions with $1.22 \mathrm{~m}$ (48-in.) and then place $30 \mathrm{~cm}$ (12-in.) above all areas not already covered by at least $30 \mathrm{~cm}$ (12-in.) was calculated to be $334.1 \pm 14.2 \mathrm{~m}^{3}(11,800 \pm$ $500 \mathrm{ft}^{3}$ ).

The total volume of bentonite required to fill the low portions with $1.37 \mathrm{~m}$ (54-in.) and then place $30 \mathrm{~cm}$ (12-in.) above all areas not already covered by at least $30 \mathrm{~cm}(12-$ in. $)$ was calculated to be $399.3 \pm 14.2 \mathrm{~m}^{3}(14,100 \pm$ $500 \mathrm{ft}^{3}$ ).

The total volume of bentonite required to fill the low portions with $1.52 \mathrm{~m}$ (60-in.) and then place $30 \mathrm{~cm}$ (12-in.) above all areas not already covered by at least $30 \mathrm{~cm}$ (12-in.) was calculated to be $467.2 \pm 14.2 \mathrm{~m}^{3}(16,500 \pm$ $500 \mathrm{ft}^{3}$ ). 
Table 5.5. Waste, bentonite, and head space volumes in Silos 1 and 2 calculated by using the structured light surface data.

\begin{tabular}{lcc}
\hline \multicolumn{1}{c}{ Volume } & Silo 1 & Silo 2 \\
\hline Waste & $3280 \pm 35 \mathrm{~m}^{3}$ & $2840 \pm 35 \mathrm{~m}^{3}$ \\
& $115,900 \pm 1,250 \mathrm{ft}^{3}$ & $100,400 \pm 1,250 \mathrm{ft}^{3}$ \\
Head space before bentonite & $1150 \pm 35 \mathrm{~m}^{3}$ & $1580 \pm 35 \mathrm{~m}^{3}$ \\
& $40,500 \pm 1,250 \mathrm{ft}^{3}$ & $55,900 \pm 1,250 \mathrm{ft}^{3}$ \\
Bentonite & $360 \pm 14 \mathrm{~m}^{3}$ & $310 \pm 14 \mathrm{~m}^{3}$ \\
& $12,600 \pm 500 \mathrm{ft}^{3}$ & $11,100 \pm 500 \mathrm{ft}^{3}$ \\
Head space after bentonite & $790 \pm 35 \mathrm{~m}^{3}$ & $1270 \pm 35 \mathrm{~m}^{3}$ \\
& $27,900 \pm 1,250 \mathrm{ft}^{3}$ & $44,800 \pm 1,250 \mathrm{ft}^{3}$ \\
Total waste and bentonite & $3160 \pm 35 \mathrm{~m}^{3}$ & $3640 \pm 35 \mathrm{~m}^{3}$ \\
& $128,400 \pm 1,250 \mathrm{ft}^{3}$ & $111,500 \pm 1,250 \mathrm{ft}^{3}$ \\
\hline
\end{tabular}

As indicated in Table 5.5, the volume of bentonite applied in Silos 1 and 2 totaled about $670 \mathrm{~m}^{3}\left(23,700 \mathrm{ft}^{3}\right)$. The difference between the highest and lowest points in the two silos was measured as $1.7 \mathrm{~m}(5.5 \mathrm{ft})$ and $2.6 \mathrm{~m}(8.5 \mathrm{ft})$, respectively for Silos 1 and 2 . Simply adding $0.3 \mathrm{~m}(1 \mathrm{ft})$ to the highest points and depositing $2.0 \mathrm{~m}(6.5 \mathrm{ft})$ and $2.9 \mathrm{~m}(9.5 \mathrm{ft})$ of bentonite would require $920 \mathrm{~m}^{3}$ $\left(32,500 \mathrm{ft}^{3}\right)$ and $1350 \mathrm{~m}^{3}\left(47,500 \mathrm{ft}^{3}\right)$, respectively, totaling $2270 \mathrm{~m}^{3}\left(80,000 \mathrm{ft}^{3}\right)$ of bentonite required. However, the lowest points measured in each silo were in crevices and, therefore, lower than the nominal baseline. Using the integrated surface data to calculate bentonite volume required to cover the highest points in each silo with a $0.3 \mathrm{~m}$ levei layer, results in $640 \mathrm{~m}^{3}\left(22,500 \mathrm{ft}^{3}\right)$ and $1090 \mathrm{~m}^{3}$ $\left(38,600 \mathrm{ft}^{3}\right)$, respectively, totaling about $1730 \mathrm{~m}^{3}\left(61,100 \mathrm{ft}^{3}\right)$. The actual bentonite savings is then calculated as the difference between $1730 \mathrm{~m}^{3}\left(61,100 \mathrm{ft}^{3}\right)$ and the $670 \mathrm{~m}^{3}\left(23,700 \mathrm{ft}^{3}\right)$ deposited, giving a value of $1060 \mathrm{~m}^{3}\left(37,400 \mathrm{ft}^{3}\right)$ bentonite reduction. By studying the surface shapes of waste in the two silos, WEMCO was able to place the $30-\mathrm{cm}$ (1-ft) or greater thickness of bentonite over the largest part of the surfaces and place a thinner layer of bentonite on the small areas remaining at the tops of the mounds. 


\section{CONCLUSIONS}

In 1991, ORNL Robotics \& Process Systems Division staff designed, fabricated, assembled, tested, demonstrated, and operated a structured light system for mapping surface contours in waste-storage silos at the Fernald site. A field test and technology development demonstration were performed at Fernald from late July to early August. Following the Silo 4 test, the system was further developed and enhanced for field deployment in radioactive waste storage silos. Development activities were sponsored by the DOE-OTD, Robotics Technology Development Program. Field deployment support and major equipment costs were funded by DOE-ER.

From September 24 through October 11, 1991, ORNL staff operated the surface-mapping system in K-65 Silos 1 and 2 at Fernald. Baseline surface maps were obtained under difficult field conditions much more challenging than the laboratory testing environment. Because of the time constraints imposed by a Comprehensive Environmental Response, Compensation, and Liability Act Removal Action Milestone under the Amended Consent Agreement for the Fernald site, the project team worked extremely long hours to complete the development and testing at ORNL and then worked around the clock at Fernald to install, debug, and operate the system. Final surface maps were obtained in December, after bentonite deposition, in a mapping campaign lasting from December 2-21, 1991. During the bentonite surface mapping campaign, ORNL staff were assisted by WEMCO staff in the actual data acquisition system operation. This was made possible by the user-friendly operation interface and the high degree of automation build into the data acquisition and analysis system. Once the system was fully tested during the baseline mapping, ORNL was able to train WEMCO personnel to operate the system for subsequent mapping.

The resulting surface maps have been used for five purposes. First, the baseline waste surface maps provided the site with data needed to plan the deposition of the bentonite clay cap over the waste including amount of bentonite to procure. Second, the bentonite-surface maps were compared to the baseline data to determine bentonite thickness over the entire waste surface. Third, these two sets of data provided planning information for the eventual removal of the cap and the waste. Fourth, the baseline data provided verification of waste volumes historical data. Fifth, the headspace volume calculations were needed to support subsequent radon data logging.

Prior to development of this mapping system, the Fernald site did not have an adequate means of measuring the waste surface shape or the bentonite cap thickness. As a result of this technology development project and the rapid and successful field deployment, a bentonite deposition scheme was determined that satisfied EPA requirements but minimized excess bentonite in the silos. Comparing the volume of bentonite applied in the silos to the volume required to fill to a level $30 \mathrm{~cm}$ ( $12 \mathrm{in}$.) above the highest point on the waste surface results in a savings of about $1060 \mathrm{~m}^{3}\left(37,400 \mathrm{ft}^{3}\right)$ of excess material. Because all material placed in the silos is thereafter considered as waste, this surface-mapping system 
directly resulted in a significant reduction of waste to be retrieved and treated from the K-65 silos. The raw bentonite material cost savings plus savings in retrieval and treatment costs for the excess material have been estimated to total $\$ 13$ million or more. The development costs at ORNL totaled about $\$ 700,000$. Development support costs at SNL $(\$ 85,000)$ and coordination and deployment costs at Fernald $(\$ 500,000)$ bring the total investment to about $\$ 1.3$ million. Approximately a 10 to 1 payback has already been realized and other applications are imminent. This project truly fulfilled the OTD objectives to develop technology that results in safer, faster, better, and cheaper environmental remediation tasks.

Potential applications of this technology are numerous and include contour mapping of most solid surfaces including extraterrestrial surface mapping. A second-generation mapping system is being developed suitable for deployment in the higher radiation fields, corrosive atmospheres, and mixed liquid and solid waste tanks at the DOE Hanford site. The success of the surface mapping campaign at Fernald attracted commercial interest in the structured light technology. ORNL and SNL will be joined in the development of the Hanford system by Mechanical Technology, Inc. (MTI), via a pair of Cooperative Research and Development Agreements (CRADAs).

Some of the significant technical achievements are summarized below. An in situ alignment scheme was developed that is suitable for use inside wastestorage tanks or other facilities. A powerful color graphical user-friendly interface was developed for highly automated data acquisition and live data display. A collection of highly efficient image-processing tools were developed that are applicable to many automated remote-handling tasks. Transfer of this ORNL-developed surface-mapping technology to a commercial vendor is included in the CRADA with MTI. 


\section{ACKNOWLEDGMENTS}

The authors express their appreciation to the many people who at one time or another pitched in to support the project team. In particular, we recognize the efforts of P. L. Butler, H. M. Costello, G. A. Armstrong, G. T. Appleton, R. C. Muller, and D. H. Thompson of ORNL; C. S. Gourley and S. W. Thayer of the University of Tennessee; R. Markus and W. Owens of WEMCO; and B. K. Christensen, and M. McDonald of SNL. A special thanks goes to all at Rust Engineering who provided excellent field support during the surface-mapping campaign. Although the list seems long, it is still only a partial list of those who contributed to the completion of the work described herein. The authors offer apologies to those who supported the surface-mapping project but were not listed explicitly in the acknowledgments. 


\section{REFERENCES}

1. B. L. Burks, F. W. DePiero, J. C. Rowe, C. B. Selleck, D. L. Jacoboski, and R. Markus, "Generation of 3-D Surface Maps in Waste Storage Silos Using a Structured Light Source," Proceedings of the Space Operations, Applications, and Research Symposium, Houston, July 9-11, 1951.

2. B. L. Burks, F. W. DePiero, M.A. Dinkins, J. C. Rowe, C. B. Selleck, and D. L. Jacoboski, "Application of a Structured Light Source for Waste Surface Mapping in the Fernald K-65 Silos," Proceedings of the Winter Annual Meeting of the American Nuclear Society, San Francisco, Nov. 11-14, 1991

3. B. L. Burks, F. W. DePiero, M. A. Dinkins, J. C. Rowe, C. B. Selleck, and D. L. Jacoboski, "Application of a Structured Light Source for Surface Mapping of the K-65 Silos," Proceedings of the Third Annual Internationa! High Level Radioactive Waste Management Conference and Exposition, Las Vegas, April 12-16, 1992.

4. B. L. Burks, F. W. DePiero, M. A. Dinkins, J. C. Rowe, C. B. Selleck, and D. L. Jacoboski, "Final Results of the Application of a Structured Light Source for Surface Mapping of the Fernald K-65 Silos," Proceedings of the Annual Meeting of the American Nuclear Society, Boston, June 7-12, 1992.

5. B. Christensen, W. Drotning, and S. Thunborg, "Model Based, Sensor Directed Remediation of Underground Storage Tanks," Proceedings of the American Nuclear Society Robotics and Remote Systems Topical Meeting, Albuquerque, N. M., Feb. 24-28, 1991, pp. 227-37.

6. B. Griebenow, L. A. Strope, C. B. Selleck, and J. D. Burke, "Imaging, Inspeciion, and Characterization Systems for Underground Storage Tanks," Proceedings of the American Nuclear Society Winter Meeting, San Francisco, Nov. 10-14, 1991.

7. B. K. P. Horn, Robot Vision, MIT Press, Cambridge, Massachusetts, and McGraw-Hill Book Co., New York, 1984.

8. G. H. Hostetter, C. J. Savant, Jr., and R. T. Stefani, Design of Feedback Control Systems, Holt, Rinehart, and Winston, New York, 1982.

9. GUO-QING Wei, and SONG De Ma, "Two Plane Camera Calibration: A Unified Model," National Laboratory of Pattern Recognition, Institute of Automation, Chinese Academy of Sciences, Bejing, 1991.

10. A. Isaguirre, $\mathrm{P}$. Pu, and J. Summers, "A New Development in Camera Calibration: Calibrating a Pair of Mobile Cameras," Department of 
Computer and Information Science, GRASP Laboratory, University of Pennsylvania, Philadelphia, 1985.

11. G. Strang, Linear Algebra and its Applications, Second Ed., Academic Press, New York, 1980.

12. W. H. Press, B. P. Flannery, S. A. Teukolsky, and W. T. Vetterling, Numerical Recipes in $C$, Cambridge University Press, Cambridge, New York, 1988.

13. H. Asada and J. J. E. Slotine, Robot Analysis and Control, Wiley New York, 1986. 
INTERNAL DISTRIBUTION

1. G. T. Appleton

2. G. A. Armstrong

3. S. M. Babcock

4. J. E. Baker

5. J. B. Berry

6. E. R. Bowers

7. H. R. Brashear

8. W. D. Burch

9. T. W. Burgess

10-20. B. L. Burks

21. P. L. Butler

22. H. M. Costello

23. N. H. Cutshall

24. R. M. Davis

25. F. W. DePiero

26. M. A. Dinkins

27. S. S. Douglass

28. B. G. Eads

29. W. Fulkerson

30. R. L. Glassel

31. M. J. Haire

32. D. C. Haley

33. W. R. Hamel

34. J. H. Hannah

35. J. N. Herndon

36. J. F. Jansen

37. R. K. Kibbe

38. S. M. Killough

39. L. N. Klatt

40. J. W. Koger
41. R. L. Kress

42. C. T. Kring

43. D. S. Kwon

44. P. D. Lloyd

45. A. P. Malinauskas

46. R. C. Mann

47. S. March-Leuba

48-50. S. A. Meacham

51. J. R. Merriman

52. R. C. Muller

53. M. W. Noakes

54. T. E. Noell

55. F. G. Pin

56. K. E. Plummer

57. B. S. Richardson

58. J. C. Rowe

59. S. L. Schrock

60. J. O. Stiegler

61. F. J. Sweeney

62. W. H. Sides

63. A. W. Trivelpiece

64. H. R. Yook

65. Central Research Library

66-67. Laboratory Records Department

68. RPSD Publications Office

69. Laboratory Records (ORNL-RC)

70. ORNL Patent Section

71. Document Reference Section 


\section{EXTERNAL DISTRIBUTION}

1. Clinton Bastin, Manager, LMR Reprocessing Projects, Division of Fuels and Reprocessing, Office of Facilities, Fuel Cycle, and Test Programs, NE-471, Department of Energy, Washington, DC 20545.

2. L. F. Blankner, Fusion and Nuclear Technology Branch, Energy Programs Division, Department of Energy, P.O. Box 2008, Oak Ridge, TN 37831-6269.

3. C. W. Frank, Department of Energy, Office of Technology Development, Room 7A049, 1000 Independence Avenue, Forrestal Building, Washington, DC 20585

4. A. B. Sibert, Director, Office of Classification and Technical Policy, (DP-323.2), Department of Energy, Washington, DC 20585

5. Office of Scientific and Technical Information, DOE Oak Ridge Field Office, P.O. Box 62, Oak Ridge, TN 37831

6. G. Armantrout, Lawrence Livermore National Laboratory, 700 East Avenue, L-440, Livermore, CA 94550

7. D. W. Bennett, Pacific Northwest Laboratories, Post Office Box 999, Richland, WA 99352

8. S. A. Couture, Lawrence Livermore National Laboratory, Post Office Box 808, L-437, Livermore, CA 94551

9. P. J. Densley, Lawrence Livermore National Laboratory, Post Office Box 808, L-437, Livermore, CA 94551

10. P. J. Eicker, Sandia National Laboratories, Post Office Box 5800, Department 1410, Albuquerque, NM 87185

11. T. Erkkila, Los Alamos National Laboratory, Post Office Box 1663, MS J-580, Los Alamos, NM 87545

12. Roger Gilchrist, Westinghouse Hanford Company, Post Office Box 1970, Richland WA 99352

13. B. Greibenow, Westinghouse Idaho Nuclear Company, Post Office Box 4000, Idaho Falls, ID 83403-5104

14. C. S. Gourley, The University of Tennessee, 409 Ferris Hall, Knoxville, TN 37996-2001

15. E. Grasz, Lawrence Livermore National Laboratory, Post Office Box 808, L-437, Livermore, CA 94551

16. R. W. Harrigan, Sandia National Laboratories, Post Office Box 5800, Division 1414, Albuquerque, NM 87185

17. D. Herman, Westinghouse Environmental Management Company of Ohio, Post Office Box 398704, Cincinnati, OH 45239-8704

18. A. C. Heywood, Lawrence Livermore National Laboratory, Post Office Box 808, L-437, Livermore, CA 94551

19. R. M. Hollen, Los Alamos National Laboratory, Post Office Box 1663, MS J-580, Los Alamos, NM 87545

20. J. P. Hopper, Westinghouse Environmental Management Company of Ohio, Post Office Box 398704, Cincinnati, OH 45239-8704 
21. D. Horschel, Sandia National Laboratories, Post Office Box 5800, Division 1414, Albuquerque, NM 87185

22-42. D. L. Jacoboski, Westinghouse Environmental Management Company of Ohio, Post Office Box 398704, Cincinnati, OH 45239-8704

43. W. Jaquish, Westinghouse Hanford Company, LO-18, Post Office Box 1970, Richland, WA 99352

44. L. Kostelnik, Westinghouse Idaho Nuclear Company, Post Office Box 4000, Idaho Falls, ID 83403-5104

45. M. Kyle, Westinghouse Savannah, River Company, Building 773-A, D-1145, Aiken, SC 29808

46. J. O. Moore, DOE-OR, Federal Office Building, Room 2116, Oak Ridge, TN 37831-2001

47. S. Moy, Department of Energy, Richland Operations Office, Post Office Box 398704, Cincinnati, OH 45239-8704

48. P. Scott, Pacific Northwest Laboratories, Post Office Box 999, Richland, WA 99352

49. C. B. Selleck, Sandia National Laboratories, Post Office Box 5800, Division 1414, Albuquerque, NM 87185

50. C. M. Shoemaker, Advanced Systems Concept Office (ASCO), ATTN: AMSLC-AT-AS, Building 459, Aberdeen Proving Ground, MD 21005-5001

51. S. W. Thayer, The University of Tennessee, 409 Ferris Hall, Knoxville, TN 37996-2001

52. S. Thunborg, Sandia National Laboratories, Post Office Box 5800, Division 1414, Albuquerque, NM 87185

53. M. Trivedi, The University of Tennessee, Ferris Hall, Knoxville, TN 37996-2100

54. J. Voyles, Pacific Northwest Laboratories, Post Office Box 999, Richland, WA 99352

55. C. R. Ward, Westinghouse Savannah, River Company, Building 773-A, D-1145, Aiken, SC 29808

56. B. Wilding, Westinghouse Idaho Nuclear Company, Post Office Box 4000, Idaho Falls, ID 83403-5104

57. A. P. Williams, Westinghouse Hanford Company, LO-18, Post Office Box 1970, Richland, WA 99352

58. L. W. Yarbrough, Department of Energy, 12800 Middlebrook Road, MS EM-55, Trevion II, Washington, DC 20874

59. J. A. Yount, Westinghouse Hanford Company, MSIN:LO-18, Post Office Box 1970, Richland, WA 99352

60. Office of Assistant Manager for Energy Research and Development, Oak Ridge Operations Office, Department of Energy, X-10 Site, Post Office Box 2008, Oak Ridge, Tennessee 37831-6269

61-62 Office of Scientific and Technical Information, P. O. Box 62, Oak Ridge,Tennessee 37830 

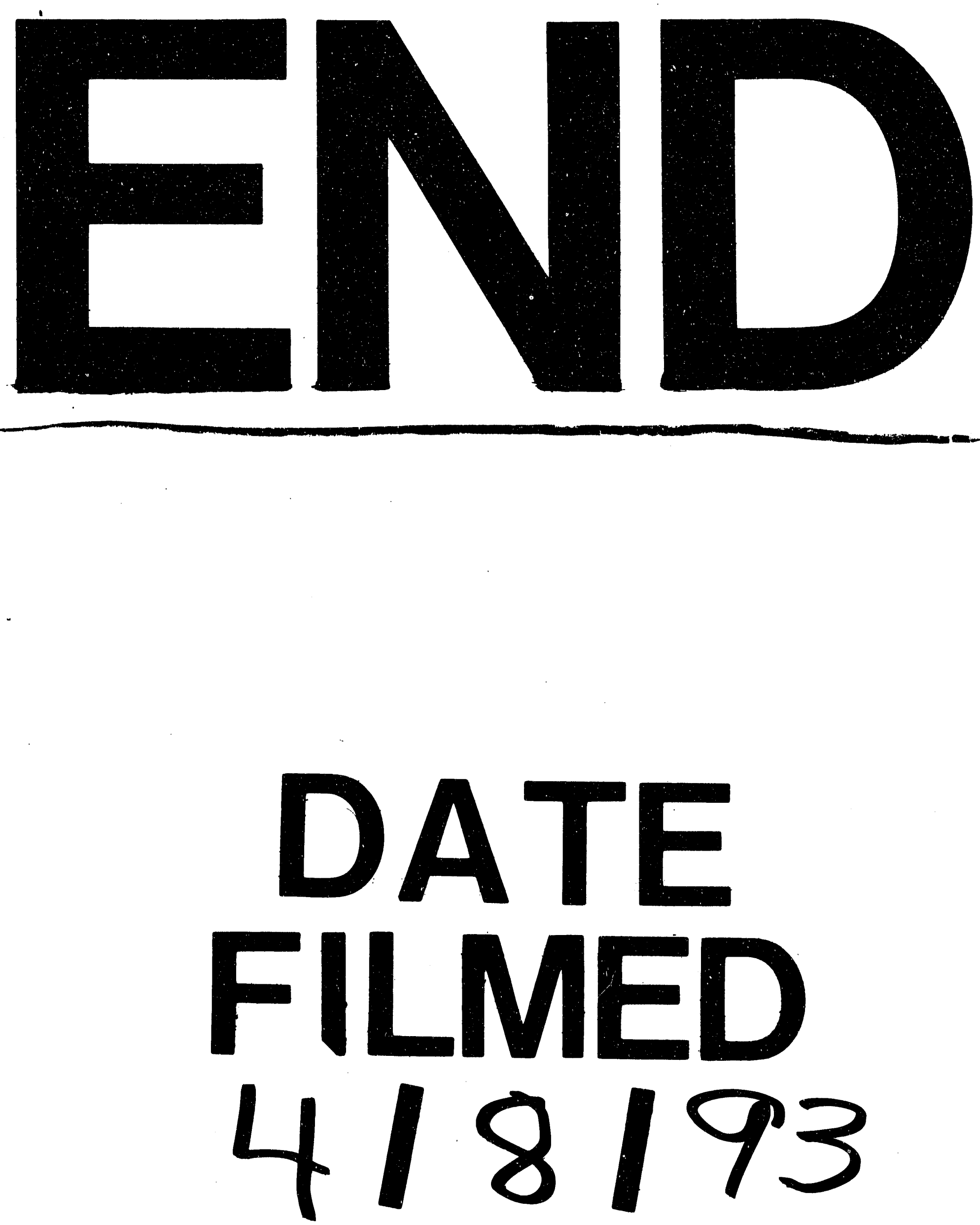


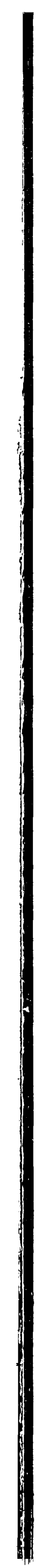

